University of New Hampshire

University of New Hampshire Scholars' Repository

Master's Theses and Capstones

Student Scholarship

Fall 2010

\title{
The experience of co-instructing on extended wilderness trips
}

Franklin Vernon

University of New Hampshire, Durham

Follow this and additional works at: https://scholars.unh.edu/thesis

\section{Recommended Citation}

Vernon, Franklin, "The experience of co-instructing on extended wilderness trips" (2010). Master's Theses and Capstones. 590.

https://scholars.unh.edu/thesis/590

This Thesis is brought to you for free and open access by the Student Scholarship at University of New Hampshire Scholars' Repository. It has been accepted for inclusion in Master's Theses and Capstones by an authorized administrator of University of New Hampshire Scholars' Repository. For more information, please contact Scholarly.Communication@unh.edu. 
THE EXPERIENCE OF CO-INSTRUCTING ON EXTENDED WILDERNESS TRIPS

BY

FRANKLIN VERNON

B.S. Indiana University, 2003

\title{
THESIS
}

Submitted to the University of New Hampshire

in Partial Fulfillment of

the Requirements for the Degree of

\author{
Master of Science \\ in \\ Kinesiology
}

September, 2010 
UMI Number: 1487005

All rights reserved

INFORMATION TO ALL USERS

The quality of this reproduction is dependent upon the quality of the copy submitted.

In the unlikely event that the author did not send a complete manuscript and there are missing pages, these will be noted. Also, if material had to be removed, a note will indicate the deletion.

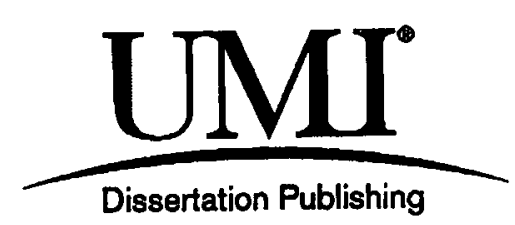

UMI 1487005

Copyright 2010 by ProQuest LLC.

All rights reserved. This edition of the work is protected against unauthorized copying under Title 17, United States Code.

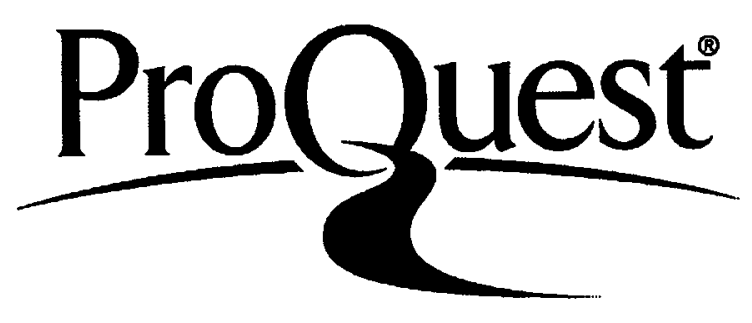

ProQuest LLC

789 East Eisenhower Parkway

P.O. Box 1346

Ann Arbor, MI 48106-1346 
This thesis has been examined and approved.

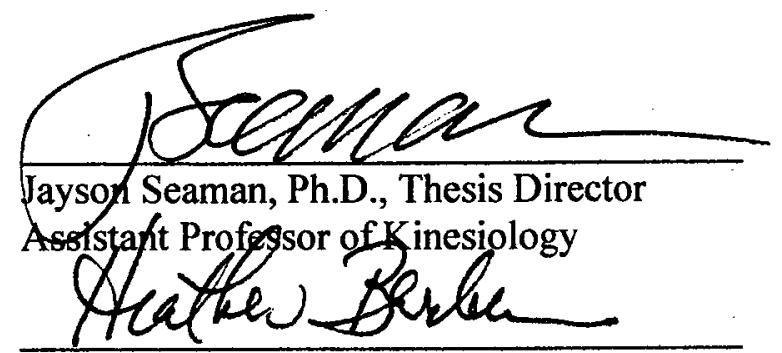

Heather Barber, Ph.D.

Associate Professor of Kinesiology

tulce Sinyeson

Jualie Simpson, Ph.b.

Manager, Research Integrity Services

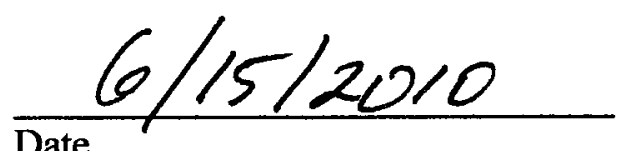

Date 


\section{ACKNOWLEDGEMENTS}

Certain individuals and groups must be acknowledged as instrumental players in the development, completion, and support of this thesis:

- Katie, without whom I would be hopelessly lost and forever misunderstood;

- the members of my committee for their patience and support;

- Thursday Night Dinner for keeping me fed and with an outlet to vent;

- the participants of my study for their honesty and insightful reflections; and

- every co-instructor I have ever worked with, regardless of whether or not we liked one another.

Thank you. 
TABLE OF CONTENTS

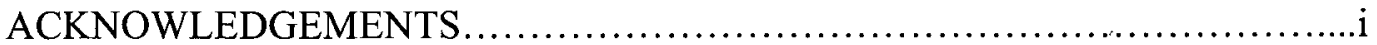

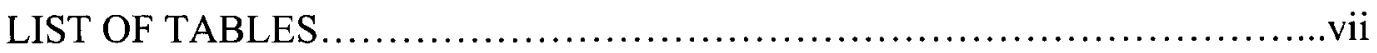

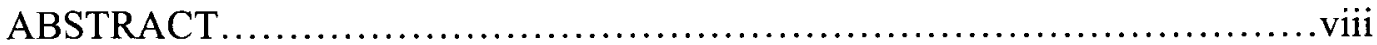

CHAPTER

PAGE

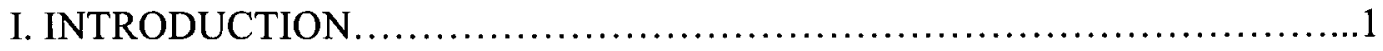

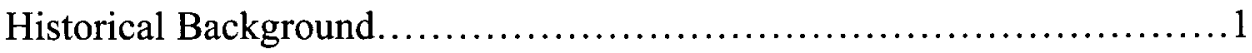

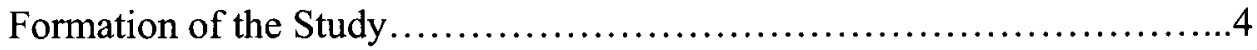

Purposes of the Study ..............................................6

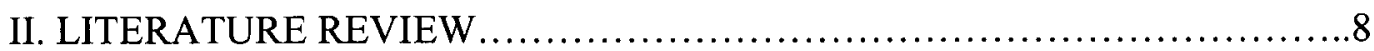

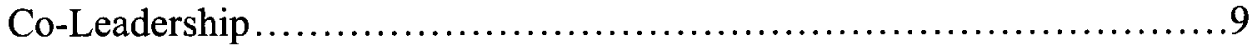

Co-Leadership: A Definition.................................9

Models of Co-Leadership..................................9

Academic Literature on Co-Leadership.......................12

Co-Leadership in Social Work and Counseling..................13

Team-Teaching in Traditional Education.......................14

Teacher Experiences.......................................15

Leadership in Adventure Education................................ 16

Outdoor Instructor Training...................................... 18

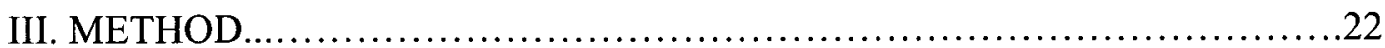


Conceptual Framework: Phenomenology .22

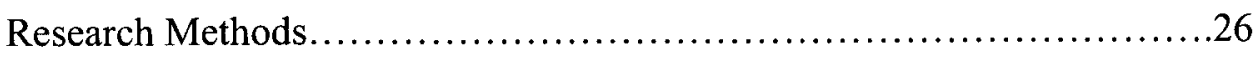

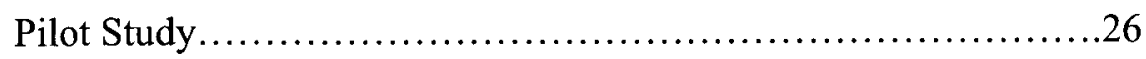

Phenomenological Interviews..................................26

Interview Protocols........................................... 28

Question Structure.....................................28

Duration and Location of the Interviews....................31

Importance of Rapport...................................32

Participant Sampling ............................................

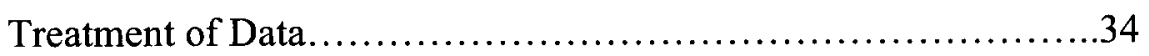

Security .................................................

Transcription.............................................. 34

Data Analysis.............................................

Bias and Risks......................................................

My Role as the Instrument.................................. 38

Diversity Beyond Appropriate Engagement........................39

Bracketing.......................................................

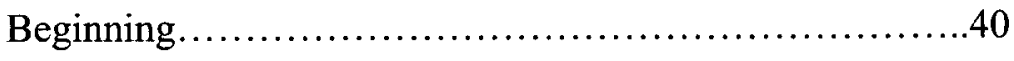

Middle..................................................40

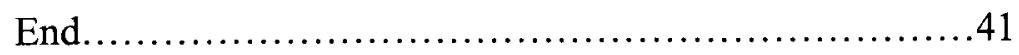

Participant Risk............................................42

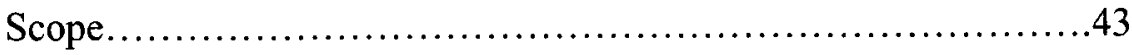

Claims.......................................................... 43 


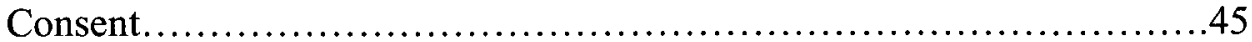

Research Timeline..................................................46

IV. CO-INSTRUCTORS' RECONSTRUCTED LIFE NARRATIVES............47

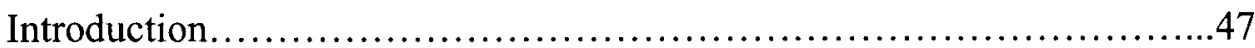

The Participants' Narratives......................................48

Participant 1: Jeremy.......................................48

Participant 2: Bethany...................................51

Participant 3: Peter.......................................55

Participant 4: Jennifer.......................................58

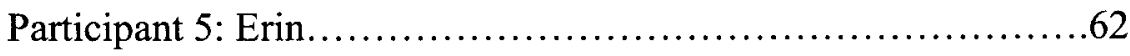

Conclusion.......................................................67

V. A THEMATIC ANALYSIS OF THE CO-INSTRUCTING EXPERIENCE....68

Theme 1: Living Work..........................................71

Work as 'Home' ............................................... 72

Inescapable Partner.......................................73

Intense Form of 'Real Life' with Other....................... 74

Support Giver..........................................75

Theme 2: The Dilemma of the Super-Instructor.........................76

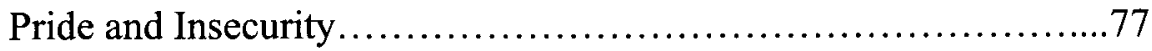

Negotiating Power.........................................78

Negotiating Self-in-Team................................... 79

Theme 3: Sizing Up............................................ 80

Roles and Power........................................... 82 
Organizationally Defined.............................82

Emergent........................................83

Evaluation of the Co-instructors.............................84

Communication between Co-instructors.........................85

Prioritizing Goals and Growth...............................86

Trust among Co-instructors.................................88

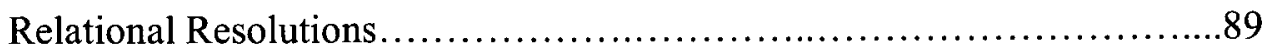

The Fulfilling Relationship.................................91

The Lackluster Relationship...............................92

The Isolating Relationship................................93

Conclusion..................................................... 94

VI. DISCUSSIONS AND IMPLICATIONS ....................................

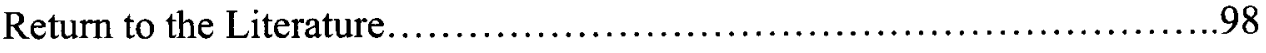

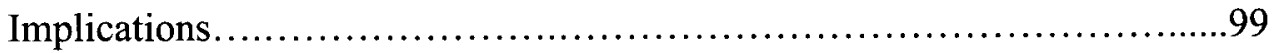

Situational Co-leadership...................................101

Consulting...................................... 102

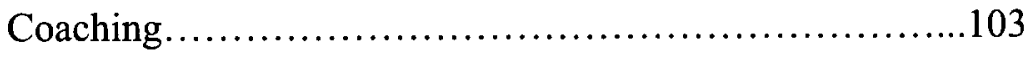

Collaboration...................................... 103

Situational.........................................104

Training ................................................ 108

Leader of the Day.................................. 108

Instructor Trainings............................... 110

Research Implications.......................................... 113

vii 
Future Research.........................................114

Instrumental Research..................................116

Scholarly Research........................................117

Conclusion................................................. 120

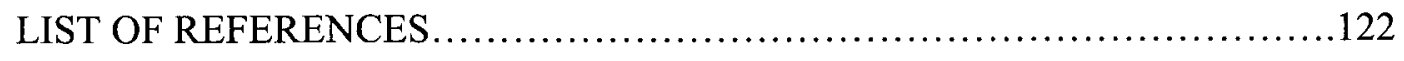

APPENDIX A IRB Approval Letter...................................... 127

APPENDIX B Written Consent Handout................................. 128

APPENDIX C Email Invitation........................................ 130

APPENDIX D Reconstructed Life Narrative................................... 131 


\section{LIST OF TABLES}

Table 1: Shared Themes by Participant...................................... 70 


\begin{abstract}
THE EXPERIENCE OF CO-INSTRUCTING ON EXTENDED WILDERNESS TRIPS

by
\end{abstract}

Franklin Vernon

University of New Hampshire, September 2010

Adventure education organizations use co-instruction as the dominant mode of staffing programs, largely for issues related to risk mitigation. Despite, or perhaps because of, the everyday nature of this common staffing arrangement, little attention has been paid to it. Moreover, a review of relevant literature on co-leadership from the human services, traditional education, and adventure education fields revealed little clear consensus regarding the nature of the co-instruction experience. This phenomenological study inquired into the experience of co-instructors through in-depth qualitative interviews, which were transcribed and inductively analyzed for emergent themes. Coinstructing, at its essence, emerged as a negotiated relationship between co-instructors that shaped their professional, social, and personal success while in the field. In this thesis, I elaborate the central themes of living work, the dilemma of the super-instructor, and sizing up, and I discuss the meaning of co-instruction in people's lives. I conclude by sharing several practical implications resulting from the study, including new ways of approaching staff training in adventure education. Future research might fruitfully examine the meaning of itinerant work in young people's lives, especially in intense environments such as wilderness co-instruction. 


\section{CHAPTER 1}

\section{INTRODUCTION}

\section{Personal and Historical Background to the Research Problem}

My interests have always found footing in the outdoors. I first got my fix through television nature programs and literature, but as I entered junior high and high school I began to interact with the outdoors personally through adventure activities. Rock climbing was gaining popularity among some of my friends and I immediately took to it. I frequented a couple of local climbing gyms as well as a climbing club and rock wall at my high school. Every so often we would drive the two hours or so north to Devil's Lake in Wisconsin, a classic Midwest climbing destination with a good deal of history in bouldering and toprope climbing. It was through that interest in climbing, and my subsequent involvement with the high school climbing club, that I found myself with the first two jobs that I actually enjoyed.

I was first hired in the outdoor industry during my junior year in high school. Initially, I became a teaching assistant for my school's alternative gym class, which incorporated rock climbing, kayaking, biking, facilitation, and camping skills into the curriculum, and included a weekend at Devil's Lake. Then, I worked as a teambuilder at a high ropes course that operated nearby, serving clientele from professional businesses to substance abuse groups from a local hospital. (How I ended up getting hired at a high 
ropes course when I was 17 is beyond me, but I appreciated the opportunity.)

I left high school and headed to a midwestern university to pursue a major in psychology, or so I thought. I knew I wanted to work with people, but was unsure what options existed. I chose a major that appeared at face value to set me on a path towards interpersonal work. I was met, however, with neurons and facts about abnormal chemical reactions to memorize. Psychology, as a subject, did not hold my interest, and I became disenchanted with what I thought would end up being my career if and when I finished college. I was starting to become recognized on campus - a campus of some 30,000 -as the guy running to class yelling about being late for a test, in his pajamas, at $5 \mathrm{pm}$. At the end of my first semester, struggling to hold on to a scholarship, I registered for a class titled "Introduction to Outdoor Recreation." Frankly, this was an effort to boost my GPA. What I ended up with, however, was a new major and renewed interest in school.

My interest in outdoor adventure, both as a recreational pursuit as well as professional undertaking, quickly branched out beyond rock climbing. I soon took up whitewater sports, snow sports, and mountain sports through personal initiative, training, and work. Through this lifestyle I developed, albeit mostly subconsciously, intuitive knowledge of the essence of the phenomenon of outdoor leadership (van Manen, 1997). I began to know the field of adventure education because I was experiencing it firsthand as recreationalist and professional.

But, as I explain below, my foray into professional outdoor leadership has led to persistent questions about how I should approach my role as a co-instructor: a task for which I found little training, research, or theory to adequately prepare me. Studying the intuitive knowledge of a topic, therefore, may begin, as I have done here, by probing 
individuals' biographies and experiences to reach its essence. This is especially true in understudied areas (Bertaux, 1981).

I quickly began a progression towards professional outdoor leadership, including two semester-long trainings with reputable outdoor leadership programs, an internship as a mountaineering instructor in the Sierras of California, and a rapid entrance into the local opportunities for outdoor instruction at school. Through these trainings I observed and came to know two different perspectives on what outdoor leadership meant. The first training I took part in focused on my outdoor skills: backpacking, rock climbing, whitewater paddling. While my instructors showed awe-inspiring comfort around the interaction of themselves and the environment, they struggled to teach interpersonal classes in a compelling way. The second training spent a great deal of time and depth in theories and models of outdoor leadership, in which each outdoor activity we took part in was focused around the abstract knowledge and skills necessary to successfully manage a group.

After these trainings, which emphasized the routine and predictable areas of technical and interpersonal skills, I joined the ranks of outdoor professionals. I apprenticed under a common, industry-wide progression: I was an 'assistant instructor' until I learned the course areas, job expectations, and minutiae of the organization, upon which I moved into the roles of 'lead instructor', and finally, 'instructor trainer'. However, neither my training programs nor my apprenticeships prepared me for what was centrally expected—but not much talked about—in each of these professional steps: the routine practice of co-instructing, or the situation in which two or more outdoor professionals are paired up and given shared responsibility in the creation and facilitation 
of a wilderness course.

My realization that co-instruction played such a large role in job performance and satisfaction made me grapple with the notion of it: I saw it first as almost derogatory, later as a necessary evil, and later as a blessing. I sometimes experienced it as a curse. My trainings had all tacitly emphasized being an individual leader when preparing me for my future role. Never had I been told that the default arrangement would be working as a 'co-leader.' The terms I learned in my early trainings pointed only to the individual who is self-reliant, made independent decisions, drew on one's own interior resources, and so forth. It was something that first drew me to the field: a vision in my mind of being this figure called an 'outdoor instructor,' who has an almost heroic and solitary "man-of-themountains" connotation. I was allowed to test this dream out through common training simulators such as the 'leader of the day' model, solo teaching topics, even being voted the sole leader of my group for an independent group travel experience on one of the trainings I attended. The truth, however, was that I was never the individualistic 'leader of the day' in my professional life: there were always two or three of us leading together, and, often, the instructor who showed too much 'self-reliance' undermined the communal nature of our work and was actually considered a burden to the rest of the instructor team.

\section{Formation of the Study}

I have now been working in the outdoor industry for eleven years and for eight different programs, filling roles from assistant instructor to director. During that time I have worked as a co-leader on more than 65 wilderness courses for over 500 days of coinstructing. In contrast, in my chosen profession of wilderness education, the amount of time I have found myself working as a solitary leader amounts to a small fraction of that. 
My felt disconnect between outdoor leadership research and training and the routine working conditions of the field has been my primary motivation for this research. After years of personally experiencing or witnessing the whole gamut of interpersonal outcomes from co-leadership in our field, from intimate relationships being born to people leaving an organization because of their nightmarish pairings, I concluded that a tension existed around 'co-instructing' that I wanted to investigate and understand.

My inquiry first took me into the training literature, including six major adventure education textbooks used widely over the last thirty years, training manuals from two major adventure education organizations, the National Outdoor Leadership School and Outward Bound, proceedings from research conferences over twenty years, and the major outdoor research journals in the United States, Canada, and Great Britain dating back 32 years. In these texts, a specific focus on co-leadership appeared a total of six times: one unpublished dissertation, one undergraduate thesis, three research articles, and one conference workshop. I found it virtually impossible to track down much detailed information about co-leadership, despite it being the dominant way programs are staffed. I also realized that, despite the rich and complex experiences of co-instructors, their voices were absent in what literature was available, hence my inability to identify with it. By default, then, the perspective that has been privileged is that of textbook authors, program administrators, and risk managers, and not that of the people most affected by the arrangement: co-instructors themselves. It was this realization, and the desire to better understand and contribute to knowledge and training in the field, that I decided to pursue academic study on the topic.

As a budding researcher in co-instruction, I am most interested in the experience 
of co-instructing, and the meanings people make of their experience. By raising awareness of how people experience the central practice of co-instructing, my aim is to help better prepare staff through training, support our programs by developing management strategies that clarify the expectations and nuances of co-instruction, and connect more thoughtfully with existing literature on the topic while respecting its unique operationalization in adventure education. A main purpose of this research was to lay the foundation for understanding the experience of co-instruction through the eyes of the practitioner, so that programs can re-evaluate training, management, and evaluation schemes to better prepare staff for what is truly expected: being co-instructors, not just instructors. Therefore, the question that drove my study was: How do wilderness educators experience the practice of co-instruction?

\section{Purposes of the Study}

Through this study I intended to contribute to the discussion of co-instruction in adventure education. Since it is now primarily known only through lived experience, one way of knowing co-instruction was through others' narratives (Seidman, 2006). By listening to the narratives of those most directly associated with the phenomenon, we become able to speak with some level of accuracy of the current state of being a coinstructor, and thus can begin to speak of where the field might go -in research and practice- with that knowledge. The purposes of this study, therefore, were to:

a) Investigate the narratives of co-instructors in the adventure education field and explain what they understand the experience of co-instructing to be, both to and for them.

b) Lay the groundwork for future inquiry into the phenomenon of co-instruction so 
organizations may better prepare and support their staff for this central job expectation.

The thesis is organized as follows. Chapter II reviews relevant literature on collaborative work arrangements in human service and education fields, before turning to its treatment in outdoor/adventure education. Chapter III discusses the conceptual framework for the study and the methods I used to conduct it, as well as ethical considerations and possible limitations. Chapter IV introduces the interview participants and shares reconstructed narratives related to their experience of co-instruction, and Chapter $\mathrm{V}$ outlines the themes, aspects, and meanings that emerged from their interviews. I discuss the significance of these findings at the start of Chapter VI before moving on to the implications of the study and directions for future research.

Before proceeding, I must point out that I focused exclusively on staff experiences of co-instruction as a central dimension of their work. Although other dimensions of the work — performing advanced technical skills, responding to emergencies, counseling youth, adhering to program policies—-figure prominently in outdoor instruction, how individuals experienced these dimensions was not the focus of the study. I therefore only discuss them when they intersect with the experience of coinstructing, as indicated by the data. 


\section{CHAPTER II}

\section{LITERATURE REVIEW}

The American adventure education field has been utilizing co-instructors to run multi-day wilderness courses as the default arrangement almost since its inception. Theory, research, and subsequent training, however, have focused almost exclusively on individual-leader paradigms (Priest, 1987), training models (Ewert \& Hollenhorst, 1984; Galloway, 2007), the nature of work in the field (Sharpe, 2005b), and academic textbooks (Ford \& Blanchard, 1993). An analogy helps explain: it is as if a tennis coach trains her team for singles matches, yet expects the players to compete in doubles meets. Where coleadership has been used in other education and human service fields, there has been a dialogue of how the pairing of professionals creates complex dynamics that impact both the practitioners and participants. As a result, in these fields, theory, research, and training have developed to address the benefits and pitfalls of utilizing co-leaders. I question how applicable are the models that have been developed in these fields. In the following section, and to gain conceptual clarity, I will examine the potential relevance of the models and the academic literature from these related fields to adventure education. 


\section{$\underline{\text { Co-Leadership }}$}

\section{Co-Leadership: A Definition}

Co-leadership has been defined in both human service and traditional education fields as putatively equal-power sharing of two or more professionals to lead a group (Austin, 2001; Starak, 1981). Starak defines co-leadership as "two professionals who jointly share the responsibility for establishing, administering, and facilitating the group activities" (p. 146). This definition mirrors the explicit and tacit expectations of coinstruction in adventure education (Wagstaff, 1997). Despite these relatively clear definitions, both human service and educational fields have found discrepancies in how they carry into practice. Each maintains that the definition indicates the paragon of a successful co-leader dynamic despite the difficulty in the way it is actually attained (Austin; Winter, 1976).

\section{Models of Co-leadership in Social Work/Therapy and Education}

The use of co-leadership has been traced to the theories and models proposed by psychologists during the 1950 s (Luke \& Hackney, 2007). An early proposal for the benefits of co-leadership in group counseling comes from an address made to the American Psychological Association in 1969 by Vincent Hanner (Hanner, 1969). Hanner proposed that while working solo, a facilitator, especially when working with difficult populations such as at-risk youth, may have difficulty stepping out of the facilitator role and then easily retrieving it due to members' grabs for power. Within a co-leader model, Hanner argues, one leader can take an observer or focal member role, gaining rapport with the group, while the other leader retains control of the facilitator role, to be switched at an appropriate time. In this way, leaders can alternately become member/leaders of a 
group, creating opportunities for other members to take the facilitator role in a less risky environment, or join with one or more leaders in the conduct of the group. To summarize, the purpose of this arrangement was to facilitate an easier trade off between being a leader and being a group member, to enhance rapport and empower group members to shape group conduct.

The human service fields began widely implementing co-leadership models in the 1980s for the opportunities they offered practitioners and participants. Social work group leaders prior to 1980 seemed primarily to be trained as single-leaders (Kolodny, 1980; Levine, 1980), but they found themselves increasingly working in co-leader settings as a form of training, often with mixed results. The practice of training leaders through coleader placements, however, has flourished despite the lack of firm agreement in the field about its purposes and value (Wright, 2002). This use introduces a second use; apprenticing one leader (or facilitator) to another. Indeed, using co-leadership as a training tool appears to be a common model in the groupwork literature. Others also exist; in a review of co-leadership use in group counseling, Wright (2002) identified three major purposes: (a) training students by pairing with an experienced leader; (b) providing support to staff working with difficult groups or situations (e.g., terminally ill patients); and (c) modeling relational diversity for group members (e.g., using a male and female therapist to present a parent dynamic to children).

Therefore, in the counseling literature, one can glean at least four collaborative work arrangements:

- Rapport-building and power sharing, when one leader maintains control while the other works with group members 'at their level'; 
- Apprenticeship, when a novice leader is paired with an expert leader for training purposes;

- Support, so leaders can relieve one another during demanding situations;

- Modeling diversity, either to connect with diverse group members or to emphasize collegiality among diverse individuals.

Traditional educators have also made use of co-leadership, but with different purposes and arrangements (Austin, 2001; Kloo \& Zigmond, 2008; Stivers, 2008). In the education literature co-leadership is more commonly referred to as "co-teaching" or "team-teaching", and primarily indicates an inter-disciplinary pairing of professional educators with diverse skill sets (Kloo \& Zigmond; Gillespie \& Israetel, 2008). These pairings generally take on two forms The first is that of pairing a general education teacher and a special education teacher (Austin; Kloo \& Zigmond; Shapiro \& Dempsey, 2008; Stivers; Wilson, 2008). This arrangement focuses on inclusivity and mainstreaming, primarily as a result of the Individuals with Disabilities in Education Act (IDEA) of 1990 (Murawski \& Swanson, 2001). The second is where two subject area teachers may be paired to teach a course (Gillespie \& Israetel; Dugan \& Letterman, 2008).

Co-teaching in traditional education settings is seen as an elastic relationship with great potential for success and failure (Kloo \& Zigmond, 2008). Wider co-teacher training publications have been a more recent development in the educational literature, primarily offering co-teaching models that revolve around working successfully with another co-teacher. Kloo and Zigmond indicate five primary co-teaching models:

- a teacher-assistant model 
- a station-teaching model

- a parallel-teaching model

- an alternative-teaching model, and

- a team-teaching/collaborative-teaching model

How teachers achieve the level of collaboration necessary to successfully navigate and implement these different models is addressed in the educational 'how-to' literature. In 20 Ways To Be an Active Co-Teacher (Wilson, 2008), for example, the 'teacherassistant model' presents actions that the 'assistant' co-teacher can engage in that will enhance learning in a classroom. The directions are specific: Wilson advocates scanning for students having trouble with the lesson being provided, interjecting different points of view, or forming mini-groups of students that are struggling. Some of these models appear to return to Hanner's (1969) original thinking, assuming that at any given time, one teacher can be in charge while the other works more closely with students. Some of these techniques, such as interjecting different points of view during a lesson, assume a specific relationship between co-teachers that allows for open and possibly conflicting dialogue in front of students. Even in this relatively evolved literature, however, there are gaps: how exactly the relationship between teachers should evolve is difficult to decipher through the available literature.

\section{Academic Literature on Co-Leadership}

Research investigating co-leadership in the human service and educational fields has been minimal (Murawski \& Swanson, 2001; Wright, 2002). These fields, however, have provided a number of models, opinions, and anecdotes that inform the concept of co-leadership and its implementation within the respective fields. There appears to be a 
resurgence in co-leadership publications in the human service fields that mirrors the trend of theory and anecdote from 30 years ago (Luke \& Hackney, 2007). This may indicate a difficulty in operationalizing co-leadership as a researchable topic, despite the desire to discuss and understand co-leadership as a job requirement. Below, I review the research literature on the topic.

\section{Co-Leadership in Social Work and Counseling. In 1980, Social Work with} Groups published an issue made up of co-leadership articles that became the textbook Co-Leadership in Social Work With Groups (1981), indicating that, at least at the time; there was a robust discussion on co-leadership occurring within that field (Luke \& Hackney, 2007). Upon review, however, the treatment of co-leadership in the field was largely anecdotal and drawn from personal experience, not grounded in research. Regardless, the literature draws an interesting and complex view of co-leadership as an often-used but little-understood phenomenon with impacts and effects on both practitioner and participant (see Kolodny, 1980; Levine, 1980; Starak, 1981).

Although little research exists regarding the effectiveness of co-leadership, it nonetheless is common in social work with groups, group therapy, and group counseling fields, indicating a belief in its benefits to both leaders and group members (Kolodny, 1980; Levine, 1980; Wright, 2002). The literature that does exist is primarily anecdotal, but it nevertheless indicates several strengths and weaknesses for using co-leadership, both for the leaders and for the group members.

In an early qualitative study of co-leadership, Starak (1981) used semi-structured interviewing of practitioners to identify the core components of a co-leader experience. In Starak's interviews having a positive view of co-leadership in groupwork was a 
prerequisite to taking part. Through the use of a questionnaire to guide discussion, 13 experienced group therapists led Starak to define co-leadership for social work with groups as being successful due to the existence of:
a) flexibility
b) sharing of responsibility and power
c) growth and learning, and
d) value-added elements

These core elements match the different approaches I outlined above, and, Starak argued, they impacted the experience for both leaders and groups in powerful ways that should support co-leadership as a viable option for commonplace use in groupwork. However, precisely what benefit co-leadership provides the group is still largely unknown leaving questions about what configurations are optimal (Luke \& Hackney, 2007). Despite the wide use of co-leadership in groupwork and general statements about its purported effectiveness, there have been few studies that have tested specific hypotheses regarding co-leadership.

Team Teaching in Traditional Education. Departing from group therapy, traditional education uses co-teaching primarily to create inclusive classrooms through placing a special education teacher with a general education teacher (Murawski \& Swanson, 2001). While multiple articles have been published on co-teaching in the traditional and special education fields, there are remarkably few quantitative studies looking at the outcomes of practice (Murawski \& Swanson; Scruggs, Mastropieri, \& McDuffie, 2007). Instead, pertinent to my interests here, the majority of publications have focused on teacher experiences and co-teaching strategies. 
Teacher Experiences. Like the groupwork literature, the traditional education literature indicates that shared power among co-teachers is preferable to hierarchical power relationships in the classroom (Austin, 2001). As a matter of practice, however, there is little evidence to suggest that teachers actually share power in ideal ways (Austin; Scruggs et al., 2007). In a mixed-methods study of co-teaching using questionnaires and interviews, Austin found a disconnect between beliefs and practice. He states that although educators responded that they "valued shared classroom management and instructional duties, they did not in practice share these responsibilities" (p. 249). Results were also not consistent across groups; Austin found that special education teachers ranked co-teaching training experiences as being more valuable than general education teachers at a statistically significant level. Even though the majority of teachers surveyed expressed a belief that co-teaching for inclusive classrooms was a worthwhile endeavor, Austin's research suggests that work arrangements which presumably look straightforward from an administrative point of view—such as pairing a special education teacher with a subject area teacher to further the organizational aim of inclusivity-may mask differences in how the arrangement is actually experienced by the professionals who enact it.

After reviewing the literature available in the human service and education fields, I conclude that:

- co-leadership is not a static concept, but can be appropriated and adapted to serve different goals;

- even when one arrangement is adopted in a given setting, it might be experienced by leaders or participants in varying ways; and 
- adopting approaches and perspectives from human service and education fields that routinely use co-leadership may not be as straightforward as one might presume.

I would now like to apply these conclusions to my review of the adventure education literature, a field that has not systematically published work specifically indicating the various models used in co-instructing, or the goals it is meant to serve. Wagstaff (1997) indicated what already seems intuitively known: that co-instructing is a construct primarily driven by risk management concerns, that is, if one instructor is needed for an emergency, the other can 'cover,' and as such it seems that instructors are paired together primarily to achieve programmatic success in the face of the physical and emotional responsibilities of the work. The research that has occurred in adventure education has based its literature review (see Rilling \& Jordan, 2007) and models of use (Millette \& Porter, 2001) on the human service and education fields, as I described above. I want, however, to suggest caution here, since the practices common to those fields derive from different purposes, values, and settings than the adventure education field where the goals and demands inherent in wilderness education are quite different from group therapy or classroom teaching. I discuss some of these concerns below. Note, throughout the remainder of the text, I will use the term co-instructing to describe the specific work done on extended wilderness courses, and the term co-leadership as an umbrella construct to discuss the generalized area of research and theory.

\section{Leadership in Adventure Education}

The field of adventure education has been engaging in research and dialogue on outdoor leadership and instruction for close to forty years. Research on leadership has 
primarily focused on competencies and training, and only recently has begun to look specifically at the effects of leaders on program outcomes (Schumann, Paisley, Sibthorp, \& Gookin, 2009). Kalisch (1979) was among the first to discuss instruction in depth, identifying the instructor in an Outward Bound program as the key to success of both the process and product of a course. The instructor has this power, Kalisch argued, through taking on multiple roles:

- skill trainer

- program designer

- translator

- group facilitator, and

- one-on-one counselor

These roles require the ability to effectively create, assess, model, and teach both the group and individual in a manner that best encourages personal development and skill mastery. Because of the overwhelming responsibility placed on an outdoor instructor to create experiences in an environment that brings with it many risks, including physical, emotional, and educational, competencies have been identified that are associated with effective outdoor instructing, and instructor training programs have subsequently been based on these competencies (Priest \& Gass, 1997). Priest (1987) conducted a metaanalysis of research and writings concerning outdoor leadership competencies and came up with twelve core attributes: technical, safety, environmental, organizational, instructional, problem solving, decision making, and facilitation skills; a flexible leadership style, experience-based judgment, effective communication, and professional ethics. When viewed with Kalisch's explanation of the roles involved in being an 
effective outdoor instructor, it becomes apparent that both competent instructional and leadership skills are needed to be an outdoor 'instructor.' However, how these competencies are shaped by, or shape, the dynamics of co-instruction, has been discussed little, despite it being the most common arrangement for practicing these competencies on a wilderness course.

\section{Outdoor Instructor Training}

The outdoor field began developing widespread instructor training programs largely from intuitive and institutional knowledge prior to the authoring of any training texts. The United Kingdom began the first nationalized outdoor leadership training program, and in 1969 the Scottish Mountain Leadership Board published Mountain Leadership (Ford \& Blanchard, 1993). Soon after, other countries that had seen a swell in public interest in outdoor recreation and the resulting increase in guiding and outdoor adventure programs began to follow suit. While the United States did not adopt national standards for outdoor leadership training, many programs began offering guide and instructor courses to help meet the demand for qualified staff in the growing outdoor recreation industry (Priest \& Gass, 1997). Among the first programs were Outward Bound, originally started in 1941 in the United Kingdom by Kurt Hahn; The National Outdoor Leadership School (NOLS), started by Paul Petzoldt in 1965; and The Wilderness Education Association (WEA), also started by Petzoldt in 1976. University programs likewise began offering structured outdoor instructor training during this time period, with undergraduate majors or semester-long instructor courses such as Western Illinois University's ECOEE program in 1976 (Western Illinois University, 2007) and with the University of Montana's CORE program in 1982 (Dr. Joel Meier, personal 
communication, February 7,2009 ). Many courses follow similar progressions to train outdoor instructors (Bartley, 1988), utilizing:

- Technical skill development

- Human skill development

- Educational skill development

Students are taught and tested on specific skill criteria through scenarios, student-taught lessons, and the Leader-of-the-Day (LOD) model, among others. (In the LOD model, a trainee leads a group of fellow trainees for the period of one day, often under the supervision of a program director or veteran instructor.) While there are variations in training techniques today, the twelve competencies described by Priest (1987), or some similar grouping, are largely the foundation of outdoor instructor training. It is worth noting, therefore, that all of these models predominantly focus, implicitly or explicitly, on staff as individual leaders.

Extended wilderness courses in the United States, however, routinely utilize coinstructing for programs. One can find little mention in the adventure education literature of theories, models, or research in how co-instruction should occur in order to produce a successful course. Whereas research into the competencies, responsibilities, and outcomes of an individual instructor have been widely written about in adventure education literature, research in co-instructing has been largely absent, despite being the dominant work arrangement.

The multiple responsibilities placed on adventure educators (managing physical and emotional risk while acting as educators) can create a physically and emotionally taxing environment (Sharpe, 2005b). Due to the responsibility and risk inherent in 
adventure education, the field apparently incorporated co-leadership as a way to more effectively run a program and to support staff (Wagstaff, 1997). Mirroring Kalisch's (1979) definition, the dynamics of extended courses require staff to take on balanced roles as both leaders and educators.

Of the few published empirical studies in the adventure education field on coinstructing, the most readily available was conducted by Rilling and Jordan (2007) with mixed results. Outdoor instructors with at least one 10-day wilderness course worth of instructing experience participated in a survey with follow-up questions in which they were asked to identify key outdoor instructor competencies for themselves, then asked to identify key competencies for a hypothetical co-instructor. Participants largely identified themselves as having competencies similar to the ones Priest (1987) listed, which were then coded as either technical or interpersonal. Not surprisingly, participants largely identified hypothetical co-instructors as requiring very similar competencies to their own. One problem with this study was that the competencies respondents were asked to identify were based around the competencies that apply to individual leaders, based on skills indicated by Priest \& Gass (1997). As such, the study should be read as an indication of what individualized competencies current practicing adventure instructors with varying levels of experience prefer to work with, rather than a statement on the specific dynamics of co-instructing. This still leaves open the question of how practicing wilderness educators experience and manage their co-instructor relationship.

It is possible to conclude, given the literature from education and human service fields, that the adventure education field may find research in co-instructing to be of worth from both scholarly and practical perspectives. It is tempting to suggest that 
adventure educators should simply adopt the arrangements that have been advocated in these fields; after all, some of the goals are similar. Adventure educators often wish to share power with participants, to train novices alongside experts, and to pair instructors based on complementary skills. But, the wilderness environment is unlike therapy groups and schools. Moreover, across these literatures, one notices a conspicuous deficit in the voices of those who practice co-leadership as part of their routine work environment; in other words, by default, and absent other alternatives (or even careful attention to the topic), the perspective that has been privileged in the adventure education literature is that of program administrators and textbook writers. This may hide the unique dynamics of the co-instruction relationship and make co-instruction (or instruction itself, at least when two people try to do it together) seem more straightforward than it is. And where the experiences of co-leaders have been sought out (e.g., Austin, 2001; Kolodny, 1980) researchers have identified a gap between institutional and practitioner expectations and experiences, but have not investigated deeply the impacts of this gap on program leaders. As a result, preference has been given to the institutional perspective on co-leadership, and little research is available that privileges the co-leader's perspective. It is my aim in this study to privilege the voice of co-instructors themselves, to enlarge the field's understanding of this common work arrangement and to better determine how to adapt co-leadership models from other fields and bodies of literature. 


\section{CHAPTER III}

\section{METHOD}

After I had reviewed scholarly literature on co-leadership, it became clear that while there are similarities between its conceptualization and practice in adventure education and in other human services fields, there are also distinct differences. The one major study on co-instruction in the adventure education field, by Rilling and Jordan (2007), primarily drew available co-leadership theory from social work. Their exploratory study, while of some usefulness, did not result in a detailed understanding of co-instruction specific to adventure education. As a budding researcher in adventure education, I was interested in the experience of those who practice co-instructing and the meanings they make of being co-instructors for themselves. The current - albeit sparse research on co-instructing in adventure education has drawn theory and models significantly from the human service and traditional education fields. My primary interest in co-instructing was gaining in the adventure education field a foundational understanding of the experience in a manner that can both inform practice and guide the development of future research.

\section{Conceptual framework: Phenomenology}

Allowing practitioners to share their experiences in a research context may be the best way to achieve clarity on concepts that are loosely formulated or have proven to be 
elusive (Bertaux, 1981). A phenomenological, qualitative approach can provide particularly valuable insights into understudied areas (Seidman, 2006). Phenomenology enables researchers to systematically investigate lived experience from the perspective of those in/with the experience (van Manen, 1997). It provides multiple techniques for arriving at a more robust conceptualization of the essence of a phenomenon: in this case, the experience of co-instruction in an extended backcountry setting.

Phenomenology is the study of the world in which humans live through investigating the natural reflective process of their experience within it (van Manen, 1997). The root of phenomenology comes from the Greek phainomenon and logos, and literally refers to giving an account of the manner in which something appears (Sokolowski, 2000). Sokolowski describes the philosophy as a counter to the Cartesian doctrine, which holds that there is a distinct separation between the outside world and the world of the mind, creating an egocentric imperative on all knowledge. Phenomenology, in contrast, understands that the intentions, or focus, of the mind must always be on an object or idea. Therefore, the mind can be seen as in relation with the world in which we live, and vice-versa. Understanding the lifeworld, from within a phenomenological attitude, must come from realizing that objects and experiences have a certain truth of being, in the way that a mountain is different from a river, and the manner in which we understand, or intend a mountain, reveals certain universal truths to the human experience with a mountain.

Phenomenology, therefore, is specifically a philosophy interested in knowing the world in which humans occupy, or the lifeworld of human experience and understanding. Sokolowski (2000) explains the phenomenological conceptualization of the 'lifeworld' as 
the subjective, experienced world within which the scientific world is studied. Thus, what is studied by phenomenology is the lifeworld that humans exist within, and through which we discover the essence of things as they are. Phenomenological methodology in research is a systematic yet emergent practice in which the researcher presents the phenomenon in question in such a way as to require the reader to self-identify (or deidentify) with the nature of the phenomenon described, revealing the essence or universal qualities of the subjects' experiences (van Manen, 1997). Research into the world in which we live becomes, then, an investigation of the context, interaction, and understanding that a person has undertaken with her experience in her lifeworld. Holding that there are essential truths to this world that exists with, but not strictly within, our consciousness, phenomenology claims knowledge of the world through an understanding of our interaction with it. As explained by Sokolowski, "Things that had been declared to be merely psychological are now found to be ontological... acknowledged as truly there, as sharing in being and as capable of appearing according to their own proper style" (p. 15). The manner in which things appear or are understood are, therefore, part of the way things actually are.

Phenomenology as a methodology of scientific inquiry is interested in the way in which we come to understand our experiences post-reflectively, which allows the essence, or universal $i t$-ness of the experience, to be grasped by explaining the nature of a phenomenon and the meanings that are derived from that direct experience. Research is directed towards the human lifeworld "as we find it" (van Manen, 1997, p. 18), explaining knowledge not through a laboratory experiment but through the manner in which we naturally interact with the world. As the experience, such as running, is 
investigated from multiple people's action and interaction with running, salient truths about running in our lifeworld become evident so that we can claim knowledge of what running is.

Co-instructing in wilderness programming does not exist without the practitioners who are directly engaged in the experience. My goals as a researcher were two-fold: first, to understand what co-instruction in wilderness programming is as a designed experience; second, to understand what co-instructing is for those who experience it. While these may seem two separate notions, they are in fact inextricably linked within a phenomenological understanding of knowledge and the manner of being. The intention in a natural sense (Sokolowski, 2000) of co-instruction has already been outlined by Wagstaff (1997) as a shared-power responsibility of leadership that has been adopted by the field to mitigate risk. The definition given, however, is pre-experiential, meaning that this 'ideal' conception, however useful in a general way, may still be distant from how people experience and come to know co-instruction. While it is of significant worth in any practice to know the intended purpose of an idea or object, to not reflect upon its use is to not fully understand the nature of its being.

A phenomenological approach best uses and explains the available data (here, the lived experiences of those who practice co-instruction) so as to investigate the nature of co-instruction in wilderness programming. Phenomenology's primary investigative techniques include self-reflective journaling, literature analyses, focus group discussions, participant observation, and one-on-one in-depth interviewing. In order to allow robust conceptual themes to emerge across diverse experiences within a typically transient population, I chose in-depth interviewing as the primary method of data collection in my 
study. The purpose of in-depth interviewing is to achieve insight into the essential nature of a lived experience for an individual (van Manen, 1997), not "to get answers to questions, nor to test hypotheses, and not to "evaluate' as the term is normally used" (Seidman, 2006, p. 9).

Because the purpose of phenomenological interviewing is to gain a deeper conceptual understanding of a phenomenon, interviews were designed around a beginning-middle-end (Seidman, 2006) structure. This structure helped gain a more complete picture of the meanings that co-instructors have found within their experiences over time. Seidman's beginning-middle-end approach combines life-history interviews and laddered, semi-structured sessions of open-ended questions that build upon the interviewee's responses. I detail this approach below.

\section{Research Methods}

\section{Pilot Study}

Between May and August of 2009, I conducted a set of pilot interviews with an extended wilderness trip instructor. The pilot work was grounded in Seidman's (2006) indepth phenomenological interview techniques, and the information gathered was used as a basis for review and/or revision of guiding methodology. The participant closely matched my interviewee requirements (see p. 33), allowing the data collected to be as informative as possible. The pilot interviews were insightful regarding content, style, and preliminary investigation into the type of data that may be collected within this study. Results of the pilot study are discussed throughout this chapter.

\section{Phenomenological Interviews}

The phenomenological interviews used for this research were grounded in and 
adapted from the techniques developed by Seidman (2006), who recommends a threestep interviewing approach:

1. a life-history interview to put the participant's experience in perspective;

2. a detail of experience interview to concretely describe the experience; and

3. a meaning reflection interview to conceptually describe the experience and its meaning.

Prior to the start of the first (life history) interview, I asked interviewees to select a single wilderness course that they would describe in detail during the second (detail of experience) interview. During the life-history interview, I asked participants to talk about their life before the start of their selected wilderness course. I asked open-ended questions and directed questions towards reconstructing the context of the participant leading up to their selected course. The historical perspective helped to put the participant's experience in context within their greater life experience.

During the detail of experience interview I focused on the concrete details of what co-instructing was on their extended wilderness trip chosen before the first interview. I asked participants that they reconstruct their course in detail, and steered them away from meaning making. At this stage, my participants generally began to reflect on the meaning of their course after fully reconstructing the experience, creating an appropriate closing for the interview. After they had shared their initial understanding of their co-instructing experience in a single narrative, I used questions derived through their initial narrative to move them toward specifics. Those specifics generally focused on an event in their coinstructing that they had indicated as being potentially important. The specific events dealt with both the typical and atypical aspects of their experiences. Through these 
interviews, I was able to understand what was required of them as a co-instructor and what they experienced through their sharing of the course.

During the final meaning reflection interview, I asked participants to reflect on the meaning of their co-instructing experiences. Seidman (2006) explains the 'meaning' investigated within phenomenological research as "the intellectual and emotional connections between the participants' work and life" (p. 18). It is, in essence, the manner in which a person understands, or makes sense of, their experience within their life context. If questioned about what was meant by 'meaning,' I responded, "What did you get out of co-instructing that course, given what you had experienced leading up to and your experience while on course?" or, "Given what you experienced while on course, what do you understand co-instructing to be for you?" The previous interviews informed but did not necessarily direct this session. The details of the experiences they described in the previous sessions, whether general or specific, helped guide the prompts given if not arrived at naturally during the third interview.

\section{Interview Protocols}

Question Structure. I began each of the three interviews with a generalized question appropriate to the session. This general exploration created a baseline of information from the interviewee that I followed up on. Because the participants were being asked to discuss an experience they were intimately familiar with, yet rarely invited to discuss, I found that I spoke very little during the interview process. As such, the interviews followed emergent themes that were unique to each individual.

During my pilot set of interviews, I tested follow-up questions in both an ongoing and post-narrative format. Pursuing a deeper description of the participant's 
experience in a manner that disrupted their thought process revealed itself, however, as an unacceptable option in most circumstances. This practice not only created disjointed information, but it was also difficult as the researcher to ask questions in the moment that were still open-ended and not leading. By allowing the interviewee to finish their general description while I took notes, I created a more appropriate atmosphere in which I could pursue a deeper explanation without the risk of either losing potential future description, or pushing for descriptions in a manner that led to conclusions that may have been construed as pre-determined or biased. Taking notes throughout the process, I was able to use follow up questions that encouraged the interviewee to further explain any number of comments they made in a manner that focused on a more detailed understanding from their initial baseline comments.

While Seidman (2006) cautions against the use of strict interview guides for indepth interviews, advocating questions to be primarily derived from the responses of the participant, some interview preparation was necessary. I prepared general exploration questions to give each participant the same entryway to each interview, even though each discussed different experiences. General starting points for each interview were as follows:

a. life history: Can you talk to me about your life before this course, going right up until the course started?

b. detail experience: Can you reconstruct for me what co-instructing this course looked like? Walk me through the whole experience in detail.

c. meaning making: So given what you had experienced before the course, and what you experienced while co-instructing this course, can you talk 
to me about what meaning co-instructing the course has for you?

In the third and final interview, I had prepared a more focused interview guide for use if necessary. I asked participants about statements made during the detail experience session that appeared to have significant potential for investigation during the meaning making session, if they did not explore them organically in their own meaning-making discussion. For instance, in reflecting on the detail experience interview of the pilot study, the idea of relationship consistently emerged. During the final interview I invited my pilot study interviewee to explain what the relationships with his co-instructors meant to him:

... independent cooking away from your students, independent travel not with your students, I think that's something that most instructors look forward to. That's something that I'm going to need, because for the most part the people that I work with are amazing people that I get to meet for 30 days, and learn from, and get to know, and get to hear their crazy stories. I live in the northeast and have a house or an apartment... and I get to go meet people that are, you know, just dirtbag climbers that are just back from Patagonia, and I get to hear crazy stories from their crazy-ass instructor lives that I don't necessarily have. And they look at me and think like, 'wow, you have a roof and stuff and a place to put it' (laughs). And you know, I think we sort of thrive on each other, like a 'the grass is always greener' kind of thing. (PI III, p. 7)

My prompt, which was a question that emerged from a previous interview with this individual, yielded a rich discussion that had not emerged naturally through his initial reflection on the meaning that they had derived from his course. Due to this and similar occurrences, I paid attention to the potentials of both initially shared information and prompted information throughout the interview process.

In lieu of an extensive set of questions, which may have predetermined the interview's focus, I took copious notes as the participant shared their initial thoughts on their experience. The notes focused predominantly on two areas: 
- Participant cues (i.e., laughter, facial expressions or interesting body language, etc.) that may indicate a potentially ripe topic to explore.

- Areas in which I needed further explanation to adequately analyze or process (i.e., terminology that requires definition, comments that I did not understand, or topics that I would want further explanation of, or statements that I was otherwise struck as potentially important).

Accompanying my notes and the questions that I derived out of them was a subsidiary set of questions in the interview guide:

- Questions or topics for exploration that emerged from the participants' previous session(s), to be addressed if not arrived at organically and that I deemed appropriate to that session (e.g., looking into the meaning behind the experience of mentorship, if it was a concept addressed in the detail experience session). Duration and Location of Interviews. Seidman (2006) advocates that each interview last roughly 90 minutes for three reasons: (a) to cover topics sufficiently, at a pace that is comfortable to the respondent; (b) to avoid the clock-watching that is commonplace in one hour interviews, and (c) to avoid the draining experience of interviews lasting two hours or more. If, however, a topic is adequately treated during a shorter session, or if the interviewee continues to discuss and share past the 90 -minute mark, the session would not be considered a failure. The 90 -minute interview is thus not "magical or absolute" (p. 20), but served as a guide in this study.

Each set of interviews took place over the winter of 2009/2010 to allow the interviewees and myself time to decompress between each session, but not to fully separate from the interview process. This time also allowed me as the interviewer to 
review previous interview sessions to help guide questions for the next session if necessary. All interviews took place in locations mutually agreed upon by both the participants and myself. The locations sometimes changed throughout the process, but all were:

- Relatively free of distraction

- Quiet enough to carry on a conversation that could be clearly recorded

- Comfortable for the duration of the interview

- A place where the participant felt safe to discuss their experiences

- Not in any way burdensome on the participant to get to

- Other terms that were naturally agreed upon between the participant and myself (i.e., provision of drink or food, a part-way break, etc.)

The Importance of Rapport. In Seidman's (2006) approach, developing a strong rapport between researcher and respondent is crucial. The interviews and the quality of the data they generate depend on the creation of an "I-Thou" relationship that delicately toes the edge of a "We" relationship (p. 96). An "I-Thou" relationship, argues Seidman, is the recognition that the participant is not an object or data, but rather is an actual person that deserves our interest and respect. The result is an interview that is conversational while remaining focused. Despite this juxtaposition, the interviews always focused foremost on the participants' experiences and their ability to convey those experiences as independently as possible.

I tried to keep this need for rapport in the tone and focus of the interview sessions. Appropriate eye contact, active listening that did not lead responses (e.g., non-committal responses such as, "okay", “interesting", or "uh-huh"), and most importantly being 
genuinely interested in the stories of the participant were some of the techniques that I used.

\section{Participant Sampling}

In searching for a deep understanding of the co-instructing experience on extended wilderness trips, it was necessary to interview practitioners with a depth of personal experience to draw from. Personally situated within the wilderness instructing community, I used my experience and knowledge of the field to guide participant selection. While this may seem like it could have created a bias, I used my experience to seek out participants who would yield a rich background of experience to draw from. Participant requirements were that they:

- $\quad$ must have co-instructed on at least 8 ten+ day wilderness courses

- must have co-instructed on at least 2 ten+ day courses within the last 2 years

- must not have been someone with whom I had personally co-instructed These requirements served three purposes: first, to ensure a strong background of experience to reflect on; second, to ensure that there was not a void of recent experience, and third; to ensure that I as the interviewer did not enter the process thinking that I somehow "knew" their experience already. The "wilderness course" was defined as any course that primarily operated in primitive outdoor settings, and in which the group was physically removed from the organization of which it is a part. The co-instructors in these settings were of particular interest due to the level of responsibility that is inherent in working for such a long period of time in a leadership team. Prospective participants were contacted through email and/or personal contact (see Appendix C) based on knowledge or recommendation via a snowball/referral technique. Because 
phenomenological research is based on the deep description of experience and not generalizable data (van Manen, 1997), the number of participants ended up being five to facilitate the opportunity for depth in my study. I attempted to obtain an even balance of female and male participants to provide possible differences in perceptions of experience (see Clemmensen, 2002); in the end I interviewed three females and two males. By

adhering to these requirements, I was able to treat each participant with adequate depth, yet still provide a diverse description of the experience of co-instruction.

\section{Treatment of Data}

Security. All interviews were digitally recorded and accompanied by my notes. All digital recordings were stored on my personal computer, which automatically locked whenever not in use and required a password to unlock. I transcribed data on an ongoing basis throughout the study. During the transcription process all names and information that would identify the organizations my participants worked for were changed to provide anonymity as best as possible without changing their story. Upon the completion of the study all digital recordings were erased, thereby leaving an altered textual copy of all interviews that should not be readily traceable to any specific participant.

Transcription. During the pilot study, I tested two transcription techniques: first, that of a voice-recognition software, and second, that of an audio software, Express Scribe, that allowed the speed of the interview to be adjusted and "hot keys" created to control the recording while typing the interview. I finally used Express Scribe as the main technique, both for convenience of use as well as for being able to use my personal computer throughout the process, as the voice recognition software required that I borrow a computer for the transcription. 
Data Analysis. I analyzed the interviews using a three step process described by van Manen (1997). This process incorporated a wholistic phase, a selective phase, and a detailed phase. The wholistic phase attempts to capture the fundamental or primary significance of a text as a whole through a sententious phrase or paragraph. This provided me with an opportunity to construct a basic thematic understanding of each participant's complete experience based on a reading of his/her narrative. It also allowed me to mentally separate each interviewee's narrative at the start of the analytic process, keeping in focus that I was attending to separate understandings of co-instruction. Stopping here, however, would have been as dangerous as the educational practitioner who reads Experience and Education (Dewey, 1938) and claims understanding through the phrase "learning by doing". That is, the goal of a phenomenological inquiry is to understand the complexity and interplay existent within a life experience and to reveal the previously hidden nature that one arrives at through a thorough treatment of a text, not an attempt at an ill-understood summation. After gleaning a generalized understanding of the individual narratives via the wholistic phase, I engaged in the selective and line-by-line phases of analysis.

During the selective phase I highlighted statements for their significance to the nature of the experience being investigated. I determined statements to be essential or incidental to the experience of co-instruction through the use of free imaginative variation (van Manen, 1997). This practice considers the experience without the theme in question to see if the phenomenon is fundamentally changed. Via this, I retained for analysis the statements that would change the fundamental meaning of co-instruction if left out. I then analyzed these statements by creating a meaning-statement given what 
they revealed about co-instruction as a way to deepen my insight to the complexity of the phenomenon.

During the line-by-line phase, I analyzed each line of the essential statements to understand how the phrase revealed an aspect of the phenomenon in question, and created a short statement that captured the meaning of the phrase. I also identified key words or phrases within each statement (e.g., relationship, support, control). I then coded these key words along with the essential statements in NVivo computer software. I organized these codes into code files, wherein I grouped together all statements with like key words. Roughly twenty code-files emerged from the narratives, with over nine hundred statements spread between them. I analyzed these code files to ascertain what themes were emerging from the data given the grouped statements.

After I ascertained what themes had emerged from the essential statements across all the narratives, I applied these themes to each interviewee's narrative to determine goodness of fit by asking myself: "Is this what the experience was really like for this person?" Once I had determined the themes to be accurate, each interviewee's narrative was re-developed into a reflected life story (for an example, see Appendix D). Within phenomenology, a reflected life story is one in which the meaning of the phenomenon has been grasped and clarified through a textual treatment, as compared to a prereflective understanding that relies on taken-for-granted or preconceived notions of the phenomenon (van Manen, 1997). I reconstructed the narratives into reflected life stories as a way to orient the transcriptions towards a concise representation of the manner in which an interviewee encountered the essence of co-instruction. This process served two purposes: first, the back-and-forth between individual, shared, and individual experience 
allowed me glean the essential and shared lived experience of co-instructing, and second, it allowed me to perceive how to present those experiences to the reader.

At this point I had been through each narrative six times and was ready to present the essential themes that had arisen through the analytic process. I treated the essential themes that described the essence of the co-instruction phenomenon in two ways for this study: analytically and thematically. Chapters IV and V present the analytic and thematic presentations of the data analyzed in this study, respectively. van Manen (1997) describes the purpose of an analytic textual treatment as appropriate for in-depth interviews as a way to reveal "a more thoughtful understanding" (p. 171) of a phenomenon when juxtaposed with commonly taken-for-granted conceptualizations. He states, "to write is to re-write" (p. 131). For the analytic treatment, I re-wrote a shortened presentation that captured how each participant encountered the shared experience. After re-writing the interviewee's representation of their co-instruction experience for Chapter IV, I gave each interviewee the option to read how I had represented his or her experience, given the phenomenological analysis. This allowed me to ask the interviewee the question of "Is this what the experience is really like?"' (van Manen, p. 99).

I also engaged in a thematic analysis, which builds on an analytic treatment, breaking down the reflected narratives into their essential themes. As such, it reveals the systematic investigation of the themes that make up a nuanced description of coinstruction. To this end I identified the three essential themes of the co-instruction phenomenon and the various aspects of those themes that emerged from the data, as well as the meanings made of the co-instructing experience. I portrayed these essential themes and their aspects with exemplar anecdotes and statements to provide access to the 
complex nature of the co-instruction. After engaging in thematic analysis, I met with and described to participants how I understood the experience they shared with me to fit within my phenomenological understanding. This collaborative process was an opportunity to gauge the accuracy of both my analysis as well as the fairness of my representation of the interviewees' experiences. Interviewees indicated that the analytic process had revealed the essence of their story accurately, and were often surprised by the ease with which they identified with the described essence of co-instructing. These member checks affirmed for me that the method of data analysis was appropriate in attending to my initial questions.

\section{$\underline{\text { Bias and Risks }}$}

\section{My Role as the Instrument}

In any qualitative inquiry, the researcher invariably influences the study in several ways. First, in reaching out to a community of which I am a part, I set myself up for possible limitations that must be acknowledged. My desire to contact instructors for interviews, or those who have been referred, may have brought with it a bias to contact those who fit my own definition of who is an "experienced" or "good" instructor. Likewise, I may have shied away from contacting people whom I did not think would be a "good" interviewee, either consciously or subconsciously. While I attempted to account for this issue by requiring myself to interview people who I had not worked with, the field is ripe with gossip and reputation that may have impacted my selection. I could, and attempted to, turn this issue around by being aware of this possibility and using my personal experience in the field as a guide. The role I took in this phenomenological study that used qualitative interviewing, was that of the instrument (Seidman, 2006). 
Second, unlike quantitative research methodologies where data is gathered and analyzed objectively, this study was a direct result of my own interplay with the data that I recorded, transcribed, analyzed, and presented. My own experience as a practitioner in the field was acknowledged and used to the advantage of the interview and analytic processes. I attended to this in several ways, which I discuss below.

\section{Diversity beyond Appropriate Engagement}

One way I attempted to handle my own subjectivity was to sample interviewees with experience in 'paradigmatic' outdoor organizations: NOLS and Outward Bound. The practices of these programs are prevalent throughout the adventure education field and have commonalities with each other (Goldenberg \& Pronsolino, 2007). Although qualitative research is not designed to provide generalizable data, interviewing professionals who work for NOLS- or Outward Bound-type programs hopefully provided a greater opportunity to understand commonalities throughout the field as a whole. The nature of the field and manner in which organizations are benchmarked or draw from common practices may allow my participants' experiences to showcase universal themes despite their limited diversity.

\section{Bracketing}

My experiences as a co-instructor for over 10 years have created my own understanding of what co-instructing is, at least for myself, and this personal experience has impacted my analysis and conclusions that are drawn from this inquiry, as any researcher's own life experience will impact their analysis (van Manen, 1997). I have attempted to attend to this risk through a process of bracketing. Berndtsson, Claesson, Friberg, and Öhlén (2007) explain the premise of phenomenological research as gaining 
"access to various phenomena...through the interpretation of people's lived experiences" (p. 261). In order to accomplish this, researchers must be able to think phenomenologically while engaged in the study. Berndtsson et al. lay out a need for a methodological process that includes openness, flexibility, and practices that "emphasize a reflective stance" (p. 261). Paralleling Seidman's (2006) beginning-middle-end structure, I attended to my involvement in this investigation in a three-fold manner:

Beginning. The process of writing a proposal, familiarizing myself with phenomenology, and reflecting on my own experience as a co-instructor allowed the space in which to examine co-instructing outside of my natural (pre-reflective) attitude towards the experience (Sokolowski, 2000). Instead of confirming or disconfirming my beliefs regarding co-instructing, this process helped me recognize the need for, and peaked my interest in, examining the phenomenon through others' experiences.

Middle. An appropriate interaction while embedded in an interview depended on the creation of the "I-Thou" relationship (Seidman, 2006, p. 96). The result was an interview that bordered the edge of conversation while remaining professional. Despite this juxtaposition, the interviews focused primarily on the participants' experiences and ability to convey those experiences as independently as possible. I attended to remaining within a phenomenological attitude, that of suspending belief or acceptance in exchange for an interest in the participants' experiences and understanding of their experiences, during the interview process in three ways:

1. Self-Preparation: I spent time reviewing previous interviews with the participant, double-checking methodology, and re-reading Sokolowski's (2000) description of the 'phenomenological attitude' (p. 47) as necessary to become 
engaged in the appropriate researcher mindset.

2. Self-Awareness: During the interview I occasionally performed a mental check to make sure that I was engaged specifically in understanding coinstructing through the participants' experience rather than my own.

3. Self-Reflection: Phenomenological thinking inherently incorporates some kind of reflective process (Sokolowski, 2000). After each interview I logged in a journal at the end of my interview notes, attending to my thoughts on the interview, comments or ideas that had struck a chord with me, and any ideas for upcoming interviews. In this way I was able to avoid a natural carry-over of any unexamined experiences that I engaged with during each interview.

End. Throughout the analytic process I was directly engaged in reflecting on and deciphering the essence of co-instructing as experienced by the participants in the study. To allow the space for this, I kept memos that detailed my analytic process, creating a logic trail that I could examine periodically. Those memos were specific about where in my transcriptions I had a particular idea or question (a detailed code was set up for participant, interview, and page; e.g., a statement in Participant 2's third interview on page 8 was coded as $P 2,13,8$ ), and allowed me to have the space to stop and ask myself later, "How and why have I arrived at these conclusions?" Periodic meetings with members of my committee during the research process also served as a way to explore alternate understandings and ensure a level of transparency in research.

During the pilot phase of this investigation, the issue also arose of allowing potentially important descriptions of the participant's meanings or definitions of phrases and terms to go un-checked. In essence, I was making the mistake of assuming that $m y$ 
definition of a phrase would be sufficient to capture their meaning. This risk was kept very much in the forefront of my mind while interviewing, and I asked participants to provide a definition of any term that they were using if there appeared to be a possibility that I would be required to assign meaning to their words later.

My background was used as an advantage, in that I was able to understand the terminology and concepts that were described by participants. This allowed my interviews to be guided through a preliminary understanding, not a blind groping for information. Instead of a detriment of bias, I believe my situation within the field created, according to Seidman (2006), a "smart, adaptable, flexible instrument who can respond to situations with skill, tact, and understanding" (p. 23).

\section{Participant Risk}

The investigation included potential emotional or legal risk for participants. Participants were being asked to reflect upon and reconstruct a personal lived experience, and the potential to reflect upon a poor working experience was possible (as we will discover was the case for Jennifer). The risk was of professional work experiences, though, and the actual risks of the interviews requiring a participant to reflect on a traumatic event were minimal. Likewise, information could have been disclosed that may have placed me in an ethical dilemma of disclosure (i.e., child abuse, threats of harm against self or others, etc.). Participants were not asked questions directed toward these issues, but the possibility of disclosure remains in any in-depth conversation. If participants did disclose illegal activity, it may have stemmed from either a feeling of safety or a desire to disclose information that weighed heavily on their conscience. If information had been disclosed that must lawfully be reported it would have resulted in 
the disclosed dialogue being reported to the appropriate authority, but luckily this did not occur. Potentially unethical or illegal activities were raised in the interviews that were not necessary to report, and the disclosures were treated on a basis of appropriateness to the subject. For instance, if ethically questionable information (such as alcohol use) was disclosed, and was determined to be relevant to the research, it remained a part of the study. If it was determined to be unrelated, dialogue was steered back to the topic in the same manner as any other interview tangent. For instance, I would ask, "can you help me understand how that relates to co-instruction?" Participants were notified prior to the start of the first interview of their rights regarding disclosure of illegal activity. Despite these possibilities, all of the participants were consenting adults and the risks were primarily minimal in nature.

\section{$\underline{\text { Scope }}$}

I encountered all aspects of this study as a novice researcher; indeed, this was my first attempt at phenomenological research. Phenomenology itself is a vast discipline with devoted scholars and multiple approaches to understanding our lifeworld, much of which I did not touch upon. Because of my own purview, my budding abilities as a scholar, and time and preparation, I appropriated a single phenomenological approach for my interest in co-instruction yet did not elaborate on implications of this study on the methods and principles of phenomenology itself. My claims, therefore, are limited by the scope of the overall research approach used in this study.

\section{Claims}

I noticed possible paradoxes and limitations to the claims of this study while engaged in the writing process. First, from a phenomenological perspective it is clear that 
there are three groups of people who experience co-instruction in their lifeworld: administrators who utilize the construct as part of a larger organizational agenda, which centers on concerns for risk management and client satisfaction, co-instructors who practice the phenomenon, and students who learn by witnessing different instructional styles and may be affected by the social dynamics of the co-instructor pair. I originally set out to determine what co-instruction is to those who practice it, and so in one regard have been successful, yet now realize that a complete understanding of the phenomenon is not possible without also investigating the experiences of those who manage and are educated by co-instructors. Therefore, on the one hand, this study is partial because it privileges one perspective. On the other hand, I have illuminated how the central practice of co-instruction is experienced by the people who live and practice it, which can help refine this crucial dimension of adventure work.

Second, my sample of co-instructors was relatively narrow at only five interviewees. I did this to provide a balance of variety and depth, and given the robust themes and resolutions that emerged from the interviews I consider myself very fortunate to have interviewed the people whom I did, but a larger group of co-instructors may yet yield a deeper understanding of the phenomenon with greater nuance. Likewise, the interviewees that took part in this study, while working for a variety of programs, were rather homogenous. All interviewees were in their late 20 's or early 30 's, had some level of graduate school education, and were people with whom I had some level of connection due to my own involvement in the adventure education field. Although phenomenology is not invested in the generalizability of findings, it is invested in discovering the universal 'itness' (van Manen, 1997) of a phenomenon. Thus, a larger sample size 
drawing from a greater pool of co-instructors may provide deeper insight into the universal qualities of co-instruction as a lived experience.

Lastly, this study provided a relatively broad overview of the shared experience of co-instruction that emerged from the interviewees' narratives. A co-instructor may have had a very specific and potentially impactful encounter that was not analyzed and addressed within this study due to the individualized nature of that encounter. Likewise, co-instructors in general may have specific encounters with the phenomenon that were not discussed with depth here. For instance, Clemmensen (2002) has addressed the nature of gender differences in co-instruction; while possibly part of the phenomenon, the issue was not addressed in depth within this study, as gender did not explicitly arise from the narratives as a shared theme. This in no way discounts the potential benefits or hardships that may arise from gender dynamics in co-instruction, but brings to light the concept that different people, and pairings of people, will have their own encounters with a phenomenon, some of which are shared as part of the universal quality of the phenomenon, and others that are distinct. Future research into the lived experience of coinstruction may continue to elucidate the various manners in which the phenomenon exists as part of the co-instructor's lifeworld.

\section{Consent}

Audio consent was recorded at the start of each interview. I provided each participant with written information about the study (see Appendix B), including:

- the length of the interviews

- the manner in which their interviews would be kept secure

- their rights as participants 
Upon reading the consent information, participants were asked to state their name and indicate whether they agreed to the terms. If they agreed to the terms of the study I began the interview process. All audio consents were fully transcribed with the interview, although I changed the names of the participants; those pseudonyms became the names used throughout the entire transcription process for each participant.

\section{Research Timeline}

I received Institutional Review Board approval for the use of human subjects in this study (See Appendix A) during the spring of 2009. I submitted a formal proposal to begin the study in November of 2009. Research then followed as the timeline below:

- interviewing during the fall and early winter of 2009/2010,

- analyzing and coding data during the winter of 2010 , and

- writing a full thesis report during the spring and early summer of 2010 .

The interview, transcription, and analytic processes of this study revealed the complexity of qualitative research. I was both surprised and pleased to act as the research instrument (Seidman, 2006), by which I mean that I enjoyed being directly engaged and linked with every step of the research process. I intuited in-depth phenomenological interviews (Seidman) to be attending appropriately to my research questions even while embedded within them. Through the analytic process and in treating the emergent results both analytically and thematically, it became clear that the co-instruction phenomenon could be elucidated via this technique. I detail the findings of the study, both analytically and thematically, in the following two chapters. 


\section{CHAPTER IV}

\section{CO-INSTRUCTORS' RECONSTRUCTED LIFE STORIES}

\section{Introduction}

This study was undertaken for two primary purposes: to extend scholarly knowledge of the ways co-instructors participate in their work, and to investigate the essence of co-instructing as a lived experience. I was drawn to the topic because I sensed a paradox: on the one hand, co-leadership is espoused in the academic and training literature as a practice characterized by equal power and shared responsibility between professionals, yet on the other hand, anecdotal information and research indicates that coleadership is rarely arranged this way in practice (Austin, 2001, Kolodny, 1980). Indeed, this was my experience with co-instructing. Therefore, co-instructing as presently defined may create an environment in which, as Van Manen (1997) writes, "our suppositions, assumptions, and the existing bodies of scientific knowledge... predispose us to interpret the nature of the experience before we have even come to grips" (p. 46) with the true nature of the phenomenon. It is therefore appropriate to enter into the co-instruction lifeworld starting with the reflected experiences of co-instructors.

A phenomenological analysis of the lived experiences of co-instruction, obtained through in-depth qualitative interviews (Seidman, 2006), may either confirm or contradict the "taken-for-granted... conceptualizations" (van Manen, 1997, p. 171) of co-instruction 
as it is currently discussed in academic literature. Regardless of their conformity to existing views, such narratives of co-instructing will enable readers to begin to grasp the essential nature of co-instruction as a lived experience. In this chapter, I present the reflected narratives of the five co-instructors who took part in this phenomenological inquiry in order to acquaint the reader with each participant, and to begin to describe the nature of his or her experience of co-instruction. Participants included:

1. Jeremy, a 28 year old male who has been working as an outdoor professional since he was an undergraduate in college;

2. Bethany, a 29 year-old female who co-instructs sailing courses off the coast of New England.

3. Peter, a 33 year-old male who has a dual role of both co-instructor and trip leader on a summer wilderness adventure program in New England;

4. Jennifer, a 28 year-old female who co-instructs wilderness programs at a Midwestern University; and

5. Erin, a 27 year-old female who was instructing year-round for a wilderness program in the mountains of the western United States.

The reconstructed co-leadership stories of Jeremy, Bethany, Peter, Jennifer, and Erin are presented below. In Chapter V, I present the central themes and their aspects that emerged from the co-instructors' narratives.

\section{The Participants' Narratives}

\section{Participant 1: Jeremy}

Jeremy's background with co-instructing had been with a university outdoor adventure program and within the wilderness therapy field; both locations where he felt 
that he had clear roles and expectations for his co-instructing arrangements. When he was hired to work a 25-day wilderness course during the summer of 2009 , he found himself in a co-instructing environment that he immediately perceived to be less clear. $\mathrm{He}$ explained,

...it was set up as 'you will be co-instructing,' so there wasn't necessarily a hierarchy defined. However, when I got there I found out that there was a hierarchy, and that technically she, her name was Susan, that technically Susan was going to be in charge. It was just because she had worked for the program before.... Our boss, though, basically confided in me that he was concerned with Susan's abilities, but confident in the two of us, especially given my strengths and her weaknesses and vice-versa. I think going into the field with that knowledge affected my understanding and my opinions of her, at least to start with. P1, I2, 1

This revelation by Jeremy's boss complicated his own need to develop an understanding of who this person was with whom he was sharing his course-life:

I'm really just operating on the blind faith that the program isn't going to hire somebody who's not qualified. Still, early on I'm putting myself out there through talking- talking about experiences and looking at their reactions. It's me saying, 'hey, I'm trying to get comfortable with this person that I'm going to be spending however many days with, and potentially putting my life and my reputation in their hands. P1, I2, 15

Jeremy's ability to operate comfortably with Susan was hampered, however, by the interplay that occurred between his assumptions, his interactions with Susan, and what he evaluated Susan's abilities to be:

That initial size up- seeing where the other person's at and going from there... I felt like it never stopped happening; there was always some level of sizing up, there were assumptions of where she was at, and then there were realizations of where she was at. In this case I didn't feel like I ever really figured it out because of her technically being the 'lead' instructor. When I walk into that situation I have a lot of assumptions about where they're at, and so I think that was when it got really confusing and frustrating for me. P1, I3, 2

Jeremy and Susan ran into challenges outside their control while on course, including a student sustaining an injury. The student was initially removed from the field, 
but later brought back in because her completion of the course was required within the program. The re-inclusion of this student meant significant changes to the course flow, and Jeremy soon discovered that he and Susan would be at odds over how to interact with the challenges they would face working together. He recounted,

[I think we had some] personality differences. When I'm given a challenge, I immediately problem solve until I have something that I feel confident or satisfied with as a solution- whereas her, she just wanted to complain. We would have issues come up on course that were out of our control, so I would throw out options, right? And she would shut them down progressively as I would go through my list because there was no perfect option. Now I'm perfectly happy to admit that none of my options were perfect, there wasn't going to be one. But what I was hoping for was to have a dialog about what the best choice was at that moment. P1, I2, 4

Jeremy's perception that Susan was not willing to acknowledge his attempts at ownership in the decision-making process of the course caused him to adjust his approach:

I began thinking, 'all right, great, you can make that call, the program has said that they trust your decision,' and the role that I took was in trying to get her to think about why whatever the idea that she would pick was better than the others. So trying to get her to be intentional with her decision-making. At some point I started to feel like I was responsible for some of her growth as a leader despite the fact that our roles wouldn't necessarily indicate that within the type of the system that I've worked in previously. I just felt impelled to try and teach her a little bit, because it seemed like she needed it, if that makes sense. P1, I2, 6

This detachment from the decision-making and outcomes of the course was frustrating for Jeremy: "It was extra stress, because the system wasn't set up that way. I thought my role was an 'assistant', I was thinking, 'I shouldn't be doing this, this isn't my job"' (P1, I3, 6). A re-interpretation of his roles was necessary to remain incorporated in the course: “...it just struck me that, well, I'm out here to educate, and I started thinking more about who I am educating. And; why am I delineating a box [laughs] around the people that I am and am not teaching, helping grow?" (P1, 13, 6). 
The newfound ownership and responsibility for the growth of Susan did not, however, offer a solution that Jeremy was content with:

I don't want to say that I checked out, but I made the realization that, 'ok, I just need to be professional, and we're probably not going to have the amazing relationship that I've developed as a co-instructor with other people on other trips, that's just not going to be my reality on this trip. But it took me a while to accept the fact that we may not leave this trip being friends, you know? P1, I2, 4

Due to previous co-instructing relationships, Jeremy had become "used to a certain level of investment in a co-instructor as a friend, because they're your ally for the next however many days" (P1, I3, 8). The lack of investment in this co-instructor as a friend, despite the clear investment in Susan as a budding professional, left Jeremy with a mixed impression:

We did what we had to do to have a successful trip, but it was never easy, it was consistently work, and we were doing our job. The trip was just lackluster, it was, 'oh, yeah, I'm out here for 25 days with you and that's not that exciting to me', you know? It wasn't awful, it wasn't like I don't ever want to talk to her again, but it just didn't have that meaningful connection that happens a lot, at least for me. Instead the dynamic really stalled out with us. It never felt like it went anywhere, and for a 25day trip that's pretty uncommon; it felt awkward and uncomfortable all of the way through. P1, I3, 9

For Jeremy, the co-instructor as friend superseded the co-instructor as professional teammate in personal priority while on course. It would appear that Jeremy lacking a 'meaningful connection' to Susan complicated both their ability to coordinate their professional relationship satisfactorily as well as meet Jeremy's expectations of a successful co-instruction experience.

\section{Participant 2: Bethany}

The program Bethany was working for provided her in many ways with an introduction into wilderness co-instructing, having spent time previously as a wildlands 
fire fighter, athletic trainer, and environmental educator in camping programs - each

largely individual roles. Her entrance into her co-instructing experience was markedly different than Jeremy's in her interpretation of the organization's role. She explained,

The program likes to do this cryptic thing where you don't find out who you're working with until a day or two before you go out on course, and usually that's only because you consult with everyone else who's staying at the staff house... it seems like [the administration] is pairing people by just saying 'well this person's available for this week, and this person's available for this week, I guess they're gonna be on this course together.' It's more or less assumed that you're both adults, you'll figure it out, but we live in a country with a divorce rate of 50 percent- people clearly can not figure stuff out. P2, I2, 1

After consulting other staff at the program's home base, she realized that she might be placed with a co-instructor, Gavin, with whom she had worked with the previous summer. The opportunity to re-visit a known relationship was recounted by her:

When I found out that I was working with Gavin, or that there was a good chance that I was working with Gavin, I was pretty excited because it was a good opportunity to build on the relationship we had started the year before. We had gotten to be good friends on the previous 25-day course we had done the year before. We had worked fairly well together, though there were some issues. I was excited because I felt like I was closer to him, so our working relationship was something that could actually be addressed now. That previous year we were still working out the kinks, and just getting used to each other- now we could actually fine-tune our work relationship, and we'd be able to call each other on stuff more. P2, I2, 1

The previous year Gavin and Bethany had become close friends, and the relationship was one in which she felt cared for outside of just her professional engagement. She described times on this course where she would take the students running while they were docked, and would return to find "some sort of little treat tucked away into my dry bag; I would open it and there would be a diet coke waiting there for me, or some sort of cookie, and it was like a little piece of heaven" (P2, 12, 10). Their non-professional relationship played out both hidden and in plain view of the students. 
She recounted,

Whenever we were docked somewhere and we had to go ashore, one of us would 'go see the harbor master about permits' while the other one was watching the kids. But 'going to see the harbor master about permits' was a euphemism about seeing what convenience store or local burger joint happened to be open where you could obtain some sort of contraband. So he'd be like, 'oh, I've gotta go see the harbor master to make sure that we have our permits for going over into this part of the water', and I'd say, 'oh, don't forget to check on the permits that I had asked you about before.' The kids would be like, 'he's been gone at the harbor master for a while,' and I'd respond, 'yeah, usually there is some paperwork you've gotta fill out, it's a little bit of a process.' Sometimes if we were there for a while he would come back from the 'harbor master' and say, 'they need to see your paperwork as well.' I'd ask, 'oh, where is it?' and he'd say, 'oh, up around the corner, look for the red awning.' And I'd get around the corner and it'd be red's lobster hut or something. We had our little secret language for how we talked to each other without the kids knowing. P2, I2, 17

While they were confident in their social relationship, Bethany explained that they

continued to develop their professional relationship. In one example,

I was trying to do some lessons on things that I wasn't as comfortable teaching. I was supposed to teach anchoring, so he was like, 'here you go, you can use my little anchor,' which is this keychain he has. We all got into 'feet in the cockpit', which is what we call it when everyone crams themselves into the world's smallest space, and we're sitting there and all of a sudden he starts teaching about anchoring. It was like he had completely, in the space of 3 minutes, forgotten that we had discussed me teaching it. P2, I2, 7

During the summer before, Bethany thought that she had "played a little bit of lip service to the 'yeah, sure, we'll have check-ins, we'll do feedback', but that's easier said than done in certain instances" $(\mathrm{P} 2, \mathrm{I} 2,8)$. Having been through that course, though, and having developed their social relationship during it, she was better prepared this time: "I definitely felt more comfortable talking to him, and felt a little bit less pressure with the whole 'boss man, captain' situation, with my 'assistant' role than I had the year before. We had the experience together, the friendship" $(\mathrm{P} 2, \mathrm{I} 2,8)$. While last year she may not have addressed Gavin taking away her teaching opportunity, this year she felt enabled by 
their relationship:

...that night that was one of the things that I mentioned to him. I said, 'you know, we had discussed initially me doing more teaching, but there have been a couple of occasions now where I was supposed to teach something and you took off like a bat outta hell', and he was totally unaware. He didn't realize he had done it. P2, I2, 8

For Bethany, her friendship with Gavin was crucial to the success of her

experience on the course. She explained their time together:

Gavin and I talked about everything, you know? Relationships, love, life, sometimes politics, sometimes our families. On parts of this course my cell phone had service, so at night before going to bed I was able to text Elizabeth, or she would send me random text messages and I would get them whenever my phone would have service again. I could talk to Gavin about that, and it was a way of staying connected to being an adult and having a world, a type of relationship that exists but sometimes seems very far away when you're dealing with the day-to-day strife of a 15 year old who can't get his pants dry, you know? P2, I3, 12

In the end, it was this relationship with Gavin that made up the primary meaning for

Bethany in her experience as a co-instructor. She explained her co-instructing

perspective:

I don't know that I have to be as close of friends with them as I am with Gavin, but I definitely have to enjoy the person. There's got to be some sort of relationship that goes beyond just this professional relationship of 'you teach this, I teach this. You do this, I do this.' There's got to be some sort of connection for me on the personal level. I don't think that would necessarily be the case if it weren't for the fact that this is your life for weeks when you are on a course. If I was just facilitating a program and then went home where I had my social network that would be one thing. But when you're talking about an experience where there is no going home, where this is my home, then for me I need to have all aspects of what I would want in my home life present. P2, I3, 18

Bethany, similar to Jeremy, spoke of the role of friendship among co-instructors as being a crucial aspect of a successful experience for her. In addition to her connection with Gavin creating a sense of 'home', it was this very friendship that also broke down the boundaries created by institutionalized power dynamics that she perceived as 
restraining her professional goals.

\section{Participant 3: Peter}

Peter explained his role as trip leader, which is the person overseeing all

components of the trips in that region over the summer, as "setting [all of the instructors]

up for success. Or that's how I try and see it, is setting them up for success and then

empowering and trusting them. I've given them what they need to do whatever their job

is" $(\mathrm{P} 3, \mathrm{I} 3,1)$. During the summer he reconstructed in our interviews, his roles as trip

leader and co-instructor overlapped in a way that paired him with his co-instructor for the

second half of the summer. He explained,

...we were half-way into the summer when one of our instructors had to go home due to a serious family illness, so we promoted our intern to being an instructor, which was Joanne. She was 18 , and not that experienced, so in the backcountry she and I were always together. Because it's always male/female pairings, certainly the first backpacking trip I'm paired with the weakest or least experienced female instructor, and I work really hard during that trip to empower her in every way I can. The hope is that that will lead to good things in the future. P3, I2, 1

He was at first concerned with having someone so young on staff, both due to her age and due to the rigor of the job:

...it's not always an easy job. We have a great saying about our role, somebody wrote out once what an instructor was, and basically you're a superhero. You have to be doing everything: as an instructor you're never cold, never hungry, never tired, your pack's never heavy. Even though you obviously are feeling all of those things, the students don't feel like you are, because you are always trying to create the positive. So I really tried to set Joanne up for that as best as I could. I tried to give her more up-front leadership than I probably would have otherwise if she had been older, because I wanted to make sure the students saw her as a leader. I had her really do everything with the group starting on day one to get them on the trail. P3, I1, 14

That professional support for Joanne was something that Peter was glad that he could provide, and he recounted how he interpreted her reaction to how she received that 
support:

You know, for me I feel like when I get in the backcountry it's the time that I can take a deep breath and relax, things in the backcountry are pretty simple- dealing with a group of eight students and one co-instructor isn't much work for me, so I really focused on helping her. Essentially each day we'd go over our highlights, lowlights, and things we would change, and then we would look at the next day and say 'how do we approach it?' We would talk about any student issues and any health concerns that were cropping up. Each night it was almost comical to debrief with her because she just would beam with excitement about what she'd learned that day, and it was so cool. She was always thanking me for ways I'd set her up for something and had a constant excitement at the experience that she was involved in, and how she felt about what was going on- it was so wonderful to be a part of. P3, I2, 15

He recounted an example from early on in the course with Joanne where he aided in her development as a professional:

I think it was the third day that she got frustrated with some students, two boys in particular, feeling like they weren't listening to her very well. She and I talked about it at a lunch break; she pulled me aside, totally appropriately, and said 'what do you think I should do?' And I said 'well, why don't you pull them aside and have a discussion with them, see how that goes?' And she did, and then they went to the back of the line with me, so that as the day went on I could talk with them about it a bit, too, and they were really apologetic. P3, I2, 15

The professional relationship he developed with Joanne began to evolve as they progressed through their course and Peter began to learn more about her as a person. Before the summer, Joanne had been a student in the school that Peter teaches at where she had developed a strong relationship with Peter's wife, who was the head of Joanne's dorm. Despite the closeness between Joanne and Peter's wife, he explained their relationship going into the summer as lacking depth. He recounted the transformation of his relationship with her:

I knew about Joanne on a very surface level. Before this course I just saw her as a really good kid who was student body president and who seemed like a responsible kid that loved the outdoors. And I think that, just like when you're in the backcountry with most people, you learn everything. I learned about her family background beyond what she'd shared with the group, learned the tough times she has had, and really what makes her who she is. And learning all those things was 
really great, and gave me a greater appreciation for her complexity as a person. I think part of it is the one-on-one environment, there's an intimacy to sharing a tent with somebody, and I think it's facilitated by showing caring throughout the day. If somebody feels like you're supporting them on a professional level, and they would like support on a personal level, they're going to test the waters and see if you can help provide some support and greater understanding for who they are. And they are willing to tell you more about themselves. P3, I3, 13

Peter took on what he described as a "big-brother" $(\mathrm{P} 3, \mathrm{I3}, 13)$ role with Joanne; in which "the type of relationship [that] we have is very caring and very real, in terms of knowing what's really going on there" $(\mathrm{P} 3, \mathrm{I} 3,14)$. He explained his understanding of the power of co-instructing:

In those backcountry times you can see why somebody is such a great leader. And at times, on the other side of it, you see that they're not. You can see that they're really nervous, or that certain things intimidate them. Working really closely with another person you can really come to appreciate them as a human being, as well as them as an instructor. I'm often amazed when I work with someone new and they start pulling out new games for kids to play on trail- things that I've never heard of. Or I see them basically sacrificing, demonstrating how much they care about their students and how comfortable they are in their role. I think a big part of that relationship that is built is modeling, for our students. When they arrive they can sense that we love each other; that we're a group of people who really genuinely care about one another. And we treat each other with respect, and that then goes to the students. But I think in terms of retention it helps that we work together, it helps to have an understanding for who somebody is. P3, 13, 10

Beyond a relational model for students, Peter explained that co-instructing also "ideally creates meaningful friendships" $(\mathrm{P} 3, \mathrm{I} 3,16)$. He recounted times that coinstructors have continued to keep in contact after courses end, and added that he and Joanne still touch base on a weekly basis. For Peter "it's always amazing; staff has a tendency at the end of the summer to hang out. They're done, and they don't want to leave. They want to go climbing together; they don't want to leave" (P3, I3, 16).

Here, Peter recounted an experience where his attention to how he could provide professional support for his co-instructor in a mentorship role blossomed into a 
meaningful friendship. His vignette adds depth to the picture painted by Jeremy and Bethany, pointing possible variations in how co-instructors may approach supportive and satisfying co-instructor relations.

\section{Participant 4: Jennifer}

Jennifer began describing her experience by recounting a winter course she had been preparing for over the previous year with a co-instructor, Paul, who had a history of instructing that very course. Outside of teaching the university's winter courses, she had known Paul from the outdoor adventure program at the university, an interaction that aided in building Jennifer's relational connection to Paul:

While we were working there he had gotten fired, and I think it was a lot of little things that led up to that. It was for not wanting to follow the University's rules about climbing, and I think he called somebody an asshole to their face while he was working. So we had worked together and I'd never cared for him, and I knew he had gotten fired. So I knew a fair amount about him. Eh, I didn't really know him that well, but I knew that he wasn't necessarily my favorite person on the whole planet. P4, I1, 6

Jennifer and Paul began to prepare for their upcoming course that October, which was to span December and January. They met weekly and also went on a scouting trip to their prospective course area. Jennifer recounted her expectations for their time spent in preparation:

I had really been hoping for that experience to give us an opportunity to talk through our relationship, because I knew that we were going to have trouble working together right from the beginning. From the moment I even began thinking of working with him, I knew it was going to be difficult for me and I knew exactly why it was going to be difficult for me. But I don't think we did a very good job of addressing any of that up front. I think we sort of skirted our issues. P4, I2, 3

As Jennifer saw it, they did not take the opportunity to address their issues up front.

Because of this, she found herself required to address those issues on her own once the 
course started. She described having to decide how to interact with Paul during his teaching opportunities:

He often says things that are incorrect, either in wording and language or something similar. I was getting really frustrated in his lessons, because every third or fourth point that he would make had an incorrect word or false statement, and so on campus I started trying to figure out how to handle it. I was thinking to myself that I couldn't correct him in the middle of his lesson, because that made him look bad in front of the group, but I had a really hard time sitting there and watching him give incorrect information, so I had this become sort of a theme for me. I had to decide; I wouldn't say anything during the lesson and make him look bad- and make me look bad for saying something in front of the class; but then, am I going to sit here and let the wrong thing be said, and by not saying anything or correcting him be essentially endorsing it, which then in turn will eventually make me look bad? So my solution to that became that I would just go do something else when he was teaching, that I would just leave. I would physically leave and then I didn't know what was going on, and I didn't have to try and decide what to do about it. P4, I2, 3-4

Jennifer's decision to ignore Paul's educational practices was not reciprocated, however. On their first day in the field, during a group meeting, Jennifer decided to sit down on her backpack instead of sitting in the snow and soon discovered that Paul had a different style of interacting with what he felt was behavior in conflict with his values.

Jennifer explained,

One of the students called me out on it, they asked, 'are you allowed to sit on your daypack? Somebody told me you're never supposed to sit on your daypack.' And I said, 'well, I don't know, it's my backpack- I know what's in it, I'm not breaking anything, I'm not doing any damage to it, it's in the snow, I'm ok with it. I thought it through before I sat down on it, I didn't just plop down on it and break all my stuff.' And then Paul got in on it too, and said 'oh, you should never sit on your backpack, you're causing unnecessary wear and tear to it.' So I got called out in front of the group for not really a very big deal. That had me feeling like 'oh jeez', you know? I mean my face turned red, and I felt really dumb for being called out in front of the group on something that I had not really thought was a big deal. P4, I2, 6

Jennifer's experience was such that she "was completely miserable. And the first couple of days got that miserable ball rolling" $(\mathrm{P} 4,12,6)$ as the gap between she and Paul grew. She recounted that as the course continued they "started to disagree more and 
more" $(\mathrm{P} 4, \mathrm{I} 2,7)$ and she began to withdraw. Jennifer was "really worried that [the students] could hear us arguing....and that that wasn't good for them to see us arguing," $(\mathrm{P} 4, \mathrm{I} 2,7)$ and so for both the students' sake and her own, her involvement in the course declined. She recounted,

...in our evening debriefs, I kind of backed off from talking there, too. And I think there was a point where I just stopped having a real presence within the group from a leadership standpoint, because I was just so sick of trying to battle it out with him. I remember sitting there in an evening debrief and feeling really bad in general and kind of bad about myself for not sharing more with the group, and being mad at Paul for not asking me to share more. He would say his bit, and he wouldn't look at me and go, 'Jennifer, do you have anything to add?' He would just keep going. And I didn't step up; I just let him continue on in that pattern, because it was easier for me at that point than continuing to confront him. P4, I2, 12

Later in the course there was an evening where all of the groups' thermometers bottomed out at minus twenty degrees Fahrenheit. Jennifer recounted running around making sure everyone was fine, while Paul stood at his stove melting water and saying, "oh I'm cold, I'm cold, I must be dehydrated. I must be dehydrated. That's why I'm cold. So I just need to drink more water" (P4, I2, 11). The two of them argued for half of an hour over whether or not it was necessary to retrieve their emergency shelter, Paul adamant that they should while Jennifer felt that the hike to get it and energy expended in setting it up would be a greater risk than just going to bed. In the end they compromised because among the students "there was a small group of people who were interested in going for a walk," $(\mathrm{P} 4, \mathrm{I} 2,12)$ and Jennifer went with them to retrieve the shelter while Paul stayed at his stove melting snow and drinking water. While away from the students a few days later, Paul told Jennifer that he was "glad that you finally saw how important it was to go get the emergency shelter" (P4, I2, 15). And that, along with Jennifer's reply that she still adhered to her own beliefs about the risks of retrieving the shelter, "started 
our feud. I don't remember what time that conversation started, but we did not go to bed until after 3 o'clock in the morning" (P4, I2, 16). As the conversation wore on, Jennifer was able to address Paul on aspects of their relationship that had been troubling her: ....all of this stuff that I'd kept bottled up the whole eight or nine days that we'd been out so far just totally came out. I remember I started crying, and I was really upset, and I told him all this stuff that had been pissing me off. About how I felt like I had taken a backseat and that he powered through everything, and I was drifting out of the picture of being in a leadership role. About how I was falling into a followership role as this natural sorting out, since he's a strong leader. I mean, l'm a strong leader, but I recognize that it didn't make any sense to try and fight, because he was never going to give up and either more equally share or become more of a follower. P4, I2, 16

She shared with me that she was able to tell Paul that part of their power struggle seemed to stem from an issue of gender, to which he replied that "he had previously worked for somebody who once told him that women didn't have any place in the outdoors, because they weren't strong enough, they weren't as strong as men... and that he had spent a large part of his recent years trying to counteract that notion" $(\mathrm{P} 4, \mathrm{I} 2,18)$. Despite this late revelation, Jennifer and Paul "didn't revisit the whole 'he and I' situation after that," (P4, I2 17) and her experience with Paul continued to be one in which she felt "isolated" (P4, I2, 10). In fact, her minimal desire and ability to be a part of the coinstructor relationship had been solidified for quite some time by that point. As Jennifer recounted her experience, she described her understanding:

Somewhere very early on in the course I had decided that there was no way I was ever working with Paul again. You know, in every day life, you can sit out if you want to. You can sit out of anything and everything if you want to. But when you're in that situation, when you're out working with someone on a course, you can't sit out of that. At that point everything becomes work; you are living work. At any other time that I would have found myself in a similar interpersonal experience, I would have just distanced myself from that person. If Paul and I were not contractually obligated to work together I would not have spent that much time with him. Instead, I had to be there, and I think that it was a fantastic learning experience if for no other reason than I just couldn't get away from him. But it was horrible. It 
was horrible. $\mathrm{P} 4, \mathrm{I} 2,17$

Jennifer's reconstructed narrative provides an interesting perspective to the potentials that exist within the co-instructor relationship. She seems to indicate that neither professional nor social-personal support or investment developed between her and Paul, with a result that is of practical concern. Her co-instructor relationship, and perhaps co-instructor relationships in general, had the power to catalyze a significantly negative life experience.

\section{Participant 5: Erin}

Over Erin's final two years in her organization, she was instructing semester-long courses during the fall and spring seasons as well as wilderness courses from five to twenty-one days in length during the summer season. During the semester-long courses she was working with the two directors of the program, which she felt added an interesting dynamic. She explained,

I was co-instructing with Brandon and Katie basically the whole semester, and so I was working a lot with these two other people who I felt were clearly my superiors. I would get these feelings of, 'these people are qualified, why am I even here?' Moments of that at least, except for when I was in Ecuador with the students, where I had much more responsibility. I think a lot depended on how much responsibility I was given within our working relationship and that team. The responsibility helped me either feel like I had more or less of a purpose. P5, I1, 5

The courses would be split between the both the western US and South America. While in South America and in the western mountains there was a greater level of responsibility and stress, during which the leadership team and Erin's involvement became much more important:

...it gets lonely out there. We needed our friendship, to meet each other on a very human level- because we're constantly teaching, we're giving feedback, we're giving encouragement, we're telling people what they're doing well, what they could do better, and that's all great. But you know, it just isn't totally human to be 
constantly thinking as an outdoor instructor, and so sharing the load together and really listening and taking that time together as an instructor team, that was big. P5, I1, 3

Erin shared that she and Katie solidified their working relationship with their students while in South America, and then returned to the US to take those students into the backcountry for an expedition. While they had developed their working relationship with their students in South America, their relationship with one another personally had already existed for quite some time:

...the thing with Katie and I that is unique in our co-instructor relationship is that our friendship is so tight. We knew each other really well going into that course- we live in the same house, we share a car, we have worked together for 3 years, we've been out in the field a lot together. Then on top of that we had worked a whole semester with these students together, including our trip to South America, so there was a lot of familiarity. I would say that there was just so much background there that helped us a lot. P5, I2, 13

This familiarity aided Erin and Katie in their entrance to the field together. While she felt that in unfamiliar working relationships there is a need to establish co-instructor norms and practices, revisiting a known relationship took away from their overall workload. She explained,

Katie and I have so many norms together already. We'd been working together; we've been in the field so much, we already had our norms and so all the conflicts that come up among co-instructors weren't a burden, which is nice and restful. It makes a course much more restful. P5, I2, 15

Erin went on to share that she and Katie had spent so much time becoming familiar with one another, and trusting one another's abilities in the backcountry, that they had moved away from roles commonly found in her other co-instructing work relationships. Instead of roles based on strengths or weaknesses, she felt that their roles were set up to help one another have a sustainable course:

We had set up our roles such that each day one of us was a little more up-front and 
was the voice, doing more of the teaching and the working. Most of the work during the bulk of the day was with the route finding, but then with the demands of the course you tend to get more or less tired and in need of breaks. That's been my experience anyways, I used to never take them, you know? I didn't know why I would lose my patience or get so discouraged or frustrated, and I soon learned why with the help of Katie and other co-instructors. They would ask me, 'hey, do you want to take a break right now?' And I thought, 'can I do that? I don't think I can do that!' 'Yeah, you can do that. Go; go do that! It's fine.' I would say, 'wow, that's exactly what I need- I would love to do that!' It was great, I would take my book and go be mindless and journal and then I could return the favor for them. It's just the nature of being out in the field, it's not that the field's exhausting- but you have so many responsibilities. You're never not on, you're always responsible- in the middle of the night, something comes up, and you're on. You're taking care of it. P5, I2, 12

Despite creating a co-instructing dynamic that on the surface revolved around aiding in the rest and rejuvenation of one instructor, Erin pointed out that an attentiveness to the needs of the other, even during your own time off, was equally important to the success of their relationship. She recounted,

I was working with [a student] in the kitchen. He got up suddenly, and knocked over the stove- it was lit, and he started freaking out. I had to raise my voice at him and say 'No, Greg, stop! Step away,' and be firm with him. I think at that point Katie was hanging out by herself and reading and having her own quiet time, but she was close enough that she could hear 'wow, Erin's kind of overwhelmed right now,' so she came over to offer some help. I remember that night I had a little breakdown of my own. I cried a bit, and said, 'I don't know if I can do this, I'm so tired', because it had been basically 6 weeks in South America, and then coming right into this course, a week of expedition planning, just a lot of work loaded on Katie and I for that much time. P5, I2, 5

Katie stepping in was not only to check on the situation, but also to offer to help Erin.

The ability to obtain support in a manner that attended to both personal and professional requirements was difficult within that situation, however. Erin explained:

She offered- she said 'hey, just step away, just walk away from Greg when you can't deal with it anymore and I'll step in.' They have so much learning and this one particular student; he required extra grace and extra patience. Which Katie had, but I wanted to be able to give that, too. She was definitely willing to carry a lot more of that load with this student than I think I was able to. Which is nice, but at the same time I had asked for support in working on my patience with him, you know? P5, I2, 5 
Although there appeared to be difficulty prioritizing requirements in that situation, Erin shared that it was still of importance to be able to request help in her relationship with Katie. A few days later she found herself managing the students' breakdown of camp and discovered that she needed Katie's help. She recounted, All of a sudden I realized that I was too cold- I couldn't just stand there over Greg and help him with each thing; I was getting too cold and I was losing my patience; I was starting to get anxious. This was getting to be a dangerous cold, I knew I had to get moving, so I asked Katie to step in and I ran laps up and down the hill behind us to stay warm. I seriously did about 45 minutes of laps, running up and down this hill to try to get warm while she stepped in and helped Greg out. And once I got warm she was too cold, so for probably the last half hour or so she ran laps while I tried to help out with the last things in camp. P5, I2, 13

The success of her and Katie's co-instructor relationship, she explained, was their willingness to "serve and sacrifice" $(\mathrm{P} 5,13,1)$ for one another, which took the form of a willingness to be in negotiation with her needs and her co-instructor's needs. She would ask herself, "Am I willing to serve this person, and willing to make sacrifices for this person, even if it wasn't my original plan to do it this way?" (P5, I3, 1). This mindset runs counter to an attitude that Erin sometimes feels she sees in co-instructing, and one that she has had to develop the ability to address in herself:

I think that's pretty important that people come in and they see themselves as a part of a team, as a part of something bigger than themselves. They're not just like, 'how can I get the best skills for myself to do the most kick-ass super-instructor job I can do?' No. I think under stress people tend to retreat and they grab onto themselves, protect themselves and clam up. But when you're co-instructing you can't do that, and so you have to work together, you have to communicate in the midst of stressyou have to talk, you have to listen to that person. You have to make big decisions together while under stress. I think that was one of my biggest learning curves as a co-instructor, of bringing my co-instructor into my thoughts. Bringing them into my life, into my process, where I wanted to go or what learning I wanted to occur. P5, I3, 9

The ability to invite her co-instructor into her lifeworld allowed Erin to acknowledge the 
power of her relationship with Katie, and the influence that they have in each others'

lifeworld as both a professional and as a person:

I talked about grace and patience with the students and with myself, and all of that was exemplified to me through my co-instructor team. If Katie was not being patient with me, and gracious with me, I'm not going be gracious with myself- I'm already tending not to be. And it goes both ways; if I'm not being gracious and supportive to this other person, my co-instructor, then she's not going have that for herself. She's going to get discouraged, and so for sustainability, especially on a longer course, it's necessary in that co-instructing team. When I see her compassion, or extra gentleness with situations, or grace, or patience- that spurs me to have more of those things. That was one of the things that I appreciated about working with Katie, because I was spurred in things that made me a better person. P5, I3, 1

Erin's co-instructing experience with Katie ended up carrying meaning beyond her immediate professional engagement. The notion of co-instructing as an honest and service-oriented relationship with Katie permeated her understanding of co-instructing in a general level as well. She explained,

...my biggest learnings [in my job] have been through co-instructing, learning to work together with somebody well and serve and sacrifice for him or her well. To not be so prideful, threatened, or insecure that I can't learn from this person, or actually keep my students from learning from this person because of my insecurities and fear. I think that's the tendency sometimes, it's sort of the raw honest truth of itif we're honest enough with ourselves we realize that, yeah, we have a lot of pride and we're really confident and competent people out there with a lot of different skills going on; but the truth is that we're pretty insecure and we don't want to be one-upped by anybody. Or be shown that, wow, we're really not that superinstructor person. So in sacrificing all that bullshit lying aside, and learning about the person next to us, that 'co', and who they are and what they bring- it's way more fun, way more adventurous, risking. P5, 13, 12

Erin appears to indicate that the environment she works in creates a dilemma: to operate under the oppression of a stressful lifeworld, Erin can project a false image of supercompetence or admit her need for and invest in relational support. It was her relationship with Katie, and her acknowledgement of the importance of their relationship, that provided Erin with an experience of both sustainability and growth. 


\section{Conclusion}

Jeremy, Bethany, Peter, Jennifer, and Erin have all lived and shared their life as a co-instructor. These portraits by no means encompass their entire experience as I outline further in the following chapter, but they introduce some of the ways different individuals come to know co-instruction. Further, they extend and deepen the standard definition of co-instructing as merely a professional arrangement between peers.

The partial life stories I have reconstructed convey an overarching characteristic that will be useful for understanding the particulars I discuss in Chapter V; co-instructing was, for my participants, not merely fulfilling a professional role with a peer of equal status. In fact, for Jeremy the purely professional engagement resulted in a lackluster experience. Each co-instructor experienced his or her practice as one of a negotiated relationship that reverberated across his or her lifeworld as he or she maintained both professional and personal identity through his or her experience. While these coinstructors appeared to intuit that the student group and course success could be impacted by their co-instructor relationship, the meaning and implications of their co-instructing experience revolved sharply around the co-instructor team and their own participation within it. The quality of their co-instructor relationship, therefore, is a driving force in the quality and particulars of their co-instructor experience. The following chapter will elucidate the themes that arose out of the experiences of my five co-instructor participants, painting a picture of co-instruction as a negotiated relationship with multiple aspects and potential resolutions. 


\section{CHAPTER V}

\section{A THEMATIC ANALYSIS OF THE CO-INSTRUCTING EXPERIENCE}

Looking across the life stories presented in Chapter IV, I am claiming that my participants experienced co-instructing as a negotiated relationship between themselves and their co-instructors. As discussed earlier, co-instructing has been treated generally in the literature as a work arrangement in which two or more professionals share the responsibility for running a wilderness expedition. Co-instructors, when given the opportunity to talk about their experience, make it clear that this engagement is much more than simply a work arrangement to them. All of the participants in this study provided a complex view of an experience that encompasses their life world for the time of the course; for instance, Bethany described her co-instructor as her "way of staying connected to being an adult" $(\mathrm{P} 2,13,12)$ when on an expedition. The essential experience of negotiated relationship arose out of each participant's narrative, in their own context, indicating the manner in which co-instructing has impacted their professional and nonprofessional lifeworld on a wilderness expedition. An anecdote from Bethany provides useful detail in how she entered into the experience:

...it feels a little bit like a dance, almost, or like starting a new romantic relationship. Gavin would laugh if he heard me say that, but the first time you're out on a course with someone... I don't know anything about this person; I don't know what their buttons are. Yes, you can sort of talk about it during pre-course, you can sort of come up with the basics- this person does not want me to talk to them before they've had coffee in the morning, etc. But really, you don't actually know what they're going be like, and even throughout the course it's this ongoing learning 
process of how to work with this other person under the watchful eye of 15 year olds. P2, I3, 1

In various ways each interviewee spoke of how she or he approached, developed, and resolved the meaning of the co-instructor relationship throughout a wilderness course. This involved co-instructors maintaining both professional and personal identities simultaneously, and my interviewees' relationship with their instructional partners became the arena where tensions between the two played out. What this means is that a distinguishing feature of wilderness co-instruction, in comparison to collaborative work in other settings, appears to be the regularity and centrality of negotiating the dilemmas that arise when people work to balance their professional and social relationships, identities, and goals. With this definition in mind, "negotiated relationship" will serve as the central category-what I am claiming is the essence of the co-instruction experience-that I will now explore for its themes and aspects.

By analyzing the narratives of my participants, I identified four themes that came to define negotiated relationship and the manner in which the relational dilemmas were resolved. The four themes addressed, at times very specifically by the majority of the interviewees, were living work, the dilemma of the super-instructor, sizing up, and relational resolutions. I also identified several aspects within each theme. The manner in which the themes were encountered and attended to catalyzed different manners in which my participants experienced the relational dilemmas on course, but reverberated across the co-instructors' broader lifeworlds. The major themes and a list of their aspects are outlined in Table 1, along with a notation showing who addressed them in their narrative. 
Table 1

Shared Themes by Participant

\begin{tabular}{|c|c|c|c|c|c|}
\hline Theme & Jeremy & Bethany & Peter & Jennifer & Erin \\
\hline $\begin{array}{l}\text { Co-I } \\
\text { Relationship }\end{array}$ & $\mathrm{X}$ & $\mathrm{X}$ & $\mathrm{X}$ & $\mathrm{X}$ & $\mathrm{X}$ \\
\hline Living Work & $\mathrm{X}$ & $\mathrm{X}$ & $\mathrm{X}$ & $\mathrm{X}$ & $X$ \\
\hline Home & & $\mathrm{X}$ & $\bar{X}$ & $\mathrm{X}$ & $\mathrm{X}$ \\
\hline $\begin{array}{l}\text { Inescapable } \\
\text { Partner }\end{array}$ & $\mathrm{X}$ & $\mathrm{X}$ & $\mathrm{X}$ & $\mathrm{X}$ & $\mathrm{X}$ \\
\hline $\begin{array}{l}\text { Intense Form of } \\
\text { "Real Life" }\end{array}$ & & $\mathrm{X}$ & $\mathrm{X}$ & $\mathrm{X}$ & $\mathrm{X}$ \\
\hline Support Giver & $\mathrm{X}$ & $\mathrm{X}$ & $\mathrm{X}$ & $\mathrm{X}$ & $\mathrm{X}$ \\
\hline $\begin{array}{l}\text { Dilemma of the } \\
\text { Super- } \\
\text { Instructor }\end{array}$ & $X$ & $\mathrm{X}$ & $\mathrm{X}$ & $\mathrm{X}$ & $\mathrm{X}$ \\
\hline $\begin{array}{l}\text { Pride and } \\
\text { Insecurity }\end{array}$ & $\mathrm{X}$ & $\mathrm{X}$ & $X$ & $X$ & $\mathrm{X}$ \\
\hline $\begin{array}{l}\text { Negotiating } \\
\text { Power }\end{array}$ & $\mathrm{X}$ & $\mathrm{X}$ & $\mathrm{X}$ & $X$ & $X$ \\
\hline Self-in-Team & $\mathrm{X}$ & $\mathrm{X}$ & $\mathrm{X}$ & $X$ & $\mathrm{X}$ \\
\hline Sizing up & $\mathrm{X}$ & $\mathrm{X}$ & $\mathrm{X}$ & $\mathrm{X}$ & $\mathrm{X}$ \\
\hline $\begin{array}{l}\text { Organizational } \\
\text { Power }\end{array}$ & $\mathrm{X}$ & $\mathrm{X}$ & $\mathrm{X}$ & $\mathrm{X}$ & $\mathrm{X}$ \\
\hline $\begin{array}{l}\text { Emergent } \\
\text { Power }\end{array}$ & $X$ & $\mathrm{X}$ & & $\mathrm{X}$ & $\mathrm{X}$ \\
\hline Evaluation & $\mathrm{X}$ & $\mathrm{X}$ & $\mathrm{X}$ & $\mathrm{X}$ & $X$ \\
\hline Communication & $\mathrm{X}$ & $\mathrm{X}$ & $\mathrm{X}$ & $\mathrm{X}$ & $X$ \\
\hline $\begin{array}{l}\text { Prioritizing } \\
\text { Goals } \\
\end{array}$ & $\mathrm{X}$ & $\mathrm{X}$ & $\mathrm{X}$ & $X$ & $X$ \\
\hline Trust & $\mathrm{X}$ & $\mathrm{X}$ & $\mathrm{X}$ & $X$ & $\mathrm{X}$ \\
\hline $\begin{array}{l}\text { Relational } \\
\text { Resolutions } \\
\end{array}$ & $\mathrm{X}$ & $\mathrm{X}$ & $\mathrm{X}$ & $\mathrm{X}$ & $\mathrm{X}$ \\
\hline Fulfilling & & $X$ & $X$ & & $\mathrm{X}$ \\
\hline Lackluster & $\mathrm{X}$ & & & & \\
\hline Isolating & & & & $\mathrm{X}$ & \\
\hline
\end{tabular}


Table 1 is provided to illustrate the connections made with each theme and its aspects for different participants, and their robustness across all the interviews. The themes and aspects shown in Tables 1 will act as "generative guides" (van Manen, 1997) towards a new understanding of co-instruction.

This chapter is divided into the four essential themes and aspects of the coinstructor relationship that emerged from the interviews. I present each theme and aspect using anecdotes from participants, and portray each aspect in the manner in which they encountered it. The anecdotes were chosen for two primary reasons:

a) To illustrate the potential diversity in how a co-instructor experience unfolds, and

b) To provide examples that are phenomenologically robust in how they address the aspect.

While the examples I provide are not to be understood as the only way in which someone might encounter the theme or aspect it illustrates, the interviewee's anecdote does provide understanding of how an individual encountered that part of the phenomenon, and therefore also helps capture its status as a feature of the experience. Due to the complex nature of systematically addressing themes that make up a larger life experience, examples within a specific theme will inform the other themes (van Manen, 1997).

\section{Theme 1: Living Work}

Wilderness programs are purposely conducted so enrollees enter into a temporary community or shared-life environment with peers and instructors. Indeed, some would suggest that a program's success depends on the extent to which the learning 
environment fosters this kind of intimacy and inclusion in the team process; Sharpe (2005a) described the instructor's role in this as "delivering communitas" (p. 257). Coinstructors are not only responsible for providing this intense, relational environment, but they are also participants in it in their own right. The responsibility of attending to the students' relational processes while also managing their own was, for my interviewees, compounded by constantly re-living this process throughout a season, and over several seasons. Thus, while delivering communitas may provide program participants with a novel home environment among their new peer group for three weeks, after which they can return to a known environment, familiarity for professional instructors is by and large achieved through a return to the field, which involves re-creating a sense of home time and again over a given season. A main theme in the experience of co-instruction was, therefore, in Jennifer's words, that of "living work" (P4, 13, 19).

I indentified four different aspects of the 'living work' theme from the interviews:

(a) work as home,

(b) co-instructor as an inescapable partner,

(c) co-instructing as occurring within an intense form of real life,

(d) co-instructor as support-giver.

I describe each of these below.

\section{Work as Home}

Co-instructors on a wilderness course work in the same place that they live for that period of time. A tent, tarp, bivouac, or boat cockpit and what they can fit in their backpack or dry bag becomes the thin veil that separates work from home. Upon restarting her co-instructing experience with Gavin, Bethany began to re-claim their home 
on the boat. She explained,

...it was actually really funny, because we literally organized the boat in the exact same way, with my gear in the same place as it was in the year before, and the same with his gear, because we had also the exact same boat we had had the year beforewhich doesn't normally happen, but somehow it worked out that we had pulled boat six again. Because we were on the exact same boat, we had the exact same setup; it was pretty funny to see that we literally gravitated to the way it had been for the previous 23 days that we had been together. $\mathrm{P} 2, \mathrm{I} 2,2$

She went on to explain this notion of home as something beyond creating their house-

space:

If I was just facilitating a program and then went home where I had my social network; that would be one thing. But when you're talking about an experience where there is no going home, where this is my home, then for me I need to have all aspects of what I would want in my home life present. Obviously I can do anything for two or three weeks, but when I talk about having a fulfilling experience that I enjoy and where I'm not starting to do the countdown after day two, then it has to have that. $\mathrm{P} 2, \mathrm{13}, 18$

Bethany's needs encompassed more than the notion of boat cockpit as 'house;' but the co-instructing experience for her, however, contained the elements of 'home' that were necessary for a fulfilling life engagement. One element, her social connection, was potentially available in the co-instructor partially due to the forced intimacy of the relationship.

\section{Inescapable Partner}

The co-instructor was seen as the relationally accessible adult on the courses. While in their professional role, co-instructors are expected to gain entrance into the student experience; but this access is often a one-way street. Because it is possible to know but not to be fully known by one's students, the co-instructor provides important human contact while in the field. While co-instruction provides a relational opportunity, Jennifer saw an environmentally and institutionally forced quality within this 
relationship. Working with Paul on their winter course, she discovered that she was not only forced into a potential relation to Paul, but she was also unable to opt out of their relation despite their unpleasant interaction. She explains,

In your everyday life you can sit out if you want to. You can sit out of anything and everything if you want to. You can sit out of relationships, you can sit out of jobs, you can sit out of friends; you can sit out of anything. You can sit out of college, you can sit out of school, you can sit out of whatever you want- but when you're in that situation, when you're out working with someone on a course, you can't sit out of that. There's no way around it- when you're in that environment as a coinstructor, you cannot sit out, you have to always be there. P4, I3, 1

Bethany's description of the co-instructing environment adds useful detail. By intentionally creating an intensive living arrangement, her co-instructor becomes a forced partner that is inescapable. The power of the environment and institution of co-instructing on an extended wilderness course heightens the nature of the co-instructor connection, or lack thereof.

\section{Intense Form of Real Life with Other}

Participants found various ways to address the environment and institution that spurred their co-instructor relationship. Across the board, it was understood to be a situation that was little mirrored in their life outside an expedition. As such, the coinstructing experience was generally described as occurring within a unique situation that is either unlike other known life experiences, or analogous to the more intense relational encounters known in life. Jennifer explained,

You are so close, and working so closely together for that period of time. I mean there's no other point in my life- I'm married, but there's no other point in my life, other than maybe when we go on vacation, where I spend that much time with one or two other people. You don't really have any time off when you're in that position. You can create little moments of time off, but it's not like the course pauses while you go sit on a rock and think about whatever. It just keeps going; it keeps going no matter what. For the most part if it's going, it's going. It's like being on a ride. $\mathrm{P} 4, \mathrm{I} 3,19$ 
The expedition environment encompasses both work and home, and the co-instructor becomes an inescapable relation within that environment. This intense form of real life encouraged my participants to seek their relational requirements from their co-instructors.

\section{Support-Giver}

Co-instructors, much as anyone else experiences in day-to-day life, have personal requirements that must be met (this is complicated by the dilemma of the super-instructor which is discussed later). While some requirements are potentially self-fulfilling, such as sleep or shelter, the notions of professional, social, and personal requirements arose from all interviewees' narratives. Some spoke of the way in which they believed the requirements to be those of their co-instructor, and worked to help meet them, while others spoke of their own requirements that they relied on their co-instructors to provide. Others spoke of the manner in which they and their co-instructor sought to support one another's requirements. Peter sought out and supported the professional requirements of Joanne while on course, and found himself being asked to address her social-personal support through that experience. He recounted:

When you're in a tent with each other, and you're showing caring throughout the day, I think it's facilitated by that. When somebody feels like you're supporting them on a professional level, and they would like support on a personal level, they're going to test the waters and see if you can help provide some support and greater understanding for who they are. They are willing to tell you more about themselves. And I think that Joanne tested the waters a little in telling me about things that had happened at school, with students that I never knew about, testing my reaction. And so me being able to laugh at things and say, 'Ha! That's great!' helped it then go on to much more personal things about family and hard times. I also think I fulfilled a big-brother role in that particular case, and she and I have talked about that since, about how our relationship has that kind of feel- I have a sister who is about her age. P3, I3, 13

The environmental and institutional power inherent in the co-instructing experience 
creates a heightened potential for the strength of the co-instructor relationship. Within this intense state of life, in which you are given an inescapable partner to share this experience, and potentially a home-life with, the participants felt that some level of a positive relationship was required to ensure a successful navigation of the course.

In summing up the first theme of living work, my participants found themselves part-and-parcel to an institutionalized intense form of real life that is both their responsibility to create (Sharpe, 2005a) as well as their own recurring lifeworld. This environment of living work with only one other potential relation added complexity the co-instructor environment as the interviewees sought to develop a sense of home and understand their self-other interactions. The development of personal-professional identity within the life-as-work arrangement found in wilderness programming acted, however, as a filter through which the co-instructor relationship was negotiated.

\section{Theme 2: Dilemma of the Super-Instructor}

Field-based wilderness education professionals are largely younger individuals who can devote long periods of their life to the living work arrangement. Most instructors have a good deal of technical skill and training, but are relatively young in life experience, especially in roles with a high degree of responsibility outside of their professional engagement. Dealing with this intense life experience of high responsibility, relationship, and leadership may seem difficult to navigate at first. The pride that comes with being physically capable, technically skilled, and in a leadership role along with the uncertainty present within the environment and relative lack of life experience can lead to what Ewert, Shellman, and Glenn (2006) call a "culture of invincibility" (p. 7) and lure staff into what they refer to as the "super-instructor syndrome" (p. 7). The dilemma of the 
super-instructor is created by the expectations put upon staff by the institution and their reality of self; these shape how the co-instructor relationship is navigated. Therefore, the culture of projecting self-as-superhero is not contained within specific individuals, but can be found within the institutional expectations of wilderness adventure programs, as

\section{Peter recounted:}

We have a great saying about our role, somebody wrote out once what an instructor was, and basically you're a superhero. You have to be doing everything: as an instructor you're never cold, never hungry, never tired, your pack's never heavy. Even though you obviously are feeling all of those things, the students don't feel like you are, because you are always trying to create the positive. P3, I1, 14

The participants in this study described feeling as though this 'super-instructor' mentality went beyond the instructor's presentation of self to his or her students, and that co-instructors negotiated their relation to one another through this filter as well. The 'super-instructor' dilemma manifested itself to the participants in three primary ways:

a) Co-instructors are balancing pride and insecurity

b) Co-instructors are negotiating power needs

c) Co-instructors are negotiating their role to the team through their sense of self as a super-instructor.

\section{Pride and Insecurity}

All participants spoke of themselves or their co-instructor interacting with the coinstructing team through a combination of pride mixed with insecurity. At times this appeared as a subversive tactic, aimed to hide inability from the other, as Jennifer encountered with Paul. Throughout their winter course Paul had objected to teaching the students how to build snow shelters called 'quinzhees', and at the end of the course Jennifer convinced Paul and the students to spend a day learning the craft. She recounted, 
I remember talking with Paul as we were building it, and thinking, 'I don't think he's ever really built a quinzhee before,' or at least I don't think he'd ever built a good quinzhee. It's no wonder he hadn't been a big proponent of building these. At one point in our conversation about the process, he said, 'oh, well you've probably built way more quinzhees than I have, so I'll let you take the lead on this.' And I said, 'um, probably not- I don't know, how many quinzhees have you built?' He responded, 'well I don't know, fifty or sixty?' And I was like, 'fifty or sixty?' I've maybe built fifteen or twenty. You know, maybe. That's a stretch. That's if you count the pile of snow I built up in my backyard before I even knew what I was doing. It hadn't dawned on me previously, but I started to realize that maybe he was really trying to puff himself up around me, because if he had built fifty or sixty quinzhees than he clearly should know how to build a quinzhee. And he did not know how to build a quinzhee. So it was like, 'ok, something is not adding up here.' $\mathrm{P} 4, \mathrm{I} 2,13$

Paul's projection of himself as a confident instructor made it difficult for Jennifer to assess his actual abilities as a professional, which Jennifer felt may have been precisely the intention. This hidden self may have allowed Paul, as co-instructor, to project an image of control or confidence, but complicated his relation with Jennifer as they "subconsciously went back and forth on who had more control in the group" (P4, I3, 3).

\section{$\underline{\text { Negotiating Power }}$}

Interviewees described the various manners in which they and their co-instructor negotiated power and control within the co-instructor dynamic, whether subversively or openly. Bethany described to me different boat captains whom she has worked with over her time within her organization. Each encounter had been accompanied by a different style of power negotiation; some that she felt were more supportive of a positive environment than others. She described the manner in which one captain she knows exercised control in what appeared to be an unsupportive style:

...they are the instructor on the boat and they see themselves as having two babysitting co-instructors. It's the Fred show with his two adults that are along for the ride for liability purposes, and he pretty much acknowledges that he's going to do everything. He's the captain of the boat, and that's the way it's going to roll. And so I think that it does require, particularly in that situation where you do have 
such a hierarchy of a captain versus not-captain, a certain degree of skill for folks to work together to create a team that is actually functional. Otherwise don't call it coinstructing, you know? P2, I3, 17

Bethany's understanding of Fred's role as the ultimate captain completely disrupted the potential for co-instruction to occur with her. His maintenance of the super-instructor image created for Bethany a power dynamic that denied others on the boat a sense of professional investment. For Bethany, this interpretation of the super-instructor image had superseded the necessity of a co-instructing team.

\section{Negotiating Self-in-Team}

Each co-instructor appeared to intuitively navigate how they would relate to their co-instructing team. This negotiation of self-in-relation to a team was complicated because of the roles and expectations around the mentality of being a needless superhero, leading to a dilemma of how to resolve seemingly disparate demands as both a professional and social being. Erin came back to the notion of the super-instructor often in our interviews as a concept that she had wrestled with during her growth as a coinstructor. She explained how it interplayed with her ability to enter into a co-instructor team:

I think co-instructing isn't really revolutionary, it's not something brand new, it's just being a team player. I mean it's new or revolutionary in the sense that it's in some really extreme and sometimes dangerous environments, where emotions and discomforts can get a little bit higher, and you're never apart from each other. So really, it's probably more like a marriage than anything else. You're with that person, you're always there and you have to work through those intense, tougher times together. You can't just decide, 'oh, I'm opting out of this course, I'm outta here,' you know. 'I'm gonna walk out.' I'm too tired, I'm too this, I'm too that. You have to figure it out- 'ok, I'm too tired right now- so what do I need? How do I ask for what I need from my co-instructor?' Because I think that's really hard- it's not just a one-sided relationship where I'm always going to serve and sacrifice, but I need to be willing to be served and be sacrificed for. Which I think is really hard for us outdoor leaders- we have a lot of pride, and think that we need to be the superinstructor, and be able to do everything on our own. But we need each other... I 
needed that to be a team effort, I needed to lean on them, I needed them to lean on me, which was really important- feeling like I was needed there. And it was

important for me to be there, and we were a team working together. P5, I3, 2

Co-instructors use a super-instructor mentality partly to help deal with the living work arrangement they find themselves in, but it seemed often to generally hamper, rather than enable, their co-instructor relationship to develop. The belief that an instructor can do everything her or himself creates confusion around how to deal with power, relating to a team, and the portrayal of self.

In summing up the second theme, the dilemma of the super-instructor, Ewert et al. (2006) describe a danger inherent in what they refer to as the 'super-instructor syndrome' (p. 7); here, individuals discount or marginalize personal needs to maintain the group, leading to self-neglect and errors that stem from the poor judgment that may result. They outline a possible mitigation of the super-instructor folly in "fostering a supportive environment/culture that encourages staff to accurately and continually assess and express their physical and emotional needs" (p. 7). For Erin, the co-instructor relationship was the most appropriate place to be honest about her inability to be super-human in an intense environment. The co-instructor team was seen as an arrangement that helped establish personal sustainability if the appropriate 'supportive culture' (p. 7) could be achieved. An assessment of the two people engaged in this relationship is still necessary to figure out how to make the relationship work.

\section{Theme 3: Sizing Up}

A theme throughout to the entire co-instructing experience, from prepping for the trip to the final handshake or hug, was the notion that Jeremy referred to as 'sizing up': "That initial size up- seeing where the other person's at and going from there... I felt like 
it never stopped happening" (P1, I3, 2). Meier (1984) likens the role of the wilderness coinstructor to that of the airline pilot: highly trained and professional, but still requiring constant focus due to the grave risk in a lapse of judgment or attentive assessment. On top of assessing students, risks, environments, and course goals as part of the everyday decision-making schema of co-instructors, the interviewees also described assessing their co-instructor, themselves, and their co-instructor team as they developed an understanding of their co-instructor relation. Bethany explained the importance of this to her:

I'm not good with not knowing what to expect. Thinking of myself with a new coinstructor- I don't know what to expect from a new co-instructor, or from the course itself for that matter... at least when I'm working with 15 year olds I know what to expect. I know to expect the unexpected emotionally; I know to expect irrationality. I don't know what to expect from a co-instructor, so that makes it all the more stressful. P2, I3, 19

The co-instructor relation may be an unknown when the course starts, and because of the impetus to create this relationship, the assessment process became an important component of the co-instructors' time and energy. The aspects of 'sizing up' addressed by the interviewees were:

a) Roles and power

a. Organizationally defined

b. Emergent

b) Evaluation of co-instructor abilities

c) Communication

d) Trust

e) Prioritizing and negotiating needs 


\section{Roles and Power}

The roles and power structures of the co-instructor relationship emerged as immensely important components of the co-instructor relationship. Many organizations define specific parameters of the co-instructor power structure; my participants, however, explained how and why emergent roles and power structures were necessary beyond the roles that are given pre-course.

Organizationally Defined. Jeremy shared that when he was learning to instruct he worked for organizations with well-defined hierarchies built into the co-instructor dynamic. Simply put, co-instructing was a tool for learning how to instruct, and a coinstructor team was composed of staff representing a spectrum of ability within the organization. He explained how in "that managerial hierarchy it was clearly defined as to what you had to do to move from one to the next [role]. I would just ask, 'hey Frank, what level are you? Oh, you're a level 5? Great, you know what's up"' $(\mathrm{P} 1, \mathrm{I1}, 16)$. Although Jeremy discovered in his experience with Susan that the organizational hierarchy does not always indicate a hierarchy of ability, the organizationally defined role of a 'lead' instructor on the course, which was common to all participants in some design, did define one important role. He explained,

Once you're out in the field, I think the 'lead' definitely always had the 'kibosh' power, I guess I would call it. I don't think it happens very often, but if there's a disagreement about whether or not something is safe, in the end the lead got to make the decision. They have the ability to say 'no, look, when it comes down to it, I get to make this decision. Please tell me what you have to say,' it was never, 'screw you dude, I'm gonna do my own thing', it was definitely a conversation, but I think it definitely is about having final word. P1, I1, 9

The 'lead' instructor, which was variously determined by who had the most time within an organization or who had the necessary legal license, appeared to be specifically 
a risk-management tool for the program. While the chance of a high-risk decision where there is no consensus is hopefully small, it was explained to be nevertheless an important role differentiation for the program's own legal responsibility. The actual impact of this role differentiation on the co-instructor dynamic varied from participant to participant. Despite titles that would appear on the surface to indicate a specific power hierarchy within the co-instructor team, Jeremy explained that the actual co-instructor relationship 'is flexible, it's dynamic, you know? Just because I'm the 'lead' instructor doesn't mean that I always know best, or that my way of doing things is always right. I think that there's some give and take" (P1, 13, 13).

Emergent. Bethany explained that the organizationally defined 'lead' and 'assistant' roles tended to be a hindrance to her success within the co-instructor relation rather than an aid. In her experience with Gavin, it was the development of their social relationship that broke down the professional roles they had been given pre-course, allowing a new power structure to emerge. She described her assessment of herself in how she approaches the co-instructor relationship, her assessment of the co-instructor relationship, and her assessment of her co-instructor as being crucial to her ability to make sure that her personal goals are met through her co-instruction:

I fear going forward a little bit because; at least with the nature of our courses on the boat, there is the captain and the not-captain. Gavin and I have such a good friendship that, despite the fact that he's the 'captain' on the boat, I can push him and ask prodding questions, or I can be more assertive than I could with another 'lead' instructor, at least until I got to know them really well. I would feel, and maybe that's my own bias from growing up in a military family, that there's a certain pecking order, a certain hierarchy, the chain of command, and that chain of command is in place until you break down some of the formality of the working relationship into the friendship relationship. So I worry that I would not be as good about getting my needs met with a new lead instructor, because I won't have that same level of connection and communication, and ability to call Gavin out- 'you said I could do this, and then you did it, what's up?' and have him respond. Because 
I know him and know his personality I can do that, whereas with a new instructor I'd start from, 'I don't know how to challenge this person, I don't know if I can.' $\mathrm{P} 2, \mathrm{I} 3,2$

Bethany needed time and self-other knowledge gained through working with Gavin to size up their relationship, and therefore how to best meet her needs within and through that relationship. Having to re-live this effort had made entering into a new co-instructor relationship a daunting task as she looked forward towards her next relational negotiation.

\section{Evaluation of the Co-Instructor}

Beyond assessing the relational qualities of the co-instructor experience, coinstructors found themselves needing to build a level of professional and social trust with their partner. To develop that trust, and to learn how to best engage in the co-instructing dynamic, participants explained the ways in which they evaluated the abilities of their coinstructor. This occurred through a variety of outlets, including observing or questioning their co-instructor (although, as Jennifer discovered, this can be complicated due to the need for co-instructors to project confidence). The evaluation of the co-instructors' abilities and attributes spanned from purely technical-professional skills to personality styles in an attempt to clarify their relational navigation. Jeremy spoke often about the coinstructor evaluation process with Susan as an important component of their relational negotiation, and described a transitional moment in their relational development:

I guess perceptions of ability and perceptions of competence were pretty different between the two of us, as well as the importance of different qualifiers of competence. I think that her assumption of me, and this is obviously a meta-level understanding of people, was that I had a lot of experience as a wilderness therapy guide, and so as a result I would be really good at working with the students, but because I didn't have experience per se with NOLS or OB or any of the big-name programs (and I don't think she knew how many field days I had and what the variety of that was), she perceived me to not be as competent as I am in some of the 
more technical skills. On the flip side of that, I think that she perceived herself, because of her affiliation and experience, to be more competent than she was. So it was an interesting dynamic, really. I heard her talk at one point about the number of trips that she's led and the number of field days that she has, and while before I was thinking, 'wow, she's the lead instructor, that's great, she's young, she's got a lot of trips in and days in,' suddenly I found myself thinking, 'wow, I have more experience than her, and probably with a bigger variety of groups.' It wasn't so much that I didn't think that she was competent, but that I thought that she was cocky. That's what it came down to. I attribute a lot of our strained relationship to our perceptions of experience, and how accurate those were. P1, I2, 4

The misaligned evaluations of one another, and perception of arrogance in Susan on the part of Jeremy resulted in a strained relationship. Jeremy and Susan appeared to size up one another's abilities and personality style with indirect communication techniques, leaving much of their relationship with one another to each person's own interpretation and perception of the other in a way that may have left room for inaccuracy.

\section{Communication between Co-Instructors}

Pervasive to the evaluation and assessment process were the communicative techniques used. Participants observed, picked up on cues, had conversations, and engaged in multiple other communication practices within their co-instructor relationship. However, communication was specifically described as being part of the assessment process and needs advocating that co-instructors were constantly engaging in as they attempted to understand their relationship in the midst of their professional engagement. Erin described how this played out between her and a co-instructor early on in her experience as a co-instructor:

...one of those people I did end up co-instructing with later on, and we were able to talk. I said, 'look, when we talk you don't look me in the eye, and you're fidgety, you look down, you start having a different conversation- I don't trust you, you know? I don't feel comfortable with you, I need to be confident that you're listening to me, and these actions are communicating that to me that you're not,' and I was able to understand a little bit more about this person through that. They shared with me that part of that was just a bit of a tick that this person had, that they had some 
minor Turret's. So it was interesting, because there was more to it than I thought, but that was a big thing, and we were able to communicate through that. P5, I1, 13

A specific communication technique that was commented on by each participant was the use of feedback between co-instructors. All instructors understood feedback, generally, as a communicative tool that was marked by institutionalized norms to ensure a clear communication pathway between co-instructors. The information disseminated during a feedback session usually focused specifically on an item that related to one coinstructor's action or inaction that the other co-instructor interpreted as being of professional or personal importance to be reflected back to the co-instructor. Bethany interpreted feedback sessions, despite their perceived importance in the co-instructor relationship, as a paradoxical event:

I feel like we generally give - I don't want to say 'corrective feedback', but, for lack of a better word, corrective feedback based on things that people do that are somehow in conflict with our way of doing things, or in conflict with our understanding of the world or the way something should be done. You know if that's the case, then we're giving feedback almost in hopes that the person will take it and become more like us, or more aligned with what our views are. So if I tell Gavin that he's being 'too abrasive' with the kids, then maybe he is, maybe it's abrasive. But maybe it's not. Based on my understanding of how I think you should interact with students it's too abrasive, and so I give this feedback in hopes that he becomes less abrasive. In which case, that's still meeting my need to have the world operate in the way in which I think the world should operate. It's like we say that we give feedback because we're trying to help people do better, but help people do better relative to what? We give feedback so you can improve, but improve on you meeting my vision of the world (laughs). P2, I3, 10

Bethany's anecdote suggests that even routine practices that are intended to enhance communication, such as feedback sessions, can be a form of 'sizing up' and of providing access to one's own statements of need, constituted by power dynamics that affect how the relationship is negotiated.

\section{Prioritizing Goals for Growth}


As Erin disclosed when discussing the dilemma of the super-instructor, coinstructors are deciding how to make sure that their desires to grow personally and professionally are being met within the co-instructor relationship. While there are issues that complicate this process, co-instructors engaged in prioritizing and balancing self, other, and group goals tried to first filter this process through the co-instructor team. Where the co-instructor relationship was a roadblock in this process, as in Jennifer's case, meeting the goals of self or group became much more difficult. In other narratives, the co-instructor relationship was judged to be an outlet for achieving these goals between group and co-instructors even where they appeared disparate. Bethany explained how this occurred among her, Gavin, and their students:

So he was in a sailing movie, and he's obsessed with the fact that he was in that movie. It's one of the top five things that he's ever done in his life, and he will tell that to just about anybody. I felt comfortable telling him, 'the course isn't about you, let it be about the kids.' And obviously I play on the national team, and I said, 'the kids don't need to know either of those two facts', at least not until well into the trip. Otherwise it starts to become the trip in which you spend the entire time answering questions about, "what was it like to be on set with this person, what was it like to be on set with that person, what was...' and it would stop being about their trip and start being about them living vicariously through others' experiences. I would rather have them spend the trip asking each other questions about their lives than asking us questions about our lives. So I made a pretty big push for that, but he can't help himself. I didn't want Gavin talking about his movie, I didn't want to talk about my playing on the national team, because I wanted the kids to be interested in each other more than they were interested in us, so they could have that connection to each other. But, that said, Gavin and I talked about his movie and my sports all the time. We just talked about it in our hidden language so that we kept it hidden from the kids pretty much until the very end. P2, I3, 13

Bethany appeared to indicate that she was able to synergize multiple goals through an accurate sizing up of Gavin, their relationship, and each of their requirements. Sizing up, then, became an aid to the ability to successfully prioritize and negotiate the tension between professional and personal requirements through the co-instructor relationship. 


\section{Trust among Co-Instructors}

Amidst the assessment process was the development of trust between co-

instructors. Each participant seemed to intuit a level of trust in his or her co-instructor and of his or her co-instructor's trust in him or herself. Erin clearly told a co-instructor in the previous example of 'communication' that trust was a specific need for her in their relational development. Jeremy had difficulty trusting Susan after evaluating her abilities as being below her projected confidence, whereas Bethany developed trust first in her friendship with Gavin, and that built later into professional comfort and trust. By her second course, with their friendship solidified, they began to actualize that professional trust, as she explained:

Gavin had put out the idea of possibly having a day of 'Bethany as captain,' even though he's the official captain, the coastguard captain, he's the one that has the legal responsibility of the boat, he said, 'we can always just have a couple of days where you take responsibility for the boat.' Obviously from a legal perspective that doesn't apply, but in terms of the way we interacted with the kids. And we actually did that a couple of different times. A whole lot of it was because we had kids that were amazing- sweet, sweet children, but horrible, horrible decisions-makers- so we had some seriously long nights, getting in and getting to bed at one in the morning, and then trying to catch a tide at five in the morning, and so in the effort to have at least one safe set of eyes on board one of us would wind up napping while the other one was maintaining the boat. And that was a testament to the fact that Gavin trusted me with the boat, because he was actually able to go to sleep and leave me in charge of the boat while we were under way. P2, I2, 2

Bethany appeared to indicate that Gavin had sized her up as trustworthy in roles outside of what would appear her defined professional identity. Because of this trust, he was able to prioritize what he had sized up to be their situational needs as superseding their professional obligations that were organizationally predetermined.

In summing up the third theme, sizing up, co-instructors could be thought to be in a constant state of 'sizing up' as part of their professional obligation to students and 
organization, as Meier (1984) indicates. However, they are not only two separate actors perceiving the environment in front of them; they also appear to be two people searching to understand the environment in which they are embedded together. The co-instructor relationship, then, became a focus of 'sizing up' as well, be it to enable professional goals, personal requirements, or both.

\section{Theme 4: Relational Resolutions}

Above all, wilderness instructors are people whose lives go beyond their time in the field, and whose work experiences_-boundless and all-encompassing as they appear in the moment-ultimately are interpreted in the larger context of their personal, social, and professional lives. The essential experience of a negotiated relationship occurs as coinstructors attempt to reconcile both professional and personal lifeworlds enmeshed within a self-other relation established mainly due to work. This duality was ultimately interpreted, for my co-instructor participants, through the manner in which their relationship was resolved. While various styles of resolution emerged from my interviews, and it appears that co-instructors' relationships may find resolution along a spectrum; my respondent specifically described their resolutions in three ways that illuminate the manner in which this theme was encountered:
a) The 'Fulfilling' Relationship
b) The 'Lackluster' Relationship
c) The 'Isolating' Relationship

Although other kinds of resolution are likely to exist (for instance, two coinstructors could become romantically involved), these three illustrate a possible spectrum and were central to the meaning co-instructing experiences for my respondents. 
Because the co-instructing experience of negotiated relationship is a primary filter through which professional wilderness co-instructors engage in their lifeworld while on an extended wilderness course, each style of relational resolution attained with one's coinstructor, whether it was 'fulfilling', 'lackluster', or 'isolating', framed my interviewees' sense of whether or not their goals were attained. By 'fulfilling', I mean a relational resolution where staff attained a successful balance between professional, social, and personal requirements within the co-instructor relationship, creating a synergistic sense of 'work' and 'home.' By 'lackluster', I mean a relational resolution in which there is some "give and take" within the relationship, but the balance of professional, social, and personal goals is only partially maintained within the co-instructor relationship. For Jeremy, the uneven balance towards professional obligation left him describing his feeling of the experience as "consistently work" (P1, I2, 13). And finally, by 'isolating', I mean a relational resolution in which the co-instructor relationship fails to meet the professional, social, or personal requirements of the staff and becomes a burden on the members in the relationship. Each example below describes the manner in which one participant experienced that resolved relationship; however, these descriptions do not encompass the only manner in which the style of relationship may be encountered, or in which relationships may be resolved in general. In fact, I am claiming that co-instructor relationships appear to be resolved on a spectrum which contains fulfilling to isolating closer to its poles, and are interpreted by the co-instructor's perception of the balance and quality of personal, social, and professional connection and support with their partner. Below, I detail three ways in which my participants interpreted the relational resolutions of their negotiated relationship. 


\section{The 'Fulfilling' Relationship}

After spending a previous course developing her friendship with Gavin, Bethany described how she was allowed to re-invest in the professional relationship that budded but did not fully blossom during the previous summer. The co-instructing experience that she described in this study left her feeling not only professionally and socially satisfied, but also scared by the prospect of having to re-learn how to co-instruct with someone else after such a positive experience with Gavin. She explained their resolved relationship,

My co-instructing experience with Gavin, I can talk about because I remember it, but I remember it because it was Gavin, and he and I are close and therefore have created this connection. There's a little bit more of an emotional response to this experience. I was trying to think of any of the other co-instructing experiences I've had, and I could think of brief instances, but I don't know to what extent I'd be able to recount the whole experience- 'oh, yeah, I remember this and this and this and this.' There's something about the fact that it's a person that I co-instructed with, but then continue to be close friends with, and so the co-instructing experience continues to be re-lived on an ongoing basis. Gavin and I talk about it still; I'm only going be able to work on maybe 2 courses this summer, and so he says 'you should make sure you request this course and this course, because those are the 2 courses that I can work,' and I'm like, 'sweet,' you know? Part of me wants to co-instruct with other people, just for the experience, but then there's part of me that just loves working with him, because we just operate so well together. It feels a little bit like a dance, almost, or maybe like starting a new romantic relationship. Gavin would laugh if he heard me say that, but... I know how to work with him. Basically how the dance will go. At one point on this last course, our students, because Gavin and I got along so well, they said we were like an old married couple in the way that we interacted and bickered but then we would crack ourselves up. A couple of the students asked if Gavin and I were, in fact, dating. And I said 'Noooo. No, no, no.' It was based on the way we interacted; I don't know if there's something about the types of people or the type of relationship you start to develop over the course of time, but it is one of those relationships that becomes like a functional marriage that is actually working, where people just figure each other out. Yes they have personality clashes, but they've somehow figured out how to make them work, because otherwise they'd be divorced. I've yet to see a team that's really successful while hating each other. P2, 13

In the above description Bethany describes a fulfilling co-instructor experience as akin to a successful long-term committed relationship; a fulfilling co-instructor 
relationship as analogous to a relationship in which members choose to be committed in their support for one another.

\section{The 'Lackluster' Relationship}

In the absence of a social connection or reciprocal professional connection with his co-instructor, Jeremy described finding himself in a confusing and uncomfortable experience on course. Instead of the co-instructor relationship as a refuge from the experience of living work, Jeremy was forced to do without; a reality that left him describing an experience that was consistently work. He explained his resolved relationship with Susan and the result,

I think that's something that I look forward to about instructing trips with people, that relationship that builds between co-instructors. You at least end up having fun, maybe it turns into a really solid friendship, or maybe it just is someone fun to hang out with for the week, in this case weeks, however long you are out there. I think I've grown used to it, because I think that happens a lot. For some reason it just didn't happen. I'm used to getting that from co-instructors- I think when I say that it makes it sound like we didn't talk or hang out, but I'm used to a certain level of investment in a co-instructor, the co-instructor as a friend almost, because they're your ally for the next however many days, but I think that I just wasn't invested in that here. We did what we had to do to have a successful trip, but it was never easy, it was consistently work, and we were doing our job. The trip was just, it was, 'oh, yeah, I'm out here for 25 days with you and that's not that exciting to me,' you know? It wasn't awful, it wasn't like I don't ever want to talk to her again, but it just didn't have that meaningful connection that happens a lot, at least for me. Instead the dynamic really stalled out with us. It never felt like it went anywhere, and for a 25-day trip that's pretty uncommon; it felt awkward and uncomfortable all of the way through. P1, I3

Mitchell (1983) describes the manner in which a rationalized society divides the time and space appropriate to engage in work and leisure, where "the opportunity for play is institutionalized in the form of paid vacations and holidays, and persons are expected to use these 'life spaces' in their designated ways, for leisure" (p. 211). Jeremy indicated that when co-instructing, where 'work space' and 'life space' are enmeshed, his lack of 
social relationship with Susan left him without a comfortable 'life space' for leisure or relaxation. This stalled out social dynamic appeared to overshadow the professional expectations they successfully attended to.

\section{The 'Isolating' Relationship}

Bethany was able to achieve professional, social, and personal success through her relationship with Gavin. Jeremy perceived professional success, but the lack of social or personal connection created a drain within the intense experience of working on an extended wilderness expedition. Jennifer, in contrast, lacked professional, social, or personal success in her relationship with Paul. She shared that her best co-instructing moment on course was the one day that they were able to be apart; a rare opportunity within the forced relationship of the co-instructing experience. She explained her relational resolution with Paul:

I remember being a little concerned afterwards, thinking 'is he still going to be around in the spring? Am I going to wind up doing a spring course with him, too? Because I can't work with him again.' He moved away and I was really happy. I never have to work with him again. It was really pretty miserable. Actually, this is probably the most in-depth I've thought about it since then... god that was horrible. It was horrible. It was the worst interpersonal experience I've ever had in the outdoors. The whole situation really put me out of who I was, or at least who I thought I was at that point in time, and it has caused a lot of re-examination of who I am and what I'm doing. That experience gave me a real picture of what I didn't want to be and what I didn't want to do, both in watching how I reacted and how Paul reacted in those situations. From a teaching, instructing, and personal perspective, I see very little good that actually happened during that course. So it has been this continual thing that I reflect back on and think about- 'oh yeah, I forgot about that. That was horrible; I never want to do that again. Oh yeah, I forgot about that part, and I never want to put students in that kind of position again. I don't want to do this, I don't want to do that.' Sometimes I feel like, to the people that I talk to about it, I become so negative about it, but it really was that negative of an experience for me. P4, I3

As stated earlier, co-instructors are maintaining both professional and personal 
identity simultaneously through the co-instructor relation. Jennifer described the manner in which her own identity was momentarily lost when filtered through her 'horrible' relationship with Paul. She described herself as feeling "isolated [when left] alone with him," $(\mathrm{P} 4,12,10)$ but one can imagine that her struggle to retain her own identity through the course left her feeling isolated not only from Paul, but also from her own potential identity as someone who is enthusiastic, invested, and feels fulfilled by their work as an outdoor instructor.

\section{Conclusion}

For professionals on extended wilderness courses there exists an imperative to synergize work and home life, as the separation that is commonly found elsewhere in human service settings, or perhaps in work more broadly, does not exist. As such, the coinstructing experience is a unique relationship with a duality of roles that each demand attention. Interviewees spoke of co-instructing as a relationship negotiated within their living work, filtered through the issues stemming from the co-instructors' dilemma of the super-instructor, and in constant evaluation as the co-instructors went through the process of sizing up. The relationships were resolved in practice as enabling, at best, a fulfilling relationship, more neutrally as a lackluster relationship, or at worst, an isolating relationship. These resolutions were the product of the co-instructors' success in developing both a professionally and personally supportive relationship with their 'inescapable' partner, and constituted the interviewee's interpretation of the quality of their overall co-instruction lifeworld. 
This chapter has provided a thematic analysis of the co-instructing experience with its themes and subsequent aspects. In Chapter VI, I discuss the scholarly and practical importance of my findings, as well as how this phenomenological understanding of co-instructing provides depth to existing treatments of both co-instructing and coleadership discussed in Chapter II. 


\section{CHAPTER VI}

\section{DISCUSSION AND IMPLICATIONS}

As I stated in my introduction to this study, my early participation within the adventure education industry made apparent the difficulty in obtaining training or knowledge regarding the practice of co-instruction, which is a major, yet taken for granted, feature of wilderness trip leadership. In Chapter II, I reviewed the literature from other fields of practice, such as education and human services, where co-instructing is used, and I argued that the co-leadership discussion within other fields is more extensive than in the adventure education field. I noted some of the risks involved in adopting and adapting co-leadership models from other fields without a more basic understanding of co-leadership's application and functioning specifically within adventure education. I also noted that current understandings of co-leadership have privileged administrative perspectives, marginalizing or ignoring the co-leader's voice in its conceptualization. This is not to say that work in other fields should be disregarded; to the contrary, the process-based research in other fields can be an example to the adventure education field, especially given the noted "over-reliance on pencil and paper measurements" (Ewert, 1987) practice that has primarily been used in adventure education research, but has been critically referred to as 'black box' research (Locke, 1977), or a style of research in which outcomes are measured without a clear understanding of the processes by which those 
outcomes are achieved. Because of this tendency, there has been a call for research into processes and practices embedded within adventure education that are as of yet understudied (Brown, 2006). I will return to this topic of adopting/adapting models from other fields shortly, since I believe this is a main contribution of this study.

The framework of phenomenology provided me with tools to understand the nature of my co-instructors' experiences in their complexity. An in-depth interviewing approach allowed me to analyze co-instructing in wilderness expeditions through the accounts of others who have known and lived the experience. Their narratives, unsurprisingly, revealed co-instructing as potentiating the quality of lived experience when in the field. In Chapters IV and V, I provided analytic and thematic analyses of the experience of co-instructing. Based on the interview data, I interpreted co-instructing to be primarily an experience of relationship through which both professional and socialpersonal identities were negotiated while operating within the living work environment of wilderness expeditions. The dilemma of the super instructor, the process of sizing up, and the relational resolutions also shape the experience. The co-instructor relationship negotiated while in the field personally affected my participants, whether they were affected through a fulfilling, lackluster, or isolating relationship. Admittedly, given my aim of privileging the instructors' voices, my analysis of co-instruction may serve outdoor field staff more than the students or institutions who are also likely to have perspectives on it. This focus shapes what conclusions and implications I can draw. Nonetheless, my analysis has implications for practice and research, which I discuss below.

In the remainder of this chapter, I revisit the existing conception of co-instruction 
and discuss how my phenomenological inquiry has elucidated some of the previously hidden qualities of the experience, discuss how my analysis of co-instructing may inform both practice and scholarship, and reflect on my own experience with this study.

\section{Return to the Literature}

The adventure education literature, although limited in scope, has incorporated co-leadership research from other fields and concluded that co-instruction is a powerful experience that impacts both instructors and students (Rilling \& Jordan, 2007). Although pointing to the meaningfulness of the experiences to co-instructors themselves, this literature primarily describes co-instruction as a practice of two professionals being paired mainly to mitigate risk, manage stress, and benefit participants, which summarizes the administrative viewpoint I am augmenting here (see Wagstaff, 1997). Participants in my study presented a much richer and more complicated picture of co-instruction, with dynamics that uniquely apply to the co-instructors themselves; Bethany, for example, shared her concern of the inherent assumptions within the given definition as "operating under [the] myth that anyone can work with anyone, and two adults should be able to figure their stuff out and work with teenagers, and it will be fine" (P2, I3, 16). The question of for whom "it will be fine" is of interest: in the living work arrangement where staff are constantly being called to re-create 'home' and find a satisfying lifeworld within the co-instructor relationship, overly simplistic accounts of co-instruction seem largely to come from an institutional vantage point, which masks some of the felt tensions described by my respondents.

My investigation of co-instruction from a phenomenological perspective provides insight into the experience that is otherwise difficult to perceive from within the 
administrative perspective that comprises much of the academic and training literature in adventure education. For the participants in my study, co-instructing provided opportunities within their life experience on course to find the richest potential for professional, social, and personal fulfillment and/or isolation. The personal dimensions of co-instructing that emerged in my interviews reveal a tapestry of interests: co-instructing may carry different meaning when viewed through the stories of administration, students, and the co-instructors themselves. This study provides access into the meaning created through the personal practice of co-instructing, but does not speak to the meanings arrived at by being co-instructed to (i.e., the students' perspectives) or by utilizing the coinstruction construct as an aspect of a greater organizational agenda (i.e., the administrative perspective). The meaning that emerged from this study did appear to indicate that the co-instructor's perspective may be suppressed by the administrative definition, which seems to have shaped the explicit and implicit understanding of 'coinstruction' to date. The experience of co-instruction, therefore, is not simply an arrangement between two professionals, but also an arrangement between two individuals engaged in an intense, shared life experience. Therefore, I submit the following conceptualization of co-instruction: Co-instruction on wilderness expeditions involves the pairing of two individuals to share in the negotiation of professional obligation, social roles, and personal requirements through the relationship they create, potentiating a sustainable and fulfilling experience for both students and staff.

\section{Implications}

Co-instructors approach and rely on their relationship with one another as a refuge from the intensity of the institutionalized aspects of their lifeworld, and this relationship 
forms a lens through which staff interpret the quality of their own experience, be it fulfilling, lackluster, or "the worst interpersonal experience" $(\mathrm{P} 4, \mathrm{I} 3,1)$ they will have in the field. This is notable, since the adventure education industry relies on staff being willing to work in a demanding setting for little pay. Attention to co-instruction as a staff experience therefore emerges as a matter of prime importance.

Looking across the adventure education field's texts, trainings, practical articles, and conference workshops, one notices a conspicuous lack of attention paid to coinstruction. My study has made it clear that this is not from a lack of intuitive knowledgein-experience, but from the prominence of an administrative perspective and a lack of sustained inquiry into the topic that privileges other viewpoints. One possible explanation for this is that the co-instruction construct is simply too nebulous to support meaningful discussion or direct inquiry. But it also may be that the historical legacy of outdoor leadership and a cultural value of individualism have been taken for granted in the literature, diverting attention from the relational dimensions of work; the dilemma of the super-instructor may provide some evidence of this. Bethany spoke of her encounter with this issue when talking about the type of 'relational' training she received on the job: ...we have this student and diversity training, which is effectively a 'dealing with students and student issues' training, but the focus is on the student. Which is good, because it's their experience, but nothing ever puts instructors in a position where they have to actually look at themselves as being in a relationship with other people, whether it's their students or co-instructor. Or in relation with, I guess, not necessarily 'relationship'. So in relation with our co-instructor, our students- it doesn't get any sense of take-up in our trainings. It's like we're these emotionless, relationship-less figures that are plopped down and we just deal with the students as they come to us without any of our own baggage or things that come up- we never actually talk about, 'oh, what if you've got some kid that totally reminds you of your younger sibling, are you going to have any transference of some of your own emotional affect onto them?' P2, I3, 8 
If co-instruction as described by the interviewees as a negotiated relationship can be understood as the essence of the experience, and since co-instructor models will continue to be used in staffing (and there is no indication that this will or should change anytime soon), it follows that the co-instructor relationship should become part of the adventure education industry consciousness and conversation.

First and foremost, the practical significance of this study is a heightened awareness of co-instruction as a component of the field's day-to-day practice. It is my hope that both scholarly and practical reflections on the co-instructor experience gain prominence, as multiple discussion points emerged through this study. The topics I will address here are emergent power and staff training as related to the co-instruction phenomenon.

\section{Situational Co-Leadership}

I would like to return to the education literature, where authors have proposed three co-teacher arrangements to be used within inclusive classrooms: (1) the consultant model, in which one teacher is used as a specialist, (2) the coaching model, in which both teachers share information with one another, and (3) the collaborative model, in which teachers share responsibility in all matters of instruction (Austin, 2001). The themes I outlined in this study provide new ways of seeing how these can be more consciously implemented in the adventure education field in ways that are better connected to practice.

It is important to note that, given the unique intensity and lack of role boundaries in wilderness co-instruction, it is unlikely that one arrangement could encompass the entire course. Therefore, I am proposing that these models be used as flexible 
frameworks for shaping different moments that arise in the same course, and organizational leaders and co-instructors should be encouraged to consciously employ them as conceptual tools that can aid in the relational negotiation that invariably occurs. In other words, while it might be possible for co-teachers in a classroom to operate within one model for the duration of their relationship (although Austin's (2001) research indicated otherwise) this does not seem possible in a wilderness setting even though organizations may staff trips with one model predominantly in mind. I am suggesting that co-instructors themselves should be informed of these models and empowered to openly choose among them to help with role clarification in an effort to help positively negotiate their evolving relationship. Below, I review each model and describe how they can be adopted in adventure education.

Consulting. Within the consulting model staff are paired with attention to one as a specialist. This specialist may be seen as a rock climbing instructor being brought in to a course specifically to aid the other staff member(s) working on the course: The consultant co-instructor aids the general co-instructor(s) in areas that they are deemed to need extra assistance, be it in managing a specific environment, creating a specific curriculum, or dealing with a specific student. How co-instruction is to occur in areas outside of the realm of the consultant's area of expertise is vague within this description, as it does not appear to have been intended to operate outside of a specific type of arrangement. Consulting would appear appropriate within a mentorship model of coinstructing, but by and large in professional wilderness programs there is a good deal of transience among instructors. Experience within an organization, due to the nature of the field, does not leave room for the assumption that it equates general experience as a 
professional instructor. Unidirectional mentorship, or co-instruction as purely a training construct, is rarely seen within a wilderness course.

Coaching. Within the coaching model each co-instructor takes turns acting as both mentor and learner. Early on in my own co-instructing experience I was paired with a staff member with the administrative intention that he would help bring me up to speed on the whitewater sections of our course, and in turn that I would mentor him through the mountaineering and rock climbing sections of our course. The coaching model acknowledges that two different people will have different areas of expertise, and the intention within this model is that power is not held by any specific staff member, but instead it is a fluctuating entity that is willingly shared dependant on ability assessment. This model seems appropriate for the co-teaching construct, where pairs are interdisciplinary, but the adventure education field generally pairs intra-disciplinary staff to maximize risk management and potential for course outcomes, and what is to be done during the times when abilities are shared is left unclear.

Collaboration. Within the collaboration model of co-leadership all members equally share in all aspects of course design and implementation. This model is predominantly espoused by the education field as the preferred interaction style, as it equally values the roles of all team members (Austin, 2001). It most closely mirrors Levine's (1980) definition of 'desireable' (p. 37) co-leadership within the social work field as well. The adventure education field likewise advocates a collaborative approach to co-instructing (Wagstaff, 1997), with one caveat: in the event of a risk management decision being required, if no consensus can be reached within the staff team, there is one instructor- generally labeled the 'lead' instructor who is given the final word in the 
decision. While co-teachers are institutionally expected to operate collaboratively, Austin found that this did not occur in practice nearly as much as expected, and that co-teachers paid lip service to the model rather than live it out. Instead, a combination of collaboration, coaching, and consulting existed within the sample of co-teachers that he studied, often successfully.

Situational. In a field of transient staff that may work at multiple organizations or bases within organizations, it may not be accurate to assume that experience with the organization is equal to experience instructing in general. At best, the team member having more experience within an organization or base can be assumed to have a greater level of experience with the policies, procedures, logistics, and mission of the organization. Even a greater level of experience within the course area can not be assumed, given the overlap of programs working in similar course areas in adventure education. The reality of the field indicates that the title of 'lead' or 'assist' may mean very little outside the risk management need for the titles, and as orientation to the program; it can not be taken for granted as an indicator of instructing experience or mentorship duties towards more universal attributes of outdoor instruction or coinstruction.

A collaborative model, where co-instructors equally share responsibility as peers, would appear beneficial to address the co-instructor dynamic when removed from the brief periods when member titles have any bearing. Austin (2001), Clemmensen (2002) and Kolodny (1980), however, claim otherwise; and the experiences of my participants support these claims; true collaboration is not the only model operating successfully (and unsuccessfully) in co-instructor dyads. Instead, a mixture of consulting, coaching, and 
individual action may occur alongside collaboration successfully throughout a course. Given that co-instructors are, at their best, negotiating their emergent power structure honestly by negotiating personal, student, and group goals and expectations, it would stand to reason that the power within the co-instructor team would shift according to who is best equipped to meet those requirements in any given situation- be it 'lead', 'assistant', or 'we'. Co-instructors are operating on demanding courses where they encounter times of disparate knowledge and ability, shared expertise, and shared inability.

While it may appear from the administrative perspective to be beneficial to anticipate and prescribe a specific co-instruction model, this may not actually be the case. For Jeremy, Bethany, Jennifer, and Erin, their co-instructor power relationships were arrived at outside and oftentimes despite the prescribed roles of 'lead' or 'assist'. What I mean is this: while there is a well-defined risk management benefit to hierarchical titles, as well as reasons to choose one model for staff training purposes, co-instructors can and should have the power to decide situationally how their relationship should be arranged. Moreover, it is likely that negotiation will occur in fluid ways, even from moment to moment, as instructors work together to shape their own and participants' wilderness courses. Instead of assigning a single model, such as 'coaching' to a co-instructor team pre-course, the availability of different models may be better used if distributed among co-instructors as a relational guide. In this way the different co-instructor models that currently exist as organizationally decided-upon relationships become situational assessment tools and guides for conduct that aid in negotiating the fundamental tension between personal, social, and institutional demands. This perspective may initially appear 
to be antagonistic to organizational power structures; however, my participants' narratives provide useful insight into the manner in which co-instructors already must adapt their institutional expectations in order to promote positive course environments. It was the prescriptive institutional expectations that oftentimes complicated my participants' assessments of their relationships, and I am suggesting that these inherent aspects of the work be discussed openly. One can imagine that some of the issues raised by Austin (2001), Kolodny (1980), and Walther-Thomas (1997) were partially a result of organizations attempting to retain power through management, rather than empowering co-leaders to autonomously and situationally negotiate their own relationship.

My recommendations are based on the data; my participants' narratives showed co-instructors' emergent interactions around power and control in the environment arose naturally through a situational assessment of one another's expertise, with both negative and positive consequences. Bethany described how she and Gavin would defer power to one another based on their assessment of situational abilities, despite their institutional roles of 'captain' and 'assistant':

...when it came to certain things that we taught, he knew the things that I was really good at teaching and I knew the things that he was really good at teaching. He didn't know the things that I was bad at teaching because I didn't teach them, but we were able to work together in such a way that if the opportunity presented itself he would send someone to me- like if someone asked a question about the environment or about the plants and animals off the coast, Gavin would tell them, 'you know what? You should really go ask Bethany about that. She's really into the birds up here, and she could probably tell you about that particular bird', or viceversa. Gavin was really big into sea shanties, so if people started asking me about the history of sea faring off the coast, I know that I'm not as familiar with that, but I knew Gavin was because of having worked with him and knowing his strengths and the things he's interested in, so I'd tell the student, 'yeah you should ask Gavin about that'. P2, I2, 17

Likewise, given his struggle in understanding the co-instructor power relationship with 
Susan, Jeremy realized that he had to check his assumption that power was unidirectional based on organizational title, and recognize the potential for a situationally determined power structure:

One of the positive spins [of my experience] is the fact that there can be interactions in a leadership team where the person who is lower in the hierarchy can still have a guiding and nurturing effect on the other staff, on the 'lead' staff. Hopefully that's also happening from higher to lower, but also from lower to higher, I think. In a situational sense, the person with the most experience and knowledge of that situation would take the lead. So for example, in a medical situation the person with the highest medical training and the most medical experience is going to take the 'lead'. But I think it also happens in an interpersonal way, so if there's somebody who's feeling homesick within a group, maybe there's one staff, not necessarily the 'lead', that has more experience talking with kids about being homesick. P1, I3, 3

The nature of co-instruction that was revealed in this study points towards a more complex arrangement than any single model can address. A situational approach to coinstructor power that varies depending on the expertise within any given situation, and in which the members of the co-instructing team are willing to act as learner, teacher, and peer towards one another may be a pragmatic alternative, and explain the nuances that occur even when an organization may staff a trip with one primary arrangement in mind. Austin (2001) found that co-teachers did not follow one specific model despite their training. Indeed, I concur with his assessment: any approach that advocates one specific model of interaction rarely captures the personal, interpersonal, and group requirements found in the multitude of situations addressed in a single day, let alone a 30-day course. I am not advocating for administrators to anticipate and define models for every possible co-instruction requirement. Rather, I believe that a situational co-instruction approach may act as an empowering aid to co-instructors' relational negotiations that arise naturally on wilderness courses outside of the specific expectations that can be 
anticipated and defined by course managers before their instructors enter the field.

I have reconstructed the narratives of five individuals who have worked as coinstructors, and their experiences appear to point towards a more complex understanding of co-leadership than what is traditionally discussed in the literature. I proposed a situational approach to co-instruction as a way to advocate for the co-instructors' complex power negotiations, such as those seen in the narratives in this study. This approach, however, depends on an informed and empowered staff in order to be successfully maintained.

\section{Training}

The traditional education field has found that "the co-teaching model is often considered by teachers to be initially difficult" (Dieker, 2001, p. 15) to create. Because of co-teachers' struggles with the administratively required model for creating inclusive classrooms (Walther-Thomas, 1997), "how-to" literature abounds on how to be an effective co-teacher. When faced with the prospect of co-teachers struggling with their work environment, organizations have focused these trainings on how to better enable coteachers' negotiations with the prescribed models, rather than critically examining the use of the models themselves (Walther-Thomas; Austin, 2001). An alternate perspective, borne of my participants' narratives, would be to develop trainings that present and entrust the application co-instruction models to the judgment of co-instructors. I have identified two areas that are common to outdoor leadership training, the leader of the day (LOD) practice and instructor trainings (ITs). These would be potential venues for developing co-instructor trainings.

Leader of the Day. From an administrative perspective, co-instruction serves the 
dual purpose of risk management and sharing training expertise (Wagstaff, 1997). Jeremy shared the manner in which co-instructing was practiced as a training tool in his involvement in university and wilderness therapy, where the pairing of instructors at various levels with clear hierarchies and directions of mentorship enabled professional growth. What few of my participants found in their lives as wilderness educators was a time in which they were actually trained for co-instruction, with the exception of Erin on her instructor's course in the Sierras. Each day of their course, which served as a staff training and orientation, a prospective trainee was given the opportunity to act as a 'coLOD' with another new staff person. She found, however, that "in the group, most [coLOD's] had gone off and done their own things" (P5, I1, 12) and struggled with the collaborative aspect of the experience. This mirrored Bethany's experience that "we operate under that myth that if you're good at a technical skill, you're good at teaching that skill, and any two people that have good technical skills can work together to teach teenagers said technical skills" (P2, I3, 17); in reality, co-instructing may not come naturally as, in Bethany's view, educational ability does not immediately follow technical skill.

The practice of assigning a 'leader of the day' as a form of training is worthwhile as a tool to independently investigate instructional style and ability. I have shown, however, that staff commonly work in leadership teams, and that they are navigating both their social-personal and professional relationships, often without adequate training to do so. While outdoor leadership was successfully practiced prior to the development of common leadership training techniques (e.g., Priest and Gass, 1997), training has been beneficial to the adventure education industry. In the same way, developing and 
extending training tools in co-instructional style and ability may help take full advantage of opportunities to enhance performance in the field. The practice of assigning LODs as a training tool is an excellent example; whereas it is useful as an early exercise in a budding instructor's training, by incorporating co-LOD opportunities the field may be better able to mimic professional expectations for staff and bring awareness to the personal and professional potentials of co-instructing. A co-LOD training could include a description of what co-instruction is known to be as both an organizational and relational entity, as well as how to work within pre-specified arrangements. Training could include: preparatory time for co-LODs to discuss information they perceive to be pertinent with the guidance of an experienced co-instructor, practice in front of a group of peers within a training expedition, and time for reflection, self-assessment, and relationship assessment both as a co-LOD team and with the whole group as a way to highlight key lessons.

Instructor Trainings. The LOD experience is not the only area in which staff are introduced to leadership theory and practice. Likewise it could be beneficial for staff to be provided with opportunities to build awareness around routine co-instructor job expectations and demands. Accomplishing a fulfilling co-instruction experience, given the narratives shared here, seems partially determined by how the dilemma of the superinstructor plays out. The nature of the wilderness educator's life as living work also should be considered, for they are not super-human, even though successfully delivering communitas (Sharpe, 2005a) has unique demands that require individuals to operate within a heightened experience. One can imagine two options for staff in this kind of environment: first, outdoor instructors can hide their vulnerabilities and 'fake it until you make it' behind the façade of the super-instructor, which can result in self-doubt and a 
need for control, as Jeremy experienced with Susan; or, second, co-instructors can "share the load" (P5, I2, 3) within what is hopefully a mutually supportive relationship, as Erin experienced with Katie.

While some in the field have operated by employing the 'super-instructor' technique (with mixed but predominantly negative consequence, as my participants discovered), this is a doubled-edged sword: it could aid staff in confidently making it through difficult situations, but even at the individual level it seems to contradict a core value, expressed by one of adventure education's most influential figures: "your disability is your opportunity" (Hahn, 1960, p. 4). Erin found that by rejecting the pride and insecurity that breeds the false presentation of self as super-instructor, the need-less, relationship-less being, and embracing the 'co' perspective,

...in sacrificing all that bullshit lying aside, and learning about the person next to us, that 'co', and who they are and what they bring- it is way more fun, way more adventurous, risking. We tell our students to take risks every day, and... we tend to forget to take those types of risks that we need to take ourselves. P5, I3, 13

Within staff trainings at universities and organizations, at conferences, and in written communication, this reality of staff experience could be more openly discussed among organizational leaders, instructional staff, and perhaps even participants at key times. Future research could be conducted to isolate the variables of positive coinstruction (as I will discuss later), but an immediate implication for professional training is to continue to expand the field's awareness of the work-life facing staff and options of how to deal with the rigors of itinerant, seasonal work (Sharpe, 2005b).

How to begin addressing the co-instruction phenomenon with minimal research to serve as a guide and scant literature to draw from may appear daunting. Further 
complicating open inquiry here may be issues of power. When faced with teaching whitewater kayaking for the first time, being self-taught with little training to guide how I would train others, my employer offered a cunning strategy: just teach what you know. From a social justice perspective, McClintock (1994) offers a more nuanced strategy: rather than portraying herself as a super-instructor, she shared her own stories and experiences in addition to skill lessons. This strategy could be worked more systematically into leadership training and after-course debriefing. For instance, opening up forums during instructor trainings and conferences where people could openly discuss their co-instructing experiences among peers may be a way to reveal the knowledge that the field currently retains.

A simple open forum, however, brings a potential risk: within a purely autonomous collective where no direction is given, one can imagine the difficulty with which a topic can be systematically discussed or investigated. My participants revealed the manner in which their experiences contain both positive and negative attributes, as well as a zest for sharing their experiences with refreshing candor. One potential discussion within a training, therefore, may be to present the various co-instructor arrangements from other fields, addressed previously, and frame a discussion around how those models may arise situationally while in the field, and how they may be used to benefit instructors and participants.

The co-instructor relationship is, to these people who have lived it, a chance to invest in a relationship for a period of time, and it holds potential for inducing personal and professional growth. But this takes time to recognize and practice to develop, and if positive relations are compromised by the dilemma of the super instructor or other power 
dynamics, staff and student experiences could be compromised. There could be other reasons to engage in such storytelling: I have shown how the wealth of information held within the experiential knowledge of co-instructors can form the basis for expanded knowledge of co-instruction. Encouraging staff to reflect on and share their own narratives with co-instructing may reveal valuable knowledge that could affect the course of the larger practical and scholarly discussion. Training programs may therefore be the place to begin to share recognition of the manners in which the field handles the intensity of the work, and the role that co-instruction can play in the life experience of staff.

\section{Research Implications}

When I set out to understand the nature of co-instruction on wilderness courses, I was interested primarily in the practical significance: can outdoor organizations train, hire, manage, and evaluate for quality co-instruction? What future exists for coinstruction's inclusion in staff manuals, practical models, and chapters in our textbooks that addresses what I perceived to be a crucial but little-mentioned component of the job's requirements? After this investigation, my notion of what co-instruction is and its place within the adventure education practice has been dramatically altered and expanded in vision and scope. When I reflect on my mindset before this study, I can see how I took for granted the notion that co-instructing was merely a professional skill. While the complex negotiation of the co-instructor relationship and its resolved reality for staff has brought to light both aids and struggles for practice, the nature of phenomenological inquiry has magnified new theoretical understandings of a topic that has, to this point, been conceived without much consideration of how it is embedded within lived experience (van Manen, 1997). The main implications arising from this study include 
new principles for adapting the various co-instructor interaction models that currently exist in the education and human service literature and areas for future research.

\section{Future Research}

Future research on co-instruction can build on this study in several ways. I will describe two instrumental, or practical directions, and two scholarly directions that build directly on the phenomenological tradition.

First, one can imagine how co-instructor dynamics could impact student experiences, and thus course outcomes. In the present study, each interviewee intuitively sensed that their co-instructor interaction would likely impact their students' experience. However, my participants did not speak directly or in depth regarding the way in which their students' experiences may have been shaped through co-instruction. This may be due to staff obligations in creating a specific environmental façade for students' experiences (Sharpe, 2005a), and therefore a perceived necessity to keep aspects of the co-instructor relationship private. The ability to effectively conceal and shelter students from the impacts of their co-instructors' relational negotiation would appear strenuous and potentially impossible, given that my data points out both personal and professional implications stemming from the co-instructors' negotiated relationship. Investigation into this connection seems to be an important direction for future research. Developing methods for testing this assumption would be a useful next step in understanding the effectiveness of different co-instructor models that are implemented based on some of the ideas I have presented here. Surveys, perhaps used as part of a program evaluation, could be useful for studying the impacts of co-instruction on student experience.

Second, while I agree that understanding co-instruction as it relates to student 
outcomes is important, it is also important to research staff experiences and outcomes so as to best understand and provide for the professionals that the field relies on. I have claimed that my co-instructors' relational resolutions were partially interpreted through their perception of existent professional and social support in their co-instructor relationship. Social support is defined as "information leading one to believe that he/she is cared for and loved, esteemed and valued, and belongs to a network of communication and mutual obligation that emphasizes the individual's perception that support is available when needed" (Cobb. 1976:312). Erin appeared to describe this phenomenon while discussing a course that she had been on with Katie before the one she shared in detailthe previous semester-long course's mountain component:

I got to the end of a day and I was like, 'why am I here? And I started to lose motivation, didn't even want to speak out and have those interventions. It's because I could recognize, 'wow, these guys are doing it', you know? And I also recognize I was tired, and we all have those moments on long courses where we'd rather be somewhere else (laughs) and not be 'on', so it was kind of my 'off day', but the off day still happens with the students, and so I was feeling worthless for not doing anything productive or feeling like I did anything productive. Those were powerful moments, speaking that out. I think I was the first one to do that, at the end of one day, where I said, 'hey guys, this is how I'm feeling. I know it's not rational, but this is the way I'm feeling', and they validated that; they said, 'oh, yeah. Of course, I can totally see that, I've had those days, I've felt that way and that's ok, you know', but they were also able to affirm me about things they'd seen me do that day, and also encourage me regarding my contributions to this instructor team and to this group. And then there were consecutive days where Katie had that same experience, and she was in tears and saying, 'maybe I'll just go out a day early,' because she was going to be leaving anyways, but she was going to leave an extra day early- she thought she was in the way or something. And then James had the same experience, and so it was just really fascinating to get to verbalize that to one another and share that, and not share that with our students but share that between ourselves and have those moments. P5, I1, 17

Cobb (1976) indicates that the presence of support networks may have a mediating effect on burnout in the workplace. In a case study of burnout among his 
college students in 1983, Mungo described two types of work activity that lead to stress: an environment in which an individual's abilities do not meet the demands of the job, either real or perceived, and an environment in which a person's needs are not met through their work experience. This stress, he argued, leads to loneliness and burnout in the work environment. While attention has been paid to issues of burnout among adventure education staff (Wilson, 2009), the possible connection that the co-instructor relationship may have with this phenomenon is yet to be studied. This is one example of a line of research focused on professional staff of which the co-instructor relationship may provide new insight. I detail out specific areas for future research below.

Instrumental Research. A fruitful line of research that could help attend to both of the areas above, among others, is the development of a Co-Instructor Dynamics Questionnaire. A quantitative or mixed-methods study of co-instructors, based on some of the themes I have presented here, may increase our knowledge of the co-instruction phenomenon and how it is established, experienced, and resolved as a team. The findings from the current study, while illuminating, cannot be generalized to the wilderness coinstructor population. However, the results may help develop a measure of co-instructor relationships. The creation and validation of a measure that can accurately indicate the style of co-instructor relationship (perhaps by measuring the balance and perceived health of professional and social-personal support) is a necessary next step in co-instructor research. In addition to helping determine the extent to which some of my themes extend to other co-instructors or other settings, survey development could form a nexus point in a web of possible research:

1. There are multiple relationships that a valid measure of co-instructor dynamics 
could study, including perceived self and/or other performance, emotional and physical stress and/or relaxation, investment in the job, personal satisfaction, burnout and/or retention, and other staff outcomes.

2. If a relationship between co-instructor dynamics and staff outcomes is established, a treatment could be designed for an experimental design study investigating how co-instruction training or treatment affects staff relationship resolutions.

3. Finally, many programs already have students fill out evaluations at the end of courses, sometimes for in-house programmatic information and other times for larger research purposes. A correlation between the co-instructor dynamic questionnaire and student evaluations containing specifically designed questions on staff and team abilities could, sampled on a very large scale, begin to investigate the relationship between co-instructor dynamics and student experience. This could be particularly important in program evaluation efforts.

Scholarly Research. As I noted earlier, my use of phenomenology was as a methodology that best fulfilled the aims of the study, and therefore my contributions to phenomenology itself are somewhat limited. The study, however, brought to light multiple avenues for future research that could deepen and extend the phenomenological tradition. A phenomenological investigation of both administrative and participant experiences with co-instructing would continue to add depth to the concept, and future research aligned with specific sub-disciplines within phenomenology would add considerable depth in my overall aim to understand and help provide for the most effective wilderness staff experiences, both programmatically and as a life-enriching 
experience. I will briefly outline two possible future phenomenological approaches that may prove useful, one in a more psychological direction, the other sociological.

The tradition of phenomenological psychology is aligned with phenomenology as a way of investigating and understanding the subjective experiences of an individual, experiences which are not easily understood by an outside observer (Snygg, 1941). Snygg points out the inadequacies of the objective approach to psychological research in understanding how an individual encounters a novel or learning experience, primarily resulting from the need in objective research to "postulate lawfulness" (p. 410) and determine essential and non-essential behavior apart from the observed. Phenomenological psychology claims that "all behavior is lawful" (p. 411), and investigates the full experience of an individual within their 'phenomenological field' ( $p$. 412) in order to understand behavior and learning. The participants in my study described their experiences with co-instruction as life encounters with powerful personal effects. Likewise, they grappled personally with issues such as power, identity, and trust, and clearly these are psychologically important. As I am interested in the decisions, assessments, learning, growth, and meaning that co-instructors make for themselves within adventure education, the lens of phenomenological psychology may prove useful as a specific phenomenological discipline for future research. One potential line of research could focus on the ways different work arrangements—-such as itinerant, seasonal employment— may help or hinder developmental growth at key phases in early adulthood. Another potential line of research could focus on the consequences of the various relational resolutions that I outlined in this study on the greater life experiences and meaning for co-instructors. 
As well as experiencing the phenomenon of co-instruction on an individual level, my participants were engaged in both a social relationship that was not just affected by local conditions, but also reflected the broader influence of institutionalized labor roles. Sharpe's (2005b) ethnographic study of wilderness leadership revealed that guides must expend considerable emotional labor throughout the course of their work, which was very taxing, and potentially exploitative. Sharpe's finding locates wilderness leadership amidst other contemporary arenas where people pay to have life-changing experiences, and professionals are paid (often not much) to perform in ways that guarantee them.

Co-instructing is, in many ways, a thoroughly societal experience within the institutionalized and culturally derived requirements, including risk management and legal responsibility, placed on the adventure education industry. Itinerant, seasonal staff are not only subject to a societal expectation to provide specific forms of leisure experiences (Sharpe, 2005b), but also life-enhancing experiences (Hahn, 1960) in ways that indicate an interesting dilemma: minimal attention appears to be paid to the work/leisure and life-enhancing experiences of the staff themselves within this labor arrangement. Likewise, the nature of being providers of what may be considered societally important experiences while being marginalized in pay and cultural validation implicates the potential for a sociological investigation of the co-instructing phenomenon and the extended wilderness staff labor role within our larger culture. Phenomenological sociology is an approach aimed at understanding our social existence through the phenomenological lens by understanding the intersubjectivity of a social lifeworld (Overgaard \& Zahavi, 2009). Specific aspects of the co-instructing experience that emerged through my study, including the institutional-personal gap, may be best studied 
via a sociological perspective that is aligned with phenomenology. Likewise, in reflecting on my study it would appear that, at heart, the co-instructing experience is an example of labor and personal life intertwining in a manner not readily perceived within a rationalized society (Mitchell, 1983). What I mean is that co-instructing emerged from my study as containing realities of practice that are contradictory to societal expectations in divisions of work and leisure, or the negotiation of professional and personal. Coinstruction and phenomenological sociology appear, therefore, to be both compatible and possibly illuminating as a future area of scholarly exploration.

The co-instruction phenomenon has historically been a little-studied practice with great potential as a researchable topic. This study was and is meant to be an entrance into the academic dialog, and by no means is intended to be the definitive statement on the matter. I have only begun to shine further light on co-instruction, building on previous studies such as Millette and Porter (1989), Wagstaff (1997), and Rilling and Jordan (2007).

\section{Conclusion}

Sixteen months ago, when I first became interested in co-instruction as a possible research topic, I was struck by the lack of attention paid to the subject in the literature. I was unsure of what to expect, and of where to begin, while studying this construct and the co-instructors engaged in it justly. Given the tensions that emerge from current discourse regarding the nature of co-leadership and co-instruction, I was wary of the scholarly treatment that I would be required to rely on for definitions, models, and analyses. Phenomenology allowed insight into the nature of co-instruction as experienced by my participants by providing a reflective description of co-instruction that can be 
compared with how it has been portrayed in the literature. The juxtaposition revealed a nuanced, and at times paradoxical, experience as a relational negotiation attempting to balance both professional and social-personal requirements in an intense life experience. Above all, it is clear that the co-instructors I interviewed have been personally affected by their practice, and wished to have their voices heard. I have provided the co-instructor perspective on the institutionalized, relational living work engagement and various meanings that are made of that intense life experience. Ultimately, I revealed the wilderness expedition profession to be placing both explicit and implicit expectations on staff, through which a self-other relationship may act as a dialectical resolution to the dilemmas that arise within their labor. I also placed the phenomenon of co-instruction within the practical and scholarly purview of the adventure education industry. While initially undertaken to answer what I hoped would be a strenuous, but ultimately lucid issue, I am struck by the notion that this study feels more like an initial step into a Mandelbrot set. I have greatly enjoyed taking part in it, and hope to continue to do so in the future both in my own time as a co-instructor and as a researcher. 


\section{REFERENCES}

Austin, V. (2001). Teachers' beliefs about co-teaching. Remedial and Special Education, 22(4), 245-255.

Berndtsson, I., Claesson, S., Friberg, F., \& Öhlén, J. (2007). Issues about thinking phenomenologically while doing Phenomenology. Journal of Phenomenological Psychology, 28, 256-277.

Bertaux, D. (Ed.). (1981). Biography and Society: The life history approach in the social sciences. Beverly Hills, CA: Sage.

Brown, M. (2006). Adventure education and physical education. In D. Kirk, D. Macdonald, \& M. O’Sullivan (Eds.), Handbook of Physical Education (pp. 685702). Thousand Oaks, CA: Sage.

Clemmensen, B. (2002). An exploration of differences and perceptions of difference between male and female challenge course instructors. Journal of Experiential Education, 25(1), 214-219.

Cobb, S. (1976). Social support as a moderator of life stress. Psychosomatic Medicine, $38(5), 300-314$.

Dieker, L. (2001). What are the characteristics of "effective" middle and high school cotaught teams for students with disabilities? Preventing School Failure, 46(1), 1423.

Dewey, J. (1938). Experience and Education. New York, NY: Touchstone.

Dugan, K., \& Letterman, M. (2008). Student appraisals of collaborative teaching. College Teaching, 56(1), 11-15.

Ewert, A. (1987). Research in outdoor adventure: overview and analysis. The Bradford Papers Annual, 2, 15-28.

Ewert, A., \& Hollenhorst, S. (1984). The development of the outdoor leadership training simulator. Proceedings from the Annual Conference of the Association of Experiential Education (12, Lake Junaluska, North Carolina, October 4-7, 1984).

Ford, P., \& Blanchard, J. (1993). Leadership and administration of outdoor pursuits $\left(2^{\text {nd }}\right.$ Ed.). State College, PA: Venture Publishing, Inc. 
Goldenberg, M., \& Pronsolino, D. (2007). A means-end investigation of outcomes associated with Outward Bound and NOLS programs. Journal of Experiential Education, 30(3), 271-276.

Galinsky, M., \& Schopler, J. (1980). Structuring co-leadership in social work training. Social Work with Groups, 3(4), 51-62.

Galloway, S. (2007). Experience and medical decision-making in outdoor leaders. Journal of Experiential Education, 30(2), 99-116.

Gillespie, D., \& Israetel, A. (2008). Benefits of co-teaching in relation to student learning. Paper delivered at the $116^{\text {th }}$ Meeting of the American Psychological Association (Boston, Massachusetts, August 2008).

Hahn, K. (1960). Outward Bound. Address delivered at the Annual Meeting of the Outward Bound Trust, July 20, 1960.

Harren, V. (1969). A model for co-therapy in groups. Paper delivered at the America Psychological Association Convention (Washington, D.C., September 1969).

Hayashi, A. (2007). Emotional intelligence and outdoor leadership. Journal of Experiential Education, 27(3), 333-335.

Kain, D. (2006). Choose colleagues before friends for teaching teams. The Education Digest, September 2006, 53-56.

Kalish, K (1979). The role of the instructor in the Outward Bound educational process. Kearney, NE: Morris Publishing.

Kloo, A., \& Zigmond, N. (2008). Coteaching revisited: Redrawing the blueprint. Preventing School Failure, 52(2), 12-20.

Kolodny, R. (1980). The dilemma of co-leadership. Social Work with Groups, 3(4), 3134.

Levine, B. (1980). Co-leadership approaches to learning groupwork. Social Work with Groups, 3(4), 35-38.

Locke, L. F. (1977). Research on teaching physical education: New hope for a dismal science. Quest, 28, 2-16.

Luke, M., \& Hackney, H. (2007). Group coleadership: A critical review. Counselor Education \& Supervision, 46, 280-293.

Meier, J. (1984). Risk and hazard management in high adventure outdoor pursuits. Proceedings of the 1984 Conference on Outdoor Recreation: A Landmark 
Conference in the Outdoor Recreation Field $\left(1^{\text {st }}\right.$, Bozeman, Montana, November 1-4, 1984).

Middleman, R. (1980). Co-leadership and solo-leadership in education for social work with groups. Social Work With Groups, 3(4), 39-50.

Millette, M., \& Porter, T. (1989). Co-leading wilderness trips with a member of the opposite sex. Pathways: the Ontario Journal of Adventure education, 13(1), 8-11.

Mitchell, R. (1983). Mountain experience: The psychology and sociology of adventure. Chicago, IL: University of Chicago Press.

Mungo, S. (1983). Stress, burnout, and culture shock: an experiential, pre-service approach. Journal of Experiential Education, 8(1), 27-31.

Murawski, W., \& Swanson, H. (2001). A meta-analysis of co-teaching research: Where are the data?. Remedial and Special Education, 22(5), 258-267.

Peart, R. (1992). Safe leadership in OE: Part 2: Effective leadership. The Journal of Adventure Education and Outdoor Leadership, 8(4), 21-25.

Priest, S. (1987). Preparing effective outdoor pursuit leaders. Eugene, OR: Institute of Recreation Research and Service.

Priest, S., \& Gass, M. (1997). Effective leadership in adventure programming. Champaign, IL: Human Kenetics.

Raiola, E. (2003). Communication and problem-solving in extended field-based outdoor adventure education courses. Journal of Experiential Education, 26(1), 50-54.

Rilling, C., \& Jordan, D. (2004). Important co-leader skills and traits on extended outdoor trips as perceived by leaders. Leisure Sciences, 26(2), 193-212.

Ringer, M., \& Gillis, L. (1998). Case studies in managing psychological depth. Proceedings of the International Adventure Therapy Conference $\left(I^{s t}\right.$, Perth, Australia, July 1997).

Schumann, S., Paisley, K., Sibthorp, J., \& Gookin, J. (2009). A typology of instructor influence on student learning. Proceedings from The Outdoor Leadership Research Symposium (1 ${ }^{\text {st }}$ Bloomington, Indiana, February 2009).

Scruggs, T., Mastropieri, M., \& McDuffie, K. (2007). Co-teaching in inclusive classrooms: A metasynthesis of qualitative research. Council for Exceptional Children, 73(4), 392-416.

Seidman, I. (2006). Interviewing as qualitative research $\left(3^{\text {rd }}\right.$ Ed.). New York, NY: 
Teachers College Press.

Shapiro, E., \& Dempsey, C. (2008). Conflict resolution in team teaching. College Teaching, 56(3), 157-162.

Sharpe, E. (2005). Delivering communitas: Wilderness adventure and the making of community. Journal of Leisure Research, 37(3), 255-280.

Sharpe, E. (2005). "Going above and beyond:" The emotional labor of adventure guides. Journal of Leisure Research, 37(1), 29-50.

Snygg, D. (1941). The need for a phenomenological system of Psychology. Psychology Review, 48, 404-424.

Sokolowski, R. (2000). Introduction to Phenomenology. Cambridge, UK: Cambridge University Press.

Starak, Y. (1981). Co-Leadership: A new look at sharing group work. Social Work with Groups, 4(3/4), 145-157.

Stivers, J. (2008). Strengthen your coteaching relationship. Intervention in School and Clinic, 44(2), 121-125.

van Manen, M. (1997). Researching lived experience $\left(2^{\text {nd }}\right.$ Ed.). London, Ontario: The Althouse Press.

Wagstaff, M. (1997). Outdoor leader self-awareness and its relationship to co-leaders' perceptions of influence. Unpublished doctoral dissertation, Oklahoma State University, Stillwater, OK.

Walther-Thomas, C. (1997). Co-teaching experiences: The benefits and problems that teachers and principals report over time. Journal of Learning Disabilities, 30(4), 395-407.

Western Illinois University. (2007). About ECOEE. Retrieved February 16, 2009, from http://www.wiu.edu/RPTA/ecoee/about/

Wilson, G. (2008). Be an active co-teacher. Intervention in School and Clinic, 43(4), 240243.

Wilson, J. (2009). The role of pay satisfaction in instructor satisfaction. Journal of Experiential Education, 31(3), 400-404.

Winter, S. K. (1976). Developmental stages in the roles and concerns of group co-leaders. Small Group Behavior, 7(3), 349-362. 
Wright, M. (2002). Co-facilitation: fashion or function?. Social Work with Groups, 25(3), $77-92$. 


\title{
APPENDIX A
}

\section{INSTITUTIONAL REVIEW BOARD LETTER OF APPROVAL}

\section{University of New Hampshire}

\author{
Research Integrity Services, Office of Sponsored Research \\ Service Building, 51 College Road, Durham, NH 03824-3585 \\ Fax: 603-862-3564
}

$13-$ Oct-2009

Vernon, Franklin

Kinesiology, New Hampshire Hall

365 Washington Street

Dover, NH 03820

IRB \#: 4593

Study: The Experience of Co-Leadership in Extended Wilderness Trips

Study Approval Date: 13-May-2009

Modification Approval Date: 07-Oct-2009

Modification: Addition of sharing deidentified data for instruction

The Institutional Review Board for the Protection of Human Subjects in Research (IRB) has reviewed and approved your modification to this study, as indicated above. Further changes in your study must be submitted to the IRB for review and approval prior to implementation.

Researchers who conduct studies involving human subjects have responsibilities as outlined in the document, Responsibilities of Directors of Research Studies Involving Human Subjects. This document is available at http://www.unh.edu/osr/compliance/irb.html or from me.

If you have questions or concerns about your study or this approval, please feel free to contact me at 603-862-2003 or Julie.simpson@unh.edu. Please refer to the IRB \# above in all correspondence related to this study. The IRB wishes you success with your research.

For the IRB,

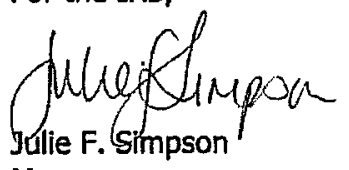

Manager

cc: File

Seaman, Jayson 


\section{APPENDIX B}

\section{WRITTEN CONSENT HANDOUT}

Thank you for volunteering for this study! The interviews you will take part in are part of a research project into the experience of co-leadership on extended wilderness courses. This research is being done in conjunction with the University of New Hampshire as part of a requirement for a Master's Degree in Adventure education.

Before we begin, I need to tell you about the interview process and about your rights as a participant. If after reading these terms you do not agree to participate, just let me know and I'll cancel the interview.

Your involvement will require three interviews spaced out over a one week period. Each interview will last for 90 minutes and will be transcribed and analyzed at a later date. The interviews will be about three different aspects of co-leadership:

- Interview I will be about your history of co-leadership in wilderness instructing

- Interview II will be about a detailed account of your co-leadership experience

- Interview III will be about the meaning you know in co-leadership

- I also might check in with you at a later date to clarify something, or to run my ideas by you. If so, I will be contacting you over email to arrange a time to talk.

Our recordings will be stored on my personal secure computer and transcribed after each interview. As I'm transcribing, I will change your name to protect your identity. In general, I will be the only person who listens to the recordings. However, I might play short sections to my advisor in case I need help with my project. De-identified data may also be used in future publications and presentations. I will be deleting the recordings after I am finished with the research project. You should also know that there is some information I am required by law to report, such as reports of child abuse or threats of harm against self or others. If you tell me about your participation in these activities, I will need to tell your supervisor or relevant authority.

Participation in these interviews is completely voluntary. Stopping the interview will in no way affect your job or your work in the field. A withdraw after the first interview will result in collected data not being used and all of your interviews deleted.

If you consent to be interviewed, I will have you state your name indicating that that you are willingly participating in this study. By stating your name, you also acknowledge that I have given you my contact information and the contact information of my advisor and of the research officer at my university.

\section{Co-leadership in Extended Wilderness Courses study contact information}


Please contact any of the following people if you have questions or concerns:

Franklin Vernon, 603-306-7141

Dr. Jayson Seaman, Research Advisor, jseaman@unh.edu, 603-862-1162

Dr. Julie Simpson, UNH Office of Sponsored Research, 603-862-2003 


\title{
APPENDIX C
}

\author{
EMAIL INVITATION
}

(name),

Hello! I'm a fellow outdoor educator working on my Master's Degree in OE at the University of New Hampshire. I'm contacting you because I would love to interview you about your experience working in co-leader arrangements. If you have a) worked at least 8 ten-day wilderness courses, and b) worked at least 2 of those courses in the last 2 years, then you are exactly who I am looking for.

The purpose of this study is to develop a deep understanding of the co-leadership experience in our field. By developing this deep understanding we can begin to have discussions on how co-leadership impacts our courses, our students, and ourselves. Your involvement in this study would be a part of the groundbreaking into these discussions that may drive future trainings and evaluations focused on co-leadership.

I will be in your area between and . If you would be free to meet three times for 90 minutes each during that time period, and would like to take part in this research, please email me and we can arrange a time to meet.

If you are not able to participate, but know of someone who you think would meet the criteria I am looking for, please forward this email on to them.

Thank you very much,

Frank 


\section{APPENDIX D}

\section{RECONSTRUCTED LIFE STORY: BETHANY}

I didn't know I was working with him initially. The program likes to do this cryptic thing where you don't find out who you're working with until a day or two before you go out on course, and usually that's only because you consult with everyone else who's staying at the staff house; you start comparing notes on who's doing what course. Someone's like, 'oh, I'm working a 21-day course', 'oh hey I'm working then, too- oh, maybe we're working together.' Sometimes you don't find out until the day you show up for prep and you get to ask 'who am I working with?' Course directors and program directors are looking at work schedules and it seems like they're pairing people by just saying 'well this person's available for this week, and this person's available for this week, I guess they're gonna be on this course together.' It's more or less assumed that you're both adults, you'll figure it out, but we live in a country with a divorce rate of 50 percent- people clearly can not figure stuff out. There are just personalities that by their nature conflict with each other. Working with people you don't get along with sometimes has its benefits because it forces you to adapt and grow, but I don't necessarily know that when working a course that we want our growth to be happening at the expense of our students' experience, you know? I could grow a ton over a 20-day course but my students could have a miserable experience because their instructors couldn't figure out how to work together until the last 3 days. On this course, luckily, I was re-visiting a known coinstructor dynamic. 
I had worked a course with Gavin the summer before; I had heard stories of him, about the sea shanties that he always sang, about how he dresses like a pirate on a regular basis. I didn't know what to make of it. That previous course had a weird setup, where we had 2 boats in convoy with Gavin and I on one boat, 2 co-instructors on the other, and one co-instructor, Tom, who split time between the two boats. It was interesting, having Tom around definitely solidified Gavin's and my relationship- he's a very bizarre guy, that there Gavin, but we developed a good working dynamic. I think sometimes it was at the expense of Tom, because he was gone for 3 days at a time, so then he would come on the boat and we had to catch him up on everything that we did over the past 3 days and figure out how to re-incorporate him. The first part of that course working with Gavin was hard, and I don't know that I got as many of my needs met as I could have, because I was still trying to figure him out. I also had the power-dynamics relationship playing out a little bit, so I didn't necessarily feel like I could express those needs. And then as the course progressed and we became closer it became clear what our personalities were like and how they would work together. Because of that, we were able to create our working relationship, but it definitely didn't happen overnight. So we worked that course together and we actually became really good friends, well, good friends in that we talked about everything on the boat. Part of it is that it's the only other adult you have, that you're around for 20-some odd days, so you wind up becoming default close friends with the person you're with, if you get along.

So yeah, when I found out that I was working with Gavin, or that there was a good chance that I was working with Gavin, I was pretty excited because it was a good opportunity to build on the relationship we had started the year before. We were going to 
be working on a 21-day sailing course off the coast of New England, and we had gotten to be good friends on the previous 25 day or 23 day course we had done the year before. We had worked fairly well together, though there were some issues. I was excited because I felt like I was closer to him, so our working relationship was something that could actually be addressed now. That previous year we were still working out the kinks, and just getting used to each other- now we could actually fine-tune our work relationship, and we'd be able to call each other on stuff more.

It was actually really funny, because we literally organized the boat in the exact same way, with my gear in the same place as it was in the year before, same with his gear, because we had the exact same boat- which doesn't normally happen, but somehow it worked out that we had pulled boat six again. So because we were on the exact same boat we had the exact same setup, and it was pretty funny to see that, we literally just gravitated to the way it had been for the previous 23 days that we had been together. While we were prepping we discussed all of the things that we wanted to do on the course, and it was nice because I was able to really push for some of my own needs up front. Gavin had also put out the idea of possibly doing a 'Bethany as captain for the day', because he's the official captain, the coastguard captain, so he's the one that has the legal responsibility of the boat, but he thought that we could have a couple of days where I would take responsibility for the boat. Obviously from a legal perspective that doesn't apply, but in terms of the way we interacted with the kids. And we actually did that a couple of different times. A lot of it was because we had kids that were amazing- sweet, sweet children, but horrible, horrible decision-makers. We had some seriously long nights getting in and getting to bed at like $1 \mathrm{am}$ and trying to catch a tide at $5 \mathrm{am}$, and so in the 
effort to have at least one safe set of eyes on board one of us would wind up napping while the other was maintaining the boat. And that was a testament, I guess, to the fact that Gavin trusted me with the boat, because he was actually able to go to sleep, and leave me in charge of the boat while we were under way.

When we weren't under way, but at dock, we would often take the students running. Well, most of the time I would take them because I was the one who wanted to get in shape. Gavin would go into town and when I would come back there would be some sort of little treat tucked away into my dry bag; I would open it and there would be a diet coke waiting there for me, or some sort of cookie, and it was like a little piece of heaven. And he took me out to breakfast at this little diner when the kids were off doing service, and then he took me out to dinner afterwards, after the course as well, mostly because he said he thinks I get paid about half as much as he does. Captains get paid way more than assistants, and assistants have a distinct cap on how much they can make if you don't have your license. I had hit that cap, and have remained at that cap, and will remain at that cap until someone comes up with some better system for how merit days work if you don't have a license within the sea program. Likewise, whenever we were docked somewhere and we had to go ashore, one of us would 'go see the harbor master about permits' while the other one was watching the kids and making sure water was getting filled. But 'going to see the harbor master about permits' was a euphemism about seeing what convenience store or local burger joint happened to be open where you could obtain some sort of contraband. So he'd be like, 'oh, I've gotta go see the harbor master to make sure that we have our permits for going over into this part of the water', and I'd say, 'oh, don't forget to check on the permits that I had asked you about before,' we had 
our own little language. The kids would be like, 'he's been gone at the harbor master for a while,' and I'd respond, 'yeah, usually there is some paperwork you gotta fill out, it's a little bit of a process.' Sometimes if we were there for a while he would come back from the 'harbor master' and say, 'they need to see your paperwork as well.' I'd ask, 'oh, where is it?' and he'd say, 'oh, up around the corner, look for the red awning.' And I'd get around the corner and it' $d$ be red's lobster hut or something. We had our little secret language for how we talked to each other without the kids knowing, how we dealt with our various needs.

Gavin and I talked about everything, you know? Relationships, love, life, sometimes politics, sometimes our families. I think that all of the positive co-instructing relationships had some element of that, of talking, of being able to communicate about everything. If I was with a co-instructor who was closed off, that I couldn't talk anything about, I would feel isolated- an experience I had my first season with the program. I would spend all my time, you know, trying to find cell phone service to try and text my world back home. Instead, on parts of this course my cell phone had service, so at night before going to bed I was able to text Elizabeth, or she would send me random text messages and I would get them whenever my phone would actually have service again. I could talk to Gavin about that, and it was a way of staying connected to being an adult and having a world, a type of relationship that exists that sometimes seems very far away when you're dealing with the day-to-day strife of 15 year old who can't get his pants dry, you know? I think sometimes when you're on a boat with 15 and 16 year olds for weeks at a time, your sense of reality of being an adult in the world can get lost unless you have some semblance of an adult relationship, so Gavin and I have that. Despite our 
friendship, though, we still have had to work out our professional relationship.

The big issue that we had is that he definitely thinks very highly of himself. And he likes to talk. And so, because of that, I definitely had to make the effort to advocate doing more teaching. Because if left to his own devices, he would teach everything all the time, a) because he's particular about the way things are taught, and b) because he likes to hear himself talk. And I don't necessarily know that I'm forceful enough at expressing what I want to teach. In some regards I'm not attached to teaching any particular thing. I just don't want to be along for the ride to deal with homesick kids, you know? I like working with the kids in that role, I like being their nurturer, but I also want to use my technical skills, and I want to impart those because I do think that I am a good teacher. So it's not to say that we didn't run into those problems on this course, too. It happened on a couple of different occasions. I was trying to do some lessons on things that I didn't know, or I did know but that I wasn't as comfortable teaching. I was supposed to teach anchoring, and Gavin has this little mock anchor keychain, so he was like, 'here you go, you can use my little anchor.' He had his little anchor out, and we all got into 'feet in the cockpit', which is what we call it when everyone crams themselves into the world's smallest space, and we're sitting there and all of a sudden he starts teaching about anchoring. It was like he had completely, in the space of 3 minutes, forgotten that we had discussed me teaching it. Each night before we would go to sleep we would be lying in the cockpit and we would touch base about any concerns, any thoughts, if anything had come up with any of the kids, stuff like that. And something else like that happened, where he had done the same thing, so that night that was one of the things that I mentioned to him. I said, 'you know, we had discussed initially me doing more teaching, 
but there have been a couple of occasions now where I was supposed to teach something and you took off like a bat outta hell', and he was totally unaware. He completely didn't realize he had done it. And he was really glad that I had pointed it out to him, but he was like, 'you're kidding. I really did that?' It was good, we would have those discussions and I felt more comfortable- we said that we were going to do that the previous year, and we did it to some extent, but I definitely felt more comfortable talking to him, and felt a little bit less pressure with the whole 'boss man, captain' situation, with my 'assistant' role than I had the year before. I think the previous year I played a little bit of lip service to the 'yeah, sure, we'll have check-ins, we'll do feedback', but that's easier said than done in certain instances. Especially when you don't know how the person deals with feedback, you don't know how they interact with it. But we had the experience together, the friendship.

I don't think that would happen as easily with anyone else that I work with. I think it is because we became such good friends and co-instructors. He's a good guy. I loved working with him again because it was so nice to have that pattern, to have the consistency of having spent a year working with him, learning his little nuances, and him learning mine. There's part of me that just loves working with him, because we operate so well together. It feels a little bit like a dance, almost, or maybe like starting a new romantic relationship. Gavin would laugh if he heard me say that, but the first time you're out on a course with someone... I don't know anything about this person, I don't know what their buttons are- yes you can talk about it during pre-course, you can come up the basics, like this person does not want me to talk to them before they've had coffee in the morning or something, but really you don't actually know what they're going to be 
like. Even throughout the course it's this ongoing learning process of how to work with this other person under the watchful eye of 15 year olds. When you are working with someone that you know those things about, you know their triggers. I had access both to knowing which buttons I could push if I was irritated with Gavin, which buttons I could push to irritate him even more, but I also knew how to work with him. Basically how the dance would go. It made the experience much more relaxing. If and when I wind up with a different instructor this summer, it's going make it really hard to make that transition, because at this point I've worked 2 long courses back-to-back with him.

I enjoy my job, and I enjoy co-instructing with someone that I like. I don't know that I have to be as close of friends with them as I am with Gavin, but I definitely have to enjoy the person. There's got to be some sort of relationship that goes beyond just this professional relationship of 'you teach this, I teach this. You do this, I do this.' There's got to be some sort of connection for me on the personal level. I don't think that would necessarily be the case if it weren't for the fact that this is your life for weeks when you are on a course. If I was just facilitating a program and then went home where I had my social network, that would be one thing. But when you're talking about an experience where there is no going home, where this is my home, then for me I need to have all aspects of what I would want in my home life present. Obviously I can do anything for 2 or 3 weeks, but when I talk about having a fulfilling experience that I enjoy and where I'm not starting to do the count-down after day 2 , then it has to have that element of personal connection, of genuinely enjoying the person I'm working with. 